\title{
Pan-Africanism in Canada: Anti-Blackness and Black Consciousness in Canada's Capital
}

\author{
by \\ Sarah George
}

A thesis submitted to the Faculty of Graduate and Postdoctoral Affairs in partial fulfillment of the requirements for the degree of

Master of Arts

in

Sociology with a specialization in African Studies

Carleton University

Ottawa, Ontario

(C)2021

Sarah George 


\begin{abstract}
This thesis examines Ottawa as a space of radical Black leadership among African, Caribbean, and Black (ACB) Canadians. I explore Ottawa’s Black Radical Tradition (BRT) through a qualitative discourse analysis of three recent anti-racism policies and twelve semistructured interviews with ACB leaders. The research explores the heuristic efficacy of the term anti-Blackness in diverse ACB leadership groups. The findings indicate that ACB leadership is diverse and yet a political commitment to the BRT binds leaders together. This thesis proposes that anti-Blackness is a useful concept for a group as diverse as Black Canadians articulating their racial experiences within a political climate of multiculturalism. This proposition is based on a non-identarian argument for the importance of anti-Blackness as an ethical and political stance in which the definition must be extended to account for transnational experiences of Blackness and simplified for use outside academia.

Key Words: Black Radical Tradition, Black and African, Caribbean, and Black, PanAfricanism, Black consciousness, anti-Blackness, racism, settler colonialism
\end{abstract}




\section{Acknowledgements}

I wish to extend my sincerest gratitude to Professor Blair Rutherford and Professor Shireen Hassim for accepting the call to be my supervisors and formally introducing me to the world of African Studies. This thesis would not have been possible without your guidance, encouragement, and patience during these strange times. Your confidence in my research was contagious and I will not soon forget the insightful advice and unwavering support.

I'd like to thank Carleton's Institute of African Studies and department of Sociology, and all the amazing faculty and support staff for their encouragement during my time at Carleton.

I am sincerely grateful to all the ACB leaders who lent their time and voices to this project. Thank you for all you have done and will continue to do.

Lastly, the support and great love of my family - Timothy and Dorothy, Ryan, and my niece Ocean. To my partner Kwame, and my Ottawa family - Aunty Christine and the Grangers. I would like to thank all the peers that I connected with during my short time at Carleton for your engagement with my ideas, everlasting encouragement, support, and words of life.

The struggle continues. 


\section{Table of Contents}

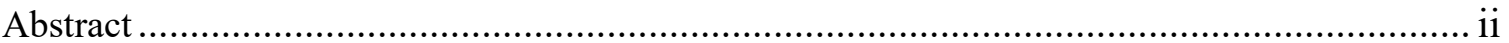

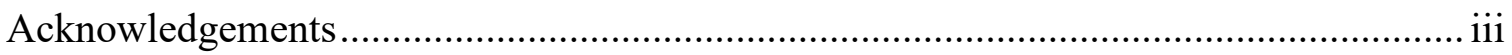

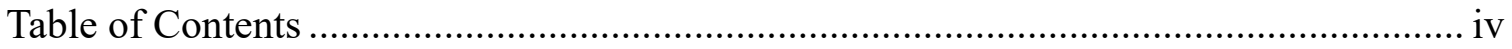

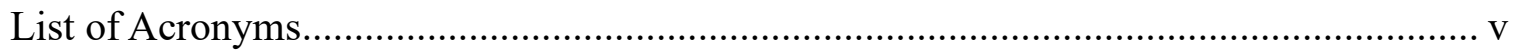

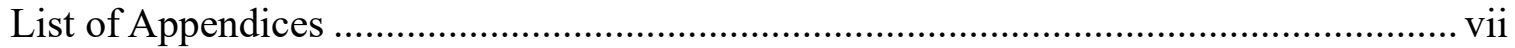

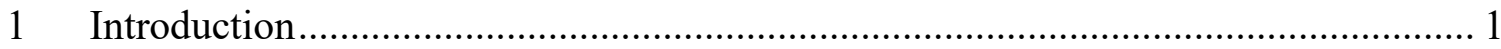

2 Academia and Activism: The Black Radical Tradition of Leadership.................... 13

3 Waves of Change: ACB Immigration, Anti-Black Legislation, and Leadership ...... 36

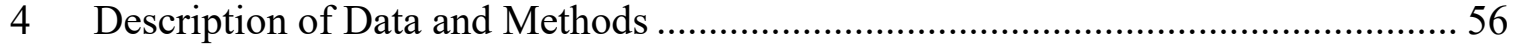

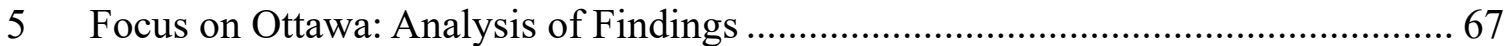

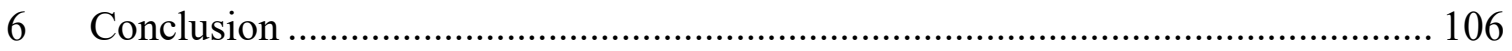

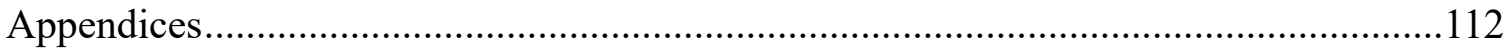

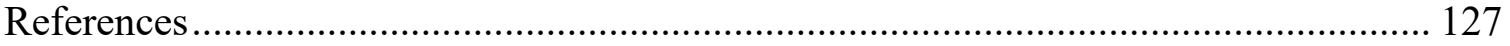




\section{List of Acronyms}

ABRS

ACB

ACLC

ACAO

ACMP

ARD

ARS

BEP

BLM

BLSA

BRT

CANWA

CBW

$\mathrm{CCC}$

CIPAD

CLACP

$\mathrm{CO}$

CPR

CRRF

CRS

CRSA

CSA
Ontario Anti Black Racism Strategy

African, Caribbean, and Black

African Canadian Legal Clinic

African Canadian Association of Ottawa

Afro-Caribbean Mentorship Program

Anti-Racism Directorate

Anti-Racism Secretariat

Black Experience Project

Black Lives Matter

Black Law Student Association of Ottawa

Black Radical Tradition

Canadian Negro Women's Association

Congress of Black Women

Caribbean Caribana Coalition

Canadian Institute for People of African Descent

Canadian League for the Advancement of Colored People

City of Ottawa

Canadian Pacific Railway

Canadian Race Relations Foundation

Canadian Review of Sociology

Canadian Review of Sociology and Anthropology

Canadian Sociological Association 
CSAA

CWC

GO

GOC

HSA

JUMC

MCSCS

MCYS

NAACP

NCC

OBDC

OBYAP

OVOV

QDA

SPCO

WIF

UN

UNHRC

UNDPAD

UNIA

U.S.
Canadian Sociological and Anthropological Association

Coloured Women's Club of Montreal

Government of Ontario

Government of Canada

Home Services Association

Joint Management Union Committee

Ministry of Community Safety and Correctional Services

Ministry of Child and Youth Services

National Association for the Advancement of Colored People

Negro Citizenship Committee

Ottawa Black Diaspora Coalition

Ontario Black Youth Action Plan

One Vision, One Voice

Qualitative Discourse Analysis

Social Planning Council of Ottawa

West Indian Federation

United Nations

United Nations Human Rights Council

United Nations Decade for People of African Descent

United Negro Improvement Association

United States of America 


\section{List of Appendices}

Appendix A: Tri-Council Policy Statement 2 - Certificate of Completion. Error! Bookmark not defined. 2

Appendix B: CUREB Ethics Approval Letter..... Error! Bookmark not defined. 13

Appendix C: Letter of Informed Consent Error! Bookmark not defined.15

Appendix D: Online Letter of Invitation Error! Bookmark not defined.19

Appendix E: Data Collection Sheet Prototype.... Error! Bookmark not defined.1 Appendix F: Federal Anti-Racism Policy Budget Error! Bookmark not defined. 2

Appendix G: Interview Guide. Error! Bookmark not defined.3

Appendix H: Codebook Error! Bookmark not defined.6 


\section{Introduction}

This project will contribute to existing literature on the Black Radical Tradition (BRT) in

Canada through examination of the continuation of a long history of Black Canadian leadership, resistance, and mobilization. African, Caribbean, and Black (ACB) Canadians are diverse groups combined under a single racial category. Ottawa has the third largest Black population in Canada, which is steadily increasing and includes an influx of continental African migrants. This thesis aims to provide data regarding Black Canadian racial consciousness and identity formation within Black leaders in the national capital region. Black people in Canada face specific forms of systemic and interpersonal racism that are hidden by Canada's culture of silence. I consider the logics and language of a concept that addresses the specificity of racism towards people racialized as Black, anti-Blackness, as both an explanatory theoretical tool and an organizing political concept within heterogenous Black communities. Centering anti-Blackness may assist with the articulation of Black people's racial experiences and the establishment of Black political unity in the national capital region.

\subsection{Black: African, Caribbean, and Black (ACB) Canadians}

In Canada, Black is a racial category assigned to people from "sub-Saharan" Africa and of "sub-Saharan” African descent (Mensah 2002). Black refers to "persons who self-identified as 'Black' in the population group question in the Census of Population”' (StatsCan 2019: n.p.). Black Canadians have "multiple, often overlapping identities" and utilize different terms to selfidentify such as Black, African, African Canadian, Afro-Canadian or one's specific ethnic group (Black Experience Project [BEP] 2017: 31). These varying forms of self-identification determined the descriptors used in this project as they represent the range of identities claimed by Afro-Canadians dependent on heritage, culture, personal or political views, self-image, 
reputation, age, level of community engagement and experiences or understanding of institutional racism (BEP 2017: 31, 32-4, 43). The Black population in Canada will collectively be referred to as African, Caribbean, and Black (ACB), Black, Afro-Canadian, and African Canadian. Not all Africans or people of African descent are Black and not all Black people are of African or immediate African descent. In acknowledgment of these complexities, reference to African descent or use of the word Black in this context is an attempt to demonstrate the political utility of Blackness in a Canadian context rather than further homogenization.

\subsubsection{Demographics: National and Regional}

Black Canadians represent over 170 nations with over 200 ethnic or cultural origins (StatsCan 2019). ACB people comprise almost half of all non-white, or non-Indigenous Canadians who are third generation or more. Over $40 \%$ of African Canadians were born in Canada; $35 \%$ second generation or born in Canada with one parent born outside; $8.3 \%$ third generation or born in Canada with both parents born in Canada; and approximately $15 \%$ of the population born outside of Canada (StatsCan 2019). Afro-Canadians are concentrated in Ontario (52.4\%), Quebec (26.6\%) and the prairie provinces (14.6\%) with $94.3 \%$ in urban areas such as Toronto, Montreal, Ottawa-Gatineau, and Calgary (StatsCan 2017). Just over half of ACB people (51.6\%) are women, slightly outnumbering the men (50.8\%) (StatsCan 2017).

From 2001 to 2016, Ottawa-Gatineau had the second highest rate of Black immigrants in the nation (StatsCanada 2019; 2017b). Canadians of African descent now represent just over six percent of Ottawa's total population, the city's largest visible minority group and third highest proportion in the country following Toronto and Montreal (StatsCanada 2019; 2017a; 2017b). The residents are diverse as $44.5 \%$ of Ottawa's Black community are Canadian born; $55 \%$ are immigrants and of those immigrants, almost half (23.1\%) are refugees (Social Planning Council 
of Ottawa [SPCO] 2015: 13 see also StatsCan 2017a). Almost a quarter (21.1\%) of Black people in Ottawa are Francophone and nearly half (42.2\%) are bilingual in relation to $37.7 \%$ of the general population (Forum 2016: 3). The median age of Afro-Canadians in Ottawa is 30.6 (StatsCanada 2017a). There are more women $(32,015)$ than men $(28,190)$ and over half $(54.8 \%)$ are children or youth (StatsCan 2017a). The seven largest ACB groups in Ottawa are Somali, Congolese, Burundian, Haitian, Jamaican, Trinidadian and Ethiopians (StatsCanada 2017a).

\subsubsection{Background}

This thesis examines racism in Canada's national capital region, leadership in AfroCanadian communities, and the language leaders utilize to navigate systemic racism or articulate the experiences of people racialized as Black in Canada. This is in line with Dei's (2019: 351) call for a "politics of language, leadership, and place." A politics of language is required to articulate Black life; a politics of leadership acknowledges the BRT and accounts for the necessity of African Canadian leaders; and politics of place, such as scales of regional specificity based on a nation's form of governance (i.e., municipal, provincial, and national) address how anti-Blackness functions in different locations. Leaders were not selected in efforts to "represent" or speak on behalf of Black communities. Rather to provide data on a specific population and the BRT in a Canadian context. This selection was based on the tradition of leaders making Canada an increasingly livable space for Afro-Canadians (Kitossa 2019). For example, enslaved and free Black people from varying locations, especially the Caribbean, have resisted anti-Black racism in Canada since its inception in the 1600s (African Canadian Legal Clinic [ACLC] 2003, Mullings et al. 2016, Wane 2009, Winks 1997). Black Canadian leaders have gathered evidence regarding the depth of institutionalized racism towards Black people, or anti-Black racism, in Canada. 
They argue this results in hyper-surveillance, under employment, over-incarceration and under education of ABC Canadians regardless of their length of stay (Maynard 2017, Tecle 2016).

The global rise of social movements such as \#Black Lives Matter (BLM) and political pressure from bodies such as the United Nations (UN) forced the Canadian government to acknowledge anti-Black racism. In 2016, members of the Ottawa community expressed a desire to address the institutional anti-blackness in the education and policing systems during an AntiBlack Racism forum. Anti-Black racism is on the national, and provincial radars as seen in the introduction of policies such as Building a Foundation for Change: Canada's Federal AntiRacism Strategy (Government of Canada [GOC] 2019) and Ontario's Anti-Black Racism Strategy (Government of Ontario [GO] 2017). However, there is no anti-Black racism policy in Ottawa. This project looks at the language these policies utilize to address institutionalized antiBlack racism. Moreover, it aims to analyze the BRT of leadership, and ACB leaders' racial identity formation in Ottawa under Canada's discourse of multiculturalism. In addition to exploring the contextual nuances of identity formation, I am interested in anti-Blackness as both an explanatory social tool and an organizing political concept in heterogenous Black Canadian communities. This latter objective is informed by an interest in a pan-African extension of the Western-centric definition of anti-Blackness offered by Afropessimists.

\subsection{Research Questions}

There are four key qualitative research questions intended to provide data on Black leadership in Ottawa. These questions will explore leaders' perceptions of race, colonialism, and anti-Blackness in Canada as well as the impact, or lack thereof, of their prior life experiences on these perceptions. Additionally, they shed light on usage of the term anti-Blackness in Black political solidarity development amongst Afro-Canadian leaders in Ottawa. The first question is 
who are the activists and leaders, recognized by either the state or the people, in Ottawa's Black communities? This question is foundational as it outlines who the leaders are; the nature of leadership; and how they perceive their leadership roles. Next, how do recognized and unrecognized leaders understand race, racism, colonialism, and anti-Blackness in a Canadian setting? This question addresses racial consciousness, as well as leaders' positions on issues pertinent to African Canadian communities. As leaders are often made to act as advocates, representatives, or liaisons on behalf of $\mathrm{ACB}$ populations, their understandings of these concepts, in relation to advancement of the BRT, is significant. The third question asks whether previous experience with colonialism influences Black community leaders' current understandings of race, colonialism, and anti-Blackness in Canada? In a Canadian context, everyone is in a sense implicated in a relationship with settler colonialism, so this question addresses the diversity of Afro-Canadian thought. As this is a group with varying backgrounds, it is important to consider how these differences may or may not influence leaders' perspectives of Black liberation in a Canadian context. Finally, Canada has a rich BRT in both the social and academic realms. Are concepts such as anti-Blackness, developed within these movements, suited to conceptualize settler colonialism, articulate African Canadian experiences, and further Pan-Africanism and political unity in such a diverse population?

\subsection{Major Arguments}

My analysis of Blackness is structured by Black feminist and postcolonial interventions into Canadian sociological studies of race, including intersectionality, positionality, and decolonization. Intersectionality enables examination of varying identities such as gender, age, socio-economic status, and positionality centers how social positioning may impact perception. Combined, intersectionality and positionality provide a framework for analysis of racial 
consciousness and thought. Arguments for decolonization present Canada as a Eurocentric settler colony, decrying the politics of recognition in favor of radical movements which strive to eliminate systemic racism (Coulthard 2014, Tuck \& Yang 2012). Race is defined as an institutionalized social determinant according to processes of racialization, or the assignment of racial meaning, and racial capitalism, or economic systems structured on racism (Robinson 1983).

I contend with the language utilized to describe racism towards Black people in Canada. For example, theories of settler colonialism and discourses of reconciliation are often articulated through the framework of a theft of Indigenous land and forced Black labor which Tuck and Yang (2012: 2) named a "triad structure of settler-Indigenous-chattel slave" (see also Wolfe 2006, Veracini 2016). Black studies theorists (King 2019, Wilderson 2020) and Indigenous studies theorists (Smith 2010, Rowe \& Tuck 2016) argue that this framework is not suitable to theorize Blackness and does not account for the constitutive relationship between anti-Blackness and settler colonialism. Presenting slavery and colonialism as two distinct historical events gives way to presentation of Canada as a historically "safe space" for African Americans during the Underground Railroad and contemporary haven for ACB migrants (King 2019, Maynard 2017). Such nationalist myths negate Canada's anti-Black policy-making practices and fail to account for the negative aspects of Black experiences (King 2019, Thobani 2018).

There is a BRT of mobilization against anti-Blackness in Canada based on resistance to the "dialectic matrix of slavery and imperialism" that racialized Africans as Black for the purposes of capitalist exploitation (Robinson 1983: 167 see also Horne 2018, Leroy 2016). Robinson (1983) argues that existing Black radical and resistant forms of thought travelled with enslaved African people to the diaspora during transatlantic enslavement. The centrality of Africa 
and the United States to Robinson's (1983) perspective have been critiqued in favor of emphasis on the hybridity of people racialized as Black in the diaspora (Gilroy 1993). Hybridity is adopted in this project to account for the diversity of the Afro-Canadian population (Gilroy 1993). However, both perspectives historicize and downplay the hybridity of Africa and the Black Atlantic has been critiqued for Gilroy's (1993) marginal inclusion of African and Caribbean leaders (Evans 2009, McNeil 2021, Piot 2001).

The remaining arguments examine the BRT of African Canadian leadership in both social movements and academic trends. My analysis of leadership is guided by a recent anthology of ACB Leadership (Howard et al. 2019) that included contributions from prominent AfroCanadian sociologists such as George Dei. Alongside Dei's (2019: 351) "politics of language, leadership, and place" my framings of the relationship between African Canadian leaders, language, and the three levels of Canadian state governance, are underscored by Kitossa's (2019) analysis of a discourse of crisis in ACB Canadian leadership. In this case, the discourse of crisis exists within and outside Black communities. Within communities, the discourse is grounded in observable issues such as the unfinished project of abolition and how best to address anti-Black racism (Kitossa 2019). Outside Black communities, this discourse of crisis has been utilized by ACB petite bourgeoise, Canadian governments and media outlets to undermine and negate Black leadership while placing the onus of responsibility on leaders to address institutionalized antiBlack racism and racial capitalism (Kitossa 2019).

Social movements such as Pan-Africanism, or the unification of all people of African descent, and Black consciousness are used to provide theoretical framing of Black leadership in Canada. The history of African Canadian participation in Pan-Africanism, as well as its potential usefulness in contemporary leadership is one major focus of this project. Black consciousness is 
defined, and then the mechanics of it examined in terms of the multiplicity of ACB Canadian identities, and comprehensions of Blackness amongst leaders in Ottawa. For example, some leaders related with a process of "Becoming Black" or adopting a Black Canadian consciousness upon arrival to or while living in Canada (Creese 2018, Dei 2018, Dei \& James 1998, Ibrahim 2004; 1999).

The academic, political, and public language used to discuss race in Canada often groups all people racialized as non-white together, diminishing the specific experiences of Black people. A group of Black Studies theorists known as Afropessimists have dedicated their scholarship to the study of the negative aspects of Black experience using the language of anti-Black racism. Here, the Afropessimist definition of anti-Blackness will be physically and temporally extended to account for its globalized nature. That is, anti-Blackness as the logic that made possible not only Transatlantic enslavement but varying forms of African colonialism (Horne 2018, Leroy 2016, Lamola 2018). Reconceptualizing anti-Blackness may present a needed specificity and basis for political solidarity by which Afro-Canadians can develop a language capable of articulating their complex racial experiences in the face of multiculturalism.

\subsection{Methods}

To answer the research questions and explore the theoretical arguments, a Qualitative Document Analysis (QDA) and twelve semi-structured in-depth interviews were conducted. The data set for the QDA featured Canada's Federal Anti-Racism Strategy (2019), Ontario's AntiBlack Racism Strategy (2017), and Ottawa's Equity and Diversity Policy (2017). These policies were analyzed to examine the government bodies" presentations of themselves as a "safe space" for people racialized as Black based on policies of multiculturalism and anti-racism. 
Additionally, a QDA provides context regarding the governmental stances, responses, and offerings to the $\mathrm{ACB}$ community.

In addition to the QDA, twelve semi-structured interviews were conducted with $\mathrm{ACB}$ leaders in Ottawa. My emphasis was on leaders who belonged to and served the seven largest groups and leaders who did not belong to or serve any of these specific seven groups but are PanAfricanist in that they seek to unify "Africa and the diaspora" or the "Black" community. Leaders had to be between the ages of 25 and 55 and the sample reflected the larger populations' gendered dimensions through seven women and five men (StatsCanada 2019). Selection was based on leaders' having served the African Canadian community in Ottawa for at least two years. The interviews enabled empirical evaluation of 1) who the leaders are in the region; 2) their perceptions on race, colonialism, and Blackness; 3) the potential influence of their positionality or past experiences on these perceptions; and 4) the heuristic potential of the term anti-Blackness outside academia.

\subsection{Positionality}

In sociological studies of ACB leadership, one must acknowledge their positionality alongside the "limitations of academia" as "the resonances depend on who is conducting the conversation and analysis" (Dei 2019: 348). Positionality is a feminist concept based on how one's social situation or "position" informs their identity as well as their hermeneutical stance towards phenomena such as race (Franks 2002). This social situatedness is informed by one's positioning in terms of social determinants such as class, race, ethnicity, ability, and sexuality, for example. Reflexivity in relation to positionality, and how it may inform one's social situatedness, enables in-depth analysis of the complexities of Blackness in Canada. 
I am writing from the position of a Black, Zimbabwean born, 27-year-old, cisgender, heterosexual, able bodied, woman. Born in 1993, my Black consciousness is influenced by the revolutionary presence in the region during that time, the aftermath of Zimbabwe's recent liberation and the then ongoing struggle against apartheid in South Africa. Racially and ethnically, my positions are complex as in Zimbabwe, I am considered "colored" or mixed. My ethnic identity is hybrid as my background includes a paternal ancestor of Indian ancestry as well as (predominantly) Ndebele, Zulu, and Shona lineage. I am a $1.5^{1}$ generation immigrant as my family, and I migrated to the United States when I was four and then to Canada when I was twelve. I have experienced every scale on the socio-economic spectrum, including upward social mobility after relocating to Calgary. Having migrated to North America when young, my Black consciousness is diasporic, and heavily informed by radical Black American and Black feminist thought. As I reflect on my positionality, it is evident that it has influenced this project.

\subsection{Significance of Research}

This research provides information regarding Black Canadian racial identity formation, leadership, and perceptions of the concept anti-Blackness outside academia. Moreover, it offers a critical analysis of the municipal, provincial, and federal strategies regarding anti-racism. Black sociologists have pointed to the "poverty of research" into African Canadian leadership acknowledged as early as 1973 (Kitossa 2019). Much of the existing research on Afro-Canadian leaders is concentrated in Toronto, Montreal, and Halifax (Arthur et al. 2012, Austin 2007, Johnson 2016, Kitossa 2019, McDuffie 2016). Of the research on African Canadian populations in Ottawa, a majority are related to health issues such as HIV (e.g., Omorodion et al. 2021,

${ }^{1} 1.5$ generation immigrants arrive in Canada during childhood or adolescence, often with their first-generation immigrant parents. 
Mbuagbaw et al. 2020) or specific ethnic groups such as Somali (e.g., Lagace et al. 2012) including work by graduate students (Abdulle 2000, Farah 2011, Mohamed 2007, Kenny 2008).

\subsection{Findings}

As I will demonstrate, anti-Blackness was on the periphery of anti-racism policies such as Canada's Federal Strategy. Ontario's strategy (2017) names anti-Black racism, however, the relationship between anti-Blackness and colonialism is understated. In all policies, racism is presented as a "barrier" to participation in society rather than a social determinant, as the interviews revealed. ACB leaders in Ottawa are a diverse group in line with the population that they serve. They have multiple consciousness, and understand Blackness, racism and colonialism based on their positionality. Leadership is formal and non-formal and takes many forms such as nationalist/ethnic/regional community organizations, maternal activism, HIV and AIDS activism, feminism, and religious leadership (Gooden 2008, Kitossa 2019, Lawson 2019, Tecle \& Austin 2019). Notably, the research indicates there is a rise in Black resistance in the Ottawa region. My emphasis is on Pan-Africanist organizing, grounded in the unity of all people of African descent, following the rise of community mobilization such as the anti-racism forum, the influence of abolitionist organizations such as BLM and political recognition of anti-Blackness via the United Nations declaration of the Decade for People of African Descent (UNDPAD). I argue that antiBlackness is a useful concept for Black Canadians to understand and articulate their specific racial experiences, however the term requires adaptation for use outside the academic and activist communities.

\subsection{Reader's Roadmap: Next Chapters}

Chapter two is a literature review and theoretical chapter. Beginning with a brief discussion of race, racism, and Blackness in Canadian sociology the chapter explores the BRT of 
resistance in Canada. My focus is on the social movements of Pan-Africanism and Black Consciousness and the academic trend of Black Studies with an emphasis on Afropessimism. Chapter three is a contextualization chapter which investigates the relationship between AfroCanadian leaders, mobilization, and Canadian law. This chapter provides context for the circumstances that developed Black Canadian leadership such as the influence of radical Caribbean thought. The final portion of the chapter discusses Ottawa's political climate. Chapter four is the description of the methodology used for the empirical study using QDA and semistructured interviews. Chapter five details the findings of the QDA and in-depth interviews and discusses the key findings in relation to the research questions and major theoretical arguments. The final chapter summarizes my arguments and makes suggestions for further contributions. 


\section{Academia and Activism: The Black Radical Tradition of Leadership}

\subsection{Introduction}

This chapter will review existing literature about the BRT of resistance against anti-Black racism in Canada. The initial section contextualizes studies of Blackness within Canadian sociology. I will then examine the rich interconnections between activism and theorizations of Blackness through social movements such as Pan-Africanism and Black Consciousness and the academic domain of the theory of Afropessimism, a tenet in Black Studies. This chapter sets the stage for empirical examination of who the Black leaders in the national capital region are, how they understand anti-Blackness, and if these understandings are influenced by their previous experiences. Lastly, it will explore if a term popularized by Afropessimists, anti-Blackness, may provide a language for a heterogenous group such as ACB Canadian leaders attempting to conceptualize settler colonialism and their racialized experiences in a multicultural society.

\subsection{Race Studies: Canadian Sociological Context}

The Anglo-English tradition of Canadian sociology ${ }^{2}$ is dominated by white scholars and a colonial canon heavily influenced by the United States (Clark 1975, McLaughlin 2005, Smith 2017). Academic courses in sociology in Canada were first offered in the 1920s and grew rapidly in the 1960s alongside the establishment of the first journal, the Canadian Review of Sociology and Anthropology (CRSA), in 1964 and the association, the Canadian Sociological and Anthropological Association (CSAA) in $1965^{3}$ (CSA 2012). Sociologists established a standalone association in 2007 when the CSAA became the Canadian Sociological Association

${ }^{2}$ Canadian sociology is bilingual -Francophone and Anglophone- with two separate histories. (CSA 2012).

\footnotetext{
${ }^{3}$ This association formed as a branch of the Canadian Political Science Association (CSA 2012).
} 
(CSA) and the academic journal the Canadian Review of Sociology (CRS) (CSA 2012). In a review of how race has been utilized in the CRS from 1964 to 2010, Ramos (2013: 342) found that $39 \%$ of all publications from 1964 to 2000 contained the key words race or ethnicity. According to Ramos (2013: 342) "when a more conservative, Title/Abstract/Keyword search is conducted, we see that overall 'ethnicity' and 'race' account for about six percent of the publications in the CRS during this period." The primary concentrations within these studies have been "stratification/class/ mobility/social status, ethnic/racial boundaries/identity, and discrimination/stereotypes/racism" (Ramos 2013: 444).

Race studies in Canada, including sociological studies, have been characterized by a culture of silence, or denial about systemic racism that manifests itself in a lack of data about Black Canadians (Smith 2017, Thompson 2018). In the 1980s a changing political climate and the increase of theoretical perspectives such as Critical Race theory, Black feminism and Postcolonialism devoted to transforming race relations resulted in "decolonial sociologies focusing on meaning and antihegemonic notions of ethnicity and especially race" (Ramos 2013: 346; see also Aylward 1999, Crenshawe et al. 1995). A focus on racial boundaries took precedence over ethnicity or social stratification (Ramos 2013). This includes a shift to center Blackness, as evidenced by recognition of a "Critical Ethnicity and Anti-Black Racism Research Cluster" which consists of Black sociologists" and "comprehensive sociological studies concerning race, racism, anti-racist feminism, Black feminism, anti-Black racist research and social inequality" including a recent $C R S$ (2021) edition on a Sociology of Black Liberation (CSA 2020: n.p.).

${ }^{4}$ Including “Dr. Daniel G. Hill, Dr. Wilson Head, Dr. Althea Prince, Dr. Agnes Calliste, and Dr. George S. Dei” (CSA 2020: n.p.) 


\subsubsection{Interventions: Intersectionality, Positionality and Decolonization}

Black feminist interventions in race studies of the late 1980s such as intersectionality influenced this shift (Flynn 2014, Mills 2015). Intersectionality is a theoretical perspective popularized by legal scholar Kimberle Crenshaw (1989) which proposes that identities intersect to inform or shape oppression. A pluralistic view of identities has long been central to Black women's radical thought and movements, such as abolition (Wekker 2020). I will focus on the intersections of the identities race, gender, age, religion, migration, nationality, and socioeconomic status amongst African Canadian leaders in Ottawa. Pluralism enables examination of the relationship between one's intersecting identities, perspectives on race, and positionality or previous exposure to racism, colonialism, anti-Blackness, or white supremacy. Reflexivity in relation to a leader's positionality, and how it may inform their social situatedness, enables in-depth analysis of the complexities of Afro-Canadian leadership.

Postcolonial studies explore the social, political, and economic impacts of colonialism on contemporary societies (McLeod 2016). Postcolonialism influences sociological studies of Blackness through theorists' critiques of anti-racism in favor of decolonization (Tuck \& Yang 2012). Decolonization speaks to an anti-colonialist, previously unseen, disruption of the current social order including the elimination of systemic racism (Tuck \& Yang 2012). This disturbance cannot be achieved through political recognition from the state as hegemonic state sanctioned Eurocentric, or Europe-centered, discourses of anti-racism are used to deflate decolonization through discursive presentation of racism as a minute social problem (Coulthard 2014, Tuck \& Yang 2012). Discourses of anti-racism relevant to this project include the Canadian state's political language of visibility, diversity, and inclusion that will be examined during the QDA. 


\subsubsection{Making White Supremacy: Racism and Racialization}

Decolonized perspectives on Blackness must consider the intersections of race and class, two co-constitutive globalized social categories required to establish European colonization (Fanon 1968). This includes the centrality of racialization to European forms of nationalism (Robinson 1983). Racialization is the colonial process of attaching racial meaning to something that was previously devoid of it, including defining racial categories, their respective meanings and how they will maintain racist relations of power (Gonzalez-Sonbrino \& Goss 2018, Kelley 2017, Robinson 1983). Racism is the mode of domination, based on processes of racialization, in which a marked group is systemically politically, socially, and economically oppressed (Robinson 1983, Mensah 2002). Prior to nationalism the British existed in feudalist societies inclusive of racialized enslavement of groups such as the Irish (Robinson 1983). The importation of African labor under the same terms of racialized enslavement contributed to the transition from feudalism into globalized racial capitalism and nationalism (Robinson 1983: 66). Racial capitalism describes the centrality of race, racialization, and racism to the socio-economic organization of Eurocentric societies (Robinson 1983: 66).

Eurocentric nations such as Canada are organized through a formal and informal racial hierarchy in which people racialized as white are deemed superior and thus have access to cultural, social, political, and economic dominance over those racialized as non-white (Bonds \& Inwood 2015, Christian 2002, Crenshawe et al. 1995, Mills 1999, Stanley 2014). This is white supremacy, and white supremacist forms of Eurocentric social organization established "the racialized distributions of economic, political, and cultural power" present in Canada today (Mills 1999: 98; see also Bonds \& Inwood 2015, Mills 1997). Black feminists point out that white supremacy is a heteropatriarchal logic that renders Black and Indigenous women flesh to 
capitalize on their "reproductive capacity" for the space-making practices of settler colonialism, racial capitalism, and nationalism (Menzel 2018: 113; see also Hartman 1997, King 2019, Spillers 1987). The abolitionist activism of Black women who are mothers threatens settler space-making practices, and as such is often criminalized. Theorizing Black maternal insurgency, or the sometimes-criminalized activism and agency of Black mothers, is central to how we theorize ACB leadership in settler colonies (Menzel 2018).

\subsubsection{Contextualizing "Canada": Settler Colonialism}

Studies of Blackness in Canada must be contextualized within the context of settler colonialism (King 2019). Settler colonialism is the racialized geopolitics of ongoing white settlement made possible by white innocence, Indigenous ${ }^{5}$ erasure, anti-Blackness, indentured servitude, and racialized labor (Day 2015, Evans et al. 2003, Hartman 1997, Leroy 2016, Rowe \& Tuck 2016, Rotz 2017, Veracini 2016). In what is now Canada, British and French settler colonial logic justified assertion of ownership over Indigenous lands through the principles of terra nullius, "nobody's land", and terra incognita, the right to "claim title to unowned land". Terra nullius erased Indigenous people to construct pre-colonial spaces as empty and allow for settlement via terra incognita (Evans et al. 2003, Nájera \& Maldonaldo 2016, Rotz 2017, Veracini 2016, Thobani 2007, Wolfe 2006). Settlers do not leave, they are "here to stay" and utilize racist immigration policies to develop and maintain white supremacist nations (Day 2015, Evans et al. 2003, Rotz 2017, Rowe \& Tuck 2016, Wolfe 2006, Veracini 2016). Based on this continuity, settler colonialism is not a historical event but a present reality (Leroy 2016, Rowe \& Tuck 2016, Wolfe 2006, Veracini 2016). Once nations, all European settler colonies have similar

${ }^{5}$ In Canada, the First Nations, Inuit, and Metis are classified as "Indigenous" or the original people who were in a space prior to contact with conquest, colonialism, or settlement. 
spatial concepts, institutions, and post or anti-racial discourses regardless of political regime change (Leroy 2016, Rowe \& Tuck 2016, Wolfe 2006).

A fully transnational or globalized analysis that is not centered on the geographical territory of one specific nation state is beyond the scope of this thesis as this project emphasizes a particular population and is domestic in scope. However, Black racialization and exploitation is transnational, and the social and capitalist function of Canadian settler colonialism and transatlantic enslavement to Britain's global imperial project should not be understated (King 2019; 2013, Wolfe 2006). During transatlantic enslavement, Canada's status as a settler colony enabled establishment of an economy that was linked in an "Atlantic triangle" to the "the Hinterland" (Africa), "the Plantation (Caribbean)", and the "Heartland (British)" (Mensah 2002). Examples such as these unveil the connections between domestic settler colonial logics and the global European imperial project in relation to how they behaved in tandem with Black colonialism and enslavement. In this case this was via an Atlantic triangle that that propelled Canadian nationalism through gains from transatlantic enslavement, imperialism, and settler colonialism (Mensah 2002, Robinson 1983).

Contemporary Canadian nationalism belies memories of Black resistance and relies on, amongst other political strategies, historical and nationalist myths to present itself as a haven for non-white migrants (King 2019, Mullings et al. 2016, Thobani 2018; 2007). As Robinson (1983: 190) argued "Black history began in the shadow of the national myths and as their dialectical negation." Canadian nationalist myths include racial homogeneity, equality, a shared line of descent, "benign national origins" and "responsible citizenship" (Thobani 2007: 76-8, 87). These false narratives are central to Canada's white supremacist presentation of itself as a benevolent Western nation with British and French roots (Thobani 2007, Rowe \& Tuck 2016, Stanley 2014). 
Nationalist discourses preserve white settler innocence via a controlling, contouring and coordination of history and memory that diminishes ongoing settler colonial relations, Indigenous genocide, transatlantic enslavement, and all other racial injustices to encourage assimilation (Cooper 2017, Evans et al. 2003, Maynard 2017, Rowe \& Tuck 2016, Smith 2010, Stanley 2014, Thobani 2007). Thus, this study engages a decolonial praxis that contextualizes Canada as a settler colony and recognizes Black Canadians' long-standing BRT (King 2019).

\subsection{The Black Radical Tradition of Leadership in Canada}

This section is focused on African Canadian leadership as well as the heuristic value of the term "anti-Blackness" for a population as diverse as ACB Canadians. I begin by reviewing existing literature on the BRT of leadership in Canada. The chapter will close with an assessment of the relationship between activism and academia through three branches of leadership and schools of thought 1) Pan-Africanism, 2) Black Consciousness, and 3) Afropessimism.

\subsubsection{Slavery and Imperialism: A Brief Theoretical History}

The BRT consists of the liberatory contributions of Black scholars, activists, and leaders seeking Black liberation and resisting oppression, colonial domination, and racism (Robinson 1983). Black radical resistance is propelled by the racialized "dialectic matrix of capitalist slavery and imperialism" (Robinson 1983: 167; see also Horne 2018, Leroy 2016). During transatlantic enslavement, African people were shipped across the Atlantic Ocean from Western coasts of Africa to the Americas in the "The Middle Passage" (King 2013, Sharpe 2016, Wright 2015). Black radicalism can be traced to the African "ontological and cosmology" systems of resistance that travelled with enslaved Africans over the Middle Passage (Robinson 1983: 122). Resistance manifested in insurrection movements ranging from various religious devices to refusing to eat, self-mutilation, taking one's life, or the "common and well documented" slave 
mutinies in which many "not related by blood but by their shared enslavement" revolted against the ship's captain and crew (Bly 1998: 179). Insurgency continued in the Americas in selfliberated Maroon groups, for instance, and informs contemporary radical thought (Robinson 1983).

A key critique of Robinson's (1983) definition of the BRT cautions against idealizing Africa or centering America in theorizations of diasporic Blackness (Gilroy 1993). Both Robinson (1983) and Gilroy (1993) present the BRT as a diasporic consciousness developed as a result of the movement of people during transatlantic enslavement and colonialism. However, Gilroy (1993: 4) argues that the BRT is a result of a unit of analysis named the Black Atlantic that traces "the image of ships in motion across the spaces between Europe, America, Africa, and the Caribbean." The Black Atlantic is informed by the movement of Africans, Europeans, Asians, and "Native Americans" (Indigenous peoples) in the new world. This is visible in the hybridity of the diaspora or the mestisjae and creolization of Blackness (Gilroy 1993).

Gilroy’s (1993) Black Atlantic creates space for acknowledgement of diversity in the Black diaspora and a basis for transracial anti-imperialist solidarity. While theorists such as George Elliot Clarke (1996) have argued that the Black Atlantic perspective fails to include Canada, others such as Rinaldo Walcott (2003) and Richard Iton (2008) demonstrate how the Black Atlantic is useful in theorizing contemporary Black Canadian radical thought (Evans 2009, McNeil 2021). However, Gilroy (1993) has been criticized for historicizing and minimizing the hybridity or connection between Africa and the diaspora as well as the minimal inclusion of African and Caribbean voices in the Black Atlantic (Evans 2009, McNeil 2021, Piot 2001). In addition, some contemporary cultural, ethnic, or nationalist forms of continental African leadership are rendered unintelligible when one utilizes theoretical perspectives grounded solely 
in the experiences of Black people in the diaspora. For this project, Robinson's (1983) matrix of enslavement and imperialism provides a framework for examination of the relationship between transatlantic slavery and settler colonialism in a Canadian context. Moreover, his Africanist perspective is fitting as while there are high levels of ethnic, racial, and cultural hybridity amongst Afro-Canadians, processes of racialization in Canada primarily and politically mark people of sub-Saharan African descent as Black (StatsCan 2019). More importantly, a higher population of African immigrants than Caribbean immigrants now make up Canada's African Canadian population (StatsCan 2017b). Robinson's (1983) emphasis on the movement of African ontological systems with enslaved people can be mapped onto contemporary African migration. This will enable examination of radically resistant thought among growing African populations and any resulting influences on ACB leadership.

\subsection{Leadership}

\subsubsection{Outside the Binary: Radicalism and Resistance}

Black Canadian leadership is often understood through an oversimplistic "good or bad" framework that emphasizes conservative perspectives (Howard et al. 2019). "Good" leaders often occupy the role of officially representing or articulating what it means to be Black in Canada within an official agenda of liberal multiculturalism or anti-racism (Howard et al. 2019). The logic of white supremacy comprehends good Black leaders in five roles: role models, corrective agents, arbitrators, change agents, and cultural curators (James 2019: 26). Good leaders may be constrained by the nature of funding, personal ambitions, or attempts to work within the system. These are ACB people such as professors, politicians, lawyers, or social workers. While recognized by the state, Black leaders who draw on these models and operate within the confines of liberalism are often rejected or treated with suspicion by their own and 
other ACB communities (Howard et al. 2019: 5). Bad leaders are not necessarily seen as "bad" by state representatives but potentially threatening to ongoing relations of white supremacy, racial capitalism, or settler colonialism. Bad leaders may have much more leeway to offer radical framings or to say the unsayable as their authority is legitimized within their respective AfroCanadian communities through social, political, religious, or cultural realms both recognized and unrecognized by the state (Howard et al. 2019).

Stepping out of this binary enables observations of ACB leadership in practice. Beyond the dualistic framework there exists not only good and bad, but radical, resistant, and regressive leadership (Kitossa 2019, Lawson 2019, Tecle \& Austin 2019). Radical and resistant leadership come from below and often take the form of active community organizing and collaboration, collective action, maternal activism, community AIDS activism, anti-hierarchical feminism, and church leadership (Kitossa 2019, Lawson 2019, Tecle \& Austin 2019). Maternal activism refers to the activist leadership of Black mothers and other caregivers who advocate for their children (Lawson 2019). Social movements led by young leaders often operate on a feminist antivanguardist form of leadership that are decentralized and non-hierarchical, and emphasize community organizing, mutual aid, and education (Syedullah 2018: 132). This form of leadership is against formation of high-profile leaders in favor of heterogenous coalitional movements working across difference and historical archives to complete the "unfinished work" of manumission and settler decolonization (Syedullah 2018: 132).

\subsubsection{Contemporary Leadership: Discourses of Crises}

In a recent anthology of ACB leadership, sociologist Tamari Kitossa (2019: 74) offers "an initial attempt at a sociology of African Canadian leadership vis-à-vis a discourse of a crisis of leadership." I will draw from this attempt to frame relations between the Canadian state and ACB 
leaders. Kitossa (2019) argues that an ongoing discourse of crises erases the BRT as well as the existence and contributions of active leaders. Crisis is defined as "a metaphor for the political process by which a problem successfully comes to be recognized by the state... and the constellation of forces with the capacity and credibility to influence the recognition and resolution of a problem" (Kitossa 2019: 74). As the Canadian state slowly begins to officially recognize racism, the "capacity and credibility" of ACB leaders to influence change or provide a solution is being brought into question.

African Canadian leaders operate within a climate of anti-Black racism complicated by a system of economic and gender-based exploitation and divisions amongst continental Africans, Caribbeans, and Black Canadians, Black elites and intelligentsia and "regular" people, and the young and the old (Adjei 2019, Crichlow 2019, Gooden 2008, Kitossa 2019, Mensah 2002). Leaders have varying levels of social capital, or access to economic resources based on group membership and knowledge acquisition (Gooden 2008, Kitossa 2019). Leadership often manifests through small programs sponsored by the federal or provincial government (Kitossa 2019). As a result, Gooden (2008: 419) argues that Black leaders and groups are often "subjugated to government funding, and as a result, become controlled by the state." This has created lasting issues for Black organizers and $\mathrm{ACB}$ led and serving organizations are said to be characterized by a cycle of demise and rejuvenation (Gooden 2008, Kitossa 2019). Therefore, Afro-Canadian leaders have yet to establish a "political process" that is not subject to co-optation or "divide and conquer" by the state in order to achieve mass reform (Kitossa 2019: 76).

Within African Canadian communities, these circumstances have created a discourse of crisis in leadership based on a genuine need for "revitalization, rejuvenation, and creation of new organizations and strategies to meet the changing conditions of African Canadian life" (Kitossa 
2019: 72). This discourse of crisis is valid because it is abolitionist in the sense that it seeks to complete the project of Black liberation through elimination of contemporary anti-Black race relations. Communities are concerned with the state's reluctance to recognize racism, ACB leaders' lack of coherent ideology, and a tendency for Black serving organizations to rely on government grants (Kitossa 2019). Leaders have heeded these concerns and are continuing to develop nationalized Black Canadian entities such as the Canadian Institute for Persons of African Descent (CIPAD) established in 2020 to address systemic racism towards Black people (Caribbean African Canadian Social Services 2019, Kitossa 2019).

This legitimate claim of crisis from within communities is corrupted by an intelligentsia class of the Black Canadian petite bourgeoisie and the Canadian state (Kitossa 2019). This intelligentsia class includes ACB people such as "community activist leaders" and social service workers who attempt "to claim authority to speak on behalf of the masses" and sometimes, though rarely, to mobilize the community for protest (Kitossa 2019: 74, 88). As ACB people are a diverse group, the interests of these intelligentsia do not represent the larger community. The Canadian state's discourse of crisis in leadership is validated in the media and communicated through anti-racism policies that emphasize chronic problems with Black organizing in Canada such as the cycle of demise and rejuvenation (Kitossa 2019: 82). The state's distortion of the discourse of crisis is a move to innocence upheld by the intelligentsia class (Tuck \& Yang 2012). This should be understood as a "tactic of responsibilization" articulated "in the context of neoliberal multiculturalism" which simultaneously recreates the anti-Black conditions Black leaders are fighting and places the onus of responsibility solely on Black leaders to reform them (Kitossa 2019: 72). 


\subsubsection{Social Movements: Pan-Africanism and Black Consciousness}

Two major social movements that manifested in Canada's BRT of leadership, PanAfricanism, and Black Consciousness, are vital to conceptualizing Afro-Canadian leadership in Ottawa. Pan-Africanism provides a platform for people of African descent to address their specific issues and unify. Black Consciousness may enable Pan-Black solidarity on the basis of shared experiences with anti-Black racism.

\section{Pan-Africanism}

Pan-Africanism is an African-centered consciousness which calls for the transnational unification of all people of African descent (Cabral 1973, Esedebe 1994, Reddock 2014). A continuation of the BRT of abolitionism and anti-imperialism, it is both an idea and a social movement with no universally accepted definition; however, it is premised on the principles of self-pride, cooperation, solidarity, and historical literacy (Esedebe 1994). Pan-Africanism is significant because it called for transnational solidarity through domestic frames of reference. According to Snail (2009: 52) "it was in Pan-Africanism that the idea of consciousness, selfactualization, self-realization and black consciousness were born.” The movement was popularized by Black Caribbean people but should be understood as a restorative African ideology based on forms of cooperation in specific pre-colonial communities that travelled with people of African descent to the new world (Robinson 1983: 122; see also Clarke 1988).

Influenced by a large Afro-Caribbean population, Black Canadians played active and diverse roles in the Pan-African movement from its inception. Theoretically, Pan-Africanism set the stage for the continuation of Black radical Canadian thought grounded in decolonization and 
anti-nationalism (Esedebe 1994, Clarke 1988). A conference in $1945^{6}$, held in a climate of formal decolonization, influenced a spring of Pan-Africanist ideologies and nationalist liberation movements on the African continent and in the diaspora. Pan-Africanism became increasingly nationalized in the 1960s as African Canadian leaders and organizations focused on attaining political, economic, and social power through equality under the law in their respective nations. In North America, these were known as the Civil Rights and Black Power movements. Canada's Black Power movements were active and impactful due to contributions by Caribbean as well as multi-generational Black Canadian radical youth and student led organizations (Austin 2007, Fatona 2006, Thompson 2018). Many Caribbean students came from backgrounds of activist and intellectual resistance against the British empire and attended institutions such as Sir George University (now Concordia) (Austin 2007). These students were mentored by Pan-Africanists such as C.L.R. James and transitioned from a Caribbean to Black consciousness (Austin 2007).

\section{Black consciousness}

Black consciousness is a sense of self awareness and acceptance of one's Blackness accompanied by an altered way of seeing, being and knowing. Studies on Black Canadian consciousness are often grounded in or build on Du Bois's (1903) notion of a double consciousness. Du Bois (1903) argues that racism is a color line that creates a veil in society which those racialized as Black exist behind, effectively on the peripherals of humanity. Existence on the fringe results in a racialized double consciousness as a Black person as well as an American (Du Bois 1903). This double consciousness develops based on one's hermeneutical

${ }^{6}$ This conference is commonly held as one of the most important moments in the movement (Esedebe 1994, Reddock 2014) 
stance, or personal interpretation, of the influence of white supremacy and racialization on one's own social, political, and economic location in society and as such, is not equally shared (Du Bois 1903). This project considers how one's hermeneutical stance may prove relevant to conceptualizing difference amongst ACB Canadians, or what Rinaldo Walcott (2003) names the multiplicities of Blackness.

Within the African Canadian population who exhibit a double consciousness, it may exist with multiple consciousness or develops as one is "Becoming Black" (Creese 2018, Dei 2018, Dei \& James 1998, Ibrahim 2004; 1999, Mensah \& Williams 2015). Becoming Black is a process of racial self-identification, or adoption of Black consciousness that may prove valuable in assessing Black Canadians hermeneutical stances on Blackness and Black consciousness formation (Creese 2018, Dei 2018, Dei \& James 1998, Ibrahim 2004; 1999). During this process, a person racialized as Black begins to center Blackness in one's identity, as opposed to other markers, and espouses a desire to learn how race and colonialism operate and are navigated (Creese 2018, Dei 2018, Dei \& James 1998, Ibrahim 2004; 1999). Becoming Black is not a universal or static process and one may experience or encounter this prior to exposure to white supremacy in a Canadian context (Creese 2018, Dei 2018, Dei \& James 1998, Ibrahim 2004; 1999).

Based on Canada and South Africa's shared status as settler colonies, I am interested in forms of Black consciousness developed by Black South Africans. In South Africa, antiapartheid movements such as the Black Consciousness Movement were defined by leaders such as Steve Biko (Magaziner 2010). For Biko, Blackness was not a biologically predetermined negative cast but rather a psychological form of liberation possible through one's pro-Black shift in mentality (Magaziner 2010). This definition of Black consciousness is unique as it emphasizes 
a pro-Black shift in thought and is racially inclusive of all seeking liberation from apartheid including Colored (mixed) people, and Indian people (Magaziner 2010). Biko (1978) broke from the biological determinism of Blackness underlying previous Pan-Africanist discourses to establish transracial solidarity centered on Black liberation in a settler colonial context. Within this movement "a white man who identified himself fully with the black cause would qualify to be referred to as black" (Snail 2009: 62). This definition was formulated based on the historical specificity of apartheid, and the oppression of people racialized as non-white in South Africa (Magaziner 2010, Snail 2009). Might settler colonies such as Canada warrant, as Biko demonstrated with Black consciousness, a politicized pro-Black shift in one's hermeneutical stance alongside curated units of analysis for Black liberation? The 'unit of analysis' here is the diasporic consciousness of Black radical resistance based on a dialectic matrix of colonialism and enslavement that continues to guide Afro-Canadian leadership within Ottawa as the national capital region of a settler colonial state (Horne 2018, Leroy 2016, Robinson 1983).

Acknowledging oneself as a person of African descent who is racialized as Black may present a source of solidarity that African Canadians can use to acknowledge and embrace difference (Bledsoe \& Wright 2018, Dei 2014, Thomas 2018, Walcott 2019). Pan-Africanism remains a viable theoretical concept to build unity amongst ACB Canadians with diverse Black consciousness who are not settlers in the same context as one another, or as white settlers, and require a regionally relevant "politics of language, leadership and place" to navigate these complexities (Dei 2019: 350-1). This domestic diasporic politic should be accompanied by what Fanon (1968: 247) named a national consciousness, or maintenance of a transnational awareness of the constitutive relationship between nationalism and colonialism, rather than a nationalist consciousness for colonized peoples during the decolonization era. Within this transition to a 
Black diasporic national consciousness exists a need for scale between 'local' and 'national' and 'regional' and 'global' guided by a Pan-Africanist awareness.

\subsubsection{Academic Trends: Afropessimism in Black Studies}

The BRT includes academic trends such as Black Studies. A recent development within Black Studies, Afropessimism, presents a key theoretical framework for Black Canadians to articulate their racial experiences as it centers the negative aspects of Black experience: antiBlackness. Anti-Blackness is a key concept that may prove heuristically helpful to African Canadian social movements in Canada.

\section{Black Studies}

Black Studies ${ }^{7}$ is an interdisciplinary and multidisciplinary academic field formally institutionalized in 1968 due to political demands of African American student based-groups (Colón 2008, Hayes 2000, Mazama 2003, Karenga 2009). Black Studies in the context of the U.S. cannot be translated over into Canada due to a "disavowal of the particularities of Black difference" (Walcott 2019: 40). A transition from a primarily domestic African American or Africana Studies to globalized Black Studies will enable recognition of the multiplicity of Blackness worldwide (Sexton 2010, Walcott 2019; 2003). Two examples of this potential are Black Canadian Feminisms and Black Canadian studies, growing disciplines that lack recognition and resources from Canadian universities (Barnstead 2008, Hudson \& Kamagusha 2014, King 2019, Wane 2009).

${ }^{7}$ Also known as Pan-African Studies, Afro-American studies, Africology, African and Afro-American Studies, Africana Studies or African American Studies (Mazama 2003) 


\section{Afropessimism}

Historically, Afro-Pessimism and Afro-Optimism were two opposing views on the future of the continent within African Studies (Rieff 1999). In the late 2000s Black Studies scholars removed the hyphen in Afro-Pessimism to describe the growing ontological study of Blackness (Day 2015, Gordon 2018). Afropessimism developed in response to the perceived failure of studies of race and colonialism to adequately theorize enslavement or the negative aspects of Black life (Curry \& Curry 2018, Dei 2014, Leroy 2016, Rotz 2017, Sexton 2016, Wilderson 2010). This perspective centers Blackness based on the notion that due to the ontological nature of anti-Black racism, Blackness should be defined and analyzed in terms of social relationality rather than cultural or personal identity (Hartman 1997, Wilderson 2010; 2020).

Although not Afropessimists, concepts provided by Orlando Patterson (1982) and Saidiya Hartman $(1997 ; 2007)$ are central to this school of thought (Wekker 2020). Patterson (1982) defines slavery as social death due to natal alienation, generalized dishonor, and violent domination. For Afropessimists "modernity emerges in the equation of slavery as social death with blackness" in which being Black equates to the exceptional social condition of enslaveability, or a violent social death that recreates itself without reason (Shulman 2018: 119; see also Day 2015, Grimes 2018, Patterson 1982, Wilderson 2010). Racism towards Black people, or anti-Blackness, is exceptional as it is the condition for participation in modern humanity for all non-Black people and central to all contemporary forms of racial discrimination (Gordon 2018, Olaloku-Teriba 2018, Sexton 2016, Shulman 2018, Wilderson 2020). There exists no triangulation of oppression or sources for solidarity for Black people, as there are for groups such as the Native American, premised on a cartography of land (Wilderson 2020). To demonstrate this, Afropessimists point to the notion that some liberation movements, such those 
under the umbrella of Indigenous sovereignty, may not encompass abolition or reparations (Day 2015, Leroy 2016). Afropessimists echo the need for transnational Black studies as they trace this position of non-being to the Trans-Saharan slave trade on the African continent prior to European imperialism (Sexton 2010, Wilderson 2020).

Afropessimism builds on Black feminist conceptualizations of the project of abolition as incomplete to present slavery as a space of unthought (Hartman 2007). Akin to settler colonialism, slavery is an ongoing dynamic and historicizing slavery minimizes ongoing legacies of Black enslavement and the continuing commodification of Black people (Bledsoe \& Wright 2018, Day 2015, Evans et al. 2003, Horne 2018, Leroy 2016). This dynamic, described as the "afterlife of slavery" is due to the infinite disposability and unpredictable, irreconcilable, unending, gratuitous violence that characterizes Black life at the hands of the settler state (Hartman 2007: 6). Afropessimist definitions of anti-Blackness are primarily articulated through the "afterlife of slavery" based on the positionality of the theorists, and the social, economic, and political impact of the Transatlantic slave trade on modern society (Day 2015, Grimes 2018, Okoth 2020, Sexton 2016, Wilderson 2020; 2010).

Slavery's afterlife is enabled by Black fungibility, or a process of commodification where enslaved folks were rendered interchangeable, non-human beings thought to exist for white supremacist exploitation (Hartman 1997; see Bledsoe \& Wright 2018, King 2014). Calls to center Blackness within studies of race, white supremacy, and settler colonialism in Canada and the U.S. should engage "Black fungibility — rather than Black labor" as this concept "represents the unfettered use of Black bodies” as 'simply' surplus, replaceable labor (King 2019: 24). Similar to the irreconcilable violence that characterizes fungibility, there are no bounds to AfroCanadian resistance (King 2019, Maynard 2019). Feminist interventions into studies of race, 
settler colonialism and enslavement such as intersectionality, positionality, the afterlife of slavery, and Black fungibility present precise conceptual tools to theorize anti-Black systems of gender, labor, ownership, privilege, and power as well as corresponding manifestations of AfroCanadian leadership and resistance (Hartman 1997, King 2019, Maynard 2019).

Critics from various perspectives have critiqued discourses of multiculturalism and postracialism for failing to theorize enslavement (Bledsoe \& Wright 2018, Hartman 1997, King 2019; 2014, Maynard 2017, Rotz 2017, Thobani 2018). Afropessimism adds to this conversation by examining how discourses of reconciliation are often negotiated as a binary between settlers and Indigenous people. When enslavement is included, colonial violence is often theorized within what Tuck and Yang's (2012: 2) "triad structure of settler-Indigenous-chattel slave" (see also Wolfe 2006, Veracini 2016). This is what Wilderson (2010: 28-30) names the "settler/ savage/ master/ slave grammatic structure" or what King (2019: 44) calls "the triadic EuropeanNative-Black frame." This frame is used to "prioritize the settler-Indigenous binary and subordinate - erase - the nation's own history of slavery and anti-Black racism through a project of multiculturalism that focuses on assimilating (Black) immigrants into its national project" (King 2019: 44). This serves to minimize the constitutive relationship between enslavement and indigenous genocide within the context of white supremacist settler colonialism and fade the colonialist relations that maintain British imperialism on the African continent as well as in the diaspora (Day 2015, Hartman 1997, King 2014, Leroy 2016, Robinson 1983, Smith 2010). Centering Blackness places one outside this triadic frame to examine the constitutive relationship between slavery, colonialism in Africa and settler colonialism in Canada, and the contributions of ACB Canadian leadership (Day 2015, King 2019; 2013, Leroy 2016, Rotz 2017, Rowe \& Tuck 2016, Wilderson 2020). 
Afropessimist definitions of anti-Blackness rely on domestic U.S. frames of thinking that disappear African experiences with imperialism and effectively undermine the "real complexity of a black world increasingly differentiated and divided" (Shulman 2018: 123; see also Bledsoe \& Wright 2018, Okoth 2020, Olaloku-Teriba 2018, Sexton 2010, Thomas 2018). Despite acknowledgement of the trans-Saharan slave trade, Black exceptionality in this frame is based on a centrality of the afterlife of transatlantic enslavement which seeks to differentiate Black people from any immigrant group (Park 2020). Therefore, it is unclear what the relationship is between Afropessimism and theorizations of Blackness for immigrants who are racialized as Black. Afropessimists' tendency to universalize African American experiences and the potential disconnect from African, Indigenous, or other oppressed groups based on Black exceptionality are main points of contention relevant to Canadian theorists (Jackson-Brown 2020, Leroy 2016, Okoth 2020, Olaloku-Teriba 2018, Schulman 2019, Wekker 2020). Some argue that Afropessimism overemphasizes social death, denying or minimizing Black agency, maternal insurgency, and hope (Jackson-Brown 2020, Shulman 2018, Wekker 2020). Others point to the sometimes radically positive results that failed revolutionary movements or colonized minds can produce (Gordon 2018, McNeil 2011).

Prominent Afropessimist Frank Wilderson III's exposure to and participation in antiapartheid movements in South Africa did not produce definitions of anti-Blackness that account for varying constructions of Blackness worldwide (Bledsoe \& Wright 2018, Okoth 2020, Thomas 2018). Olaloku-Teriba (2018: 111) names this "the Afro American desire for genealogy of 'slaveness' to overwhelm imperial encounters in Africa." It is not clear if Olaloku-Teriba (2018) is a continental African or if this critique is shared by a wide range of continental Africans. Still, anti-Blackness cannot be dismissed as a viable pan-African concept based on the 
centrality of transatlantic enslavement. Rather, multiple, transnational definitions of Blackness, anti-Blackness, and versions of Black/ Africana studies must emerge that are guided by PanAfricanism, Black feminism, and both a Black and national consciousness for use in both a domestic non-U.S. and globalized transnational context (Bledsoe \& Wright 2019, Dei 2014, Okoth 2020, Olaloku-Teriba 2018, Shulman 2018, Thomas 2018).

A pan-African extension of the Afropessimist definition of anti-Blackness would account for the afterlives of enslavement and colonialism on the African continent and the diasporas (Dei 2014, Okoth 2020, Rotz 2017). This definition of anti-Blackness may provide a community as diverse as Black Canadians a means by which to articulate their Black consciousness and the nature of anti-Black racism within Canadian multiculturalism. As Kevin Okoth (2020: 15) argued "the object of analysis is not the afterlife of slavery but the multiplicity of afterlives of slavery and colonization" in efforts to "study how these exist within a global system structured by imperialism." My focus is on the centrality of racial capitalism in white supremacist settler colonies, such as Canada, to the maintenance of British imperialism. Expanding the definition of anti-Blackness to include the global imperial project may assist Afro-Canadians from varying backgrounds with identification, conceptualization, and articulation of their racial experiences in settler colonies (Day 2015, Bledsoe \& Wright 2018, Thobani 2018). Definitions of anti-Blackness inclusive of the afterlife of slavery and varied continental experiences of colonialism create space for domesticized and globalized Black consciousness that acknowledge Black multiplicity, celebrate difference, and emphasize the interconnected nature of Africa and the diaspora (Okoth 2020). 


\subsection{Conclusion}

Influenced by rich interconnections between activism and theory and a long-standing BRT, theories of race which center Blackness are gaining prominence in Canadian sociology. Canada's BRT can be traced to resistance formulated by enslaved Africans to remove racialized relations of oppression such as enslavement and imperialism. This tradition is evident in social movements such as Pan-Africanism or Black Consciousness and academic movements such as Afropessimism which present analytical frameworks, means of comprehension, and locations for social action regarding African Canadian people's multiple identities (Gooden 2019). These analytical frameworks are vital to 'see' the BRT, navigate "the multiplicities of blackness in Canada" and respond to state policies such as multiculturalism or anti-racism (Walcott 2003: 40). Adoption of a Black diasporic national consciousness, alongside engagement with Pan-Africanist regional (provincial/municipal) conscious "language, leadership and politics of place" may account for how while anti-Black racism is globally exploitative it does not use all Black people in the same manner (Dei 2019: 350-1; see also Bledsoe \& Wright 2018, Fanon 1968, Walcott 2003). This process would be emboldened by transnational dimension such as Pan-Africanism which provides diverse accounts for varying formations of Blackness worldwide. The next chapter will provide context for the unit of analysis in this project, Afro-Canadian leaders in Ottawa, by outlining the relationship between the movement of Afro-Canadian people to Canada, law, and leadership. 


\section{Waves of Change: ACB Immigration, Anti-Black Legislation, and Leadership}

\subsection{Introduction}

The chapter begins by looking at the relationship between ACB peoples' arrival to Canada, anti-Black policy making, and the development of a BRT of resistance. Black people came to Canada in three major waves (Mensah 2002). During the most recent wave, the demographics of the ACB population has changed due to an influx of African migrants (StatsCan 2017b). Canadian race relations are negotiated through the medium of law, so it is necessary to examine policies that arose as Black populations increased (Thobani 2018). Examination of this intersection confirms a tradition of anti-Black racism in Canadian policy and the consistency of Black mobilization against it (Cooper 2007, Flynn 2014, Henry 2018, Walker 1984, Winks 1997). I will close by focusing on Ottawa and addressing the conditions of systemic antiBlackness Afro-Canadian leaders in the national are currently navigating.

\subsection{Wave One: Settler Colonialism and Enslavement, 1605 - 1867}

Black people are portrayed as "perennial newcomers" yet have been in Canada longer than any other non-European settler group (ACLC 2003, Garner 2011, Mullings et al. 2016, StatsCan 2017). The first written record of ACB people in what is now Canada were Africans who came as interpreters during European colonization (Johnston 2001). These Africans were complicit with the establishment of settlements as colonialists relied on people with specialized trading and linguistic skills known as "grumetes" (Johnston 2001: 153). Two of the first Black men in Canada in the early 1600s, Mathieu Da Costa and Jan Rodriguez, may have belonged to this class as they were hired to act as trade interpreters and guides due to their knowledge of the language and customs of Europeans and First Nations on the Atlantic coast (Henry 2018, Johnston 2001, Winks 1997). Da Costa originated from Madagascar or Guinea, while 
Rodriguez's origins are not documented (Johnston 2001, Winks 1997). While their names are not preserved in history, Wane (2009: 74) references Da Costa and Rodriguez to point out that "since the arrival of African peoples in Nova Scotia in 1605, African women were at the forefront of liberation, education, maintenance of cultural values and emotional healing."

Canada has a lengthy history of enslavement of First Nations and Black people. The French kept Indigenous slaves known as panis in defiance of prevailing European imperial logic that Indigenous people were not "suitable for slavery" (Maynard 2017: 21 see also Winks 1997). Emphasis here is on the Black experience as this reveals Canada's hidden anti-Blackness such as referral to the enslaved as "servants" (Henry 2018, Maynard 2017, Reimer 2000, Winks 1997). A boy baptized in 1628 under the name Olivier Le Jeune was the first recorded Black person to have been brought from Africa - likely Madagascar - to be enslaved (Henry 2018, Reimer 2000, Winks 1997). When asked if he desired to attain whiteness through his baptism, the boy espoused a Black consciousness responding that those performing the baptism would need to remove his skin (Henry 2018, Winks 1997).

In 1869, slavery was legalized in New France to meet increased labor demands (Cooper 2007, Winks 1997). Enslaved people worked in white owned businesses, performed domestic duties, completed general labor, and were skilled tradesmen (Cooper 2007). They completed tasks such as cooking, cleaning, childcare, gardening, caring for livestock, planting crops, constructing homes, clearing lands, mining, stone masonry, carpentry, sail making, shoemaking, hunting, sailing, navigating, and fishing (Henry 2018: 4; see also Cooper 2007, Walker 2013). Division of labor was gendered, and women performed tasks such as soap making and washing clothes (Cooper 2007, Henry 2018). Although victimized, the enslaved used individual resistance tactics such as faking sickness, breaking or destroying tools/ livestock/ property, refusing work, 
or attempting to flee (Cooper 2007). Marie Angelique, a Black woman born in Portugal, enslaved in New England and then New France, was executed for burning Montreal during an attempt to escape in 1734 (Cooper 2000). Some argue that it was an act of resistance but there is no proof that Angelique committed this crime (Cooper 2000). Angelique is a feminist symbol of the intersections between enslavement, state violence and Black women's insurgency (Cooper 2000). More threatening to the institution of slavery were collective acts of resistance such as rebellions, revolts, murder, and maroonage or self-determined emancipation (Cooper 2007).

Black slavery was subsumed and extended under British rule ${ }^{8}$ (Cooper 2007, Maynard 2017, Mensah 2002). The British allowed existing slavery to continue and encouraged Loyalists to bring enslaved people from the United States ${ }^{9}$ (Henry 2018, Maynard 2017, Reimer 2000, Whitfield 2016, Winks 1997). This led to approximately 3,000 enslaved African Americans arriving and legislation rendering children born to an enslaved mother the same status (Cooper 2017, Henry 2018, Whitfield 2016). Black Canadians fled to the northern U.S. while African Americans used British policies during the American revolutionary war to come to Canada as Black Loyalists (Hill 2007, Howe 1864, Reimer 2000, Winks 1997). After losing, the British compiled a "Book of Negroes" which was "the first massive public record of blacks in North America" (Hill 2007: 2). This ledger freed 3500 Black men, women and children who served in the British military for at least one year (Clarke 1996, Hill 2007, Winks 1997). Some went to Quebec or Europe and a large number to Nova Scotia to establish communities in Birchtown, Halifax, Shelburne, Digby, and Sydney (Hill 2007: 3). By 1784 the 1,500 Black people in

\footnotetext{
${ }^{8}$ After Britain won the Seven Years War, the Treaty of Paris in 1763 ceded New France to Britain (Winks 1997).

${ }^{9}$ The Articles of Capitulation (1760) legalized the right to own slaves during the Seven Years War on behalf of both the French and British crowns (Winks 1997).
} 
Birchtown, Nova Scotia made up the largest free settlement outside Africa (Henry 2018). Within the established Black communities were Black owned businesses, churches, fraternal organizations, mutual assistance bands, temperance societies, and anti-slavery groups (Walker 2013: np; see also Gooden 2008). Freedom from enslavement did not mean political parity. Promises made by the British did not materialize and legally free Black people were exploited as a fungible source of free labor or had working conditions that paralleled the enslaved (Hill 2007, Maynard 2017). White Loyalist soldiers, unhappy with Black people in their employment and living spaces, held what is known as the Shelburne Riots in 1784, the first recorded race riot in North America (Hill 2007).

Canada's first anti-slavery legislation occurred due to Black abolitionist mobilization for Chloe Cooley (Cooper 2007, Henry 2018, Winks 1997). Cooley was an enslaved girl who was beaten, bound, and sold to an American. British law prevented prosecution so the first antislavery bill, the Simcoe Act, was introduced in 1773 (Cooper 2007, Winks 1997). Focused on property rights, the act prohibited importation but did not free existing slaves (Cooper 2007, Winks 1997). The British formally legalized importation of slaves via the Imperial Statute of 1790 and many areas did not place limitations on importation of the enslaved until 1800 (Winks 1997). Approximately 1,200 Afro-Canadians in Nova Scotia chose to relocate to Sierra Leone in 1792 (Reimer 2000, Walker 1976). Some enslaved people were imported from the West Indies, however the first large group of Caribbean migrants in this wave arrived in 1796 when a group of exiled Jamaican Maroons landed in Halifax (Henry 2018, Mensah 2002, Walker 1984). Maroons brought with them a radical consciousness, and many refused to assimilate eventually leaving for Sierra Leone (Walker 1984). 
During the War of 1812, African Americans were again promised freedom through British military service (Maynard 2017, Winks 1997). The Black Settlement Plan of 1819 legally protected their freedom in what's now Canada (Winks 1997). However, slavery was not formally abolished or drastically reduced until $1834^{10}$ (Winks 1997). This freed children under six, committed children over six to a (maximum) six-year apprenticeship, and, notably, compensated slave owners for their property losses (Winks 1997). Afro-Canadians who were enslaved, or who are the descendants of the enslaved were not and have never been compensated. Emancipation was followed by the Fugitive Slave Act ${ }^{11}$, and a wave of fugitives and entrepreneurs who made their way north seeking freedom (Maynard 2017, Walker 2013, Winks 1997). Canada's position as a "safe space" via the Underground Railroad during this wave is officially lauded as the entirety of Canadian history in relation to slavery (Cooper 2017).

There is a myth that Canadian slavery was benign because there were no large plantations (Cooper 2007, Maynard 2017). Enslaved people, especially women, endured extreme levels of torture and surveillance alongside high rates of sexual assault due to proximity to their enslavers (Cooper 2007, Maynard 2017, Winks 1997). Take for instance fifteen-year-old Diana Bastian, who was raped by a prominent politician and lost her life while giving birth to twins in 1792 because of neglect (Cooper 2017). Conditions were so poor that a "Reverse Underground Railroad" developed in which escaped African Americans and enslaved Black Canadians fled from Canada to the Northern United States (Cooper 2017, Maynard 2017). Those that stayed or attained their freedom in Canada organized vigilant watch groups to protect their communities (Maynard 2017). A number of Black women espoused an abolitionist feminist consciousness,

\footnotetext{
${ }^{10}$ This was done through an act of the Imperial Parliament (Winks 1997).

${ }^{11}$ This act criminalized escaping from enslavement (Winks 1997).
} 
later complemented by a revolutionary Maroon consciousness, in the United States and what became Canada from the 1830s until Canada's federation in 1867 (Taylor 1998).

\subsubsection{Federation: White Supremacy and Canada's Jim Crowe}

From the start, "Canadianness", was racially defined through the praxis of white supremacist nationalism (Stanley 2014). The first Prime Minister, John A. MacDonald mandated an "Aryan Canada" and to "keep Canada white" through strict immigration laws and enforcement of the Indian Act (Stanley 2014: 29). This is often viewed as a personal or moral failure, yet it was a strategic political effort (Stanley 2014). Canadian Jim Crow laws, policies, and practices operated on the logic that Black people were lazy, sexually decrepit, and belonged in Africa because they were unfit for the Canadian climate (Mathieu 2010, Maynard 2017, Walker 1984). Canadians exhibited "negrophobia", or fear of the racial tensions in the U.S. (Mathieu 2010). Foundational Canadian leaders, such as Robert Borden (1908), asserted that "the Conservative party stands for a white Canada," a sentiment mirrored by the all-white immigration policies of the Liberal party at the time (Walker 1984: 9). Every prime minister, whether liberal or conservative, espoused a desire to preserve Canadian whiteness until 1940 (Mathieu 2010). Those who managed to bypass Canada's racist immigration policies included sleeping car porters, miners, farmers, and students and they laid the groundwork for contemporary Black Canadian leadership (Mathieu 2010, Walker 1984).

Sleeping cars were introduced to the Canadian Pacific Railway (CPR) in 1870, and young, university educated, Black men were commissioned to work as the porters (Mathieu 2010). For white Canadian passengers, this provided an environment reminiscent of the American antebellum era, reasserted white male dominance, and reaffirmed the inferiority of Black men as well as Canada's progression to a civilized nation (Mathieu 2010: 11). An updated 
Immigration Act in 1910 meant to address an increase of Black migrant farmers, banned immigration for people putatively not meant for the cold environment (Mathieu 2010, Winks 1997). Du Bois and other leaders challenged the Canadian government, citing they were using the international border to draw a color line (Mathieu 2010). Of the ACB people granted entry into Canada in between 1900 and 1940, many were men from the United States and the Caribbean coming to work as porters (Mathieu 2010). These men's travels led to a transnational awareness of Black issues and the establishment of connections between Canada and the rest of North America through a "powerful diasporic consciousness" (Mathieu 2010: 18).

Black women were heavily involved in the church, among other religious communities, at this time. In 1902, African American women in Montreal whose husbands were porters established the first organization of Black women in Canada, the Women's Club of Montreal (Colored Women's Club [CWC] 2005). Excluded from other women's groups because of their social location they later renamed themselves the Colored Women's Club of Montreal and sought to reduce poverty and enhance Black inclusion (CWC 2005). They were a "beacon in the Black community" that contributed to many "firsts" such as the first Black church in Montreal (CWC 2005: n.p.).

\subsection{Wave Two: Racialization of Labor, 1900s - 1980}

Settler colonialism and enslavement included the arrival, settlement, and departures of enslaved and free Africans, Black Europeans, African Americans, and Caribbean people. Wave two featured a transition to Caribbean dominated immigration from the early 1900s until the mid-1970s (Gooden 2008). Prior to 1981, 56.7\% of Black immigrants were born in either Haiti or Jamaica (Mensah 2002, StatsCan 2019). Today, Jamaicans (19.7\%) and Haitians (14.8\%) are the largest Black immigrant groups in Canada with the longest standing ties (Mensah 2002, 
StatsCan 2019). Approximately $20 \%$ of Caribbean migrants during this wave were of IndoCaribbean descent and have an overlapping but distinct history and contemporary experience (Walker 1984). Influence from this wave of Caribbean people characterizes Black thought (Austin 2007, Calliste 1995, Dei 2019, Maynard 2017, Mensah 2002, Walcott 2019).

\subsubsection{Immigration: Canada's Afro-Caribbean Connection}

Caribbean migrants were greeted by fourth and fifth generation African Canadians who, largely due to the failure of the Canadian government to create equal opportunity, created their own organizations (Gooden 2008). Long standing ACB people had a strong Black Canadian identity and did not take on multiple identities while Caribbean migrants espoused double or multiple consciousness of "Blackness", "Caribbean", and sometimes, "Canadian" (Gooden 2008). Some also espoused a radical, Pan-African Black consciousness and brought with them political prowess from navigating the British empire (Mathieu 2010). Many of the organizations, such as the Home Service Association (HSA), created by Black Canadians, were "avoided" by Caribbean migrants, who created their own such as the West Indian Federation (WIF) (Gooden 2008).

In 1905, prominent African Americans met in Fort Erie, Ontario and formed the Niagara Movement (Du Bois 1905, Walcott 2003, Wolf 2008). This eventually became the National Association for the Advancement of Colored People (NAACP) in the United States (Walcott 2003, Wolf 2008). No women or Black Canadians were present at the initial meeting (Walcott 2003, Wolf 2008). This exclusion is significant, since Blacks in Canada, many of whom had African American ancestry, contacted the organizers in hopes of participating (Walcott 2003). It is not clear why they were rejected however their denial represents the complexity of Canada as a site of "ambivalent freedom" for non-Canadian Black people (Walcott 2003: 32). Ambivalent 
freedom refers to how Canada has provided a "location for post-emancipation and post-national independence for Caribbean migrants, and more recently for continental African migrants" as well as "a sanctuary for escaping enslaved African-Americans and their descendants" (Walcott 2003: 40).

Following their service in World War 1 disappointed Caribbean veterans such as John Arthur Robinson took on leadership roles within the Black community (Mathieu 2010, Walker 1984). Robinson served in the Canadian League for the Advancement of Colored People (CLACP), established in 1924 when the NAACP in the United State encouraged CPR divisions in Calgary, Winnipeg, Montreal, Toronto, and Edmonton to organize (Calliste 1995). He founded the Recognized Order of the Sleeping Car Porters (OCSP) in 1930 which bettered labor conditions for porters (Mathieu 2010). Canada served as a meeting ground for organizations such as the United Negro Improvement Association (UNIA) in which the Montreal UNIA emerged as a stronghold of the worldwide movement (Esedebe 1994, McDuffie 2016, Schramm \& Buttler 2010, Reddock 2014). Students and other Black Caribbean Canadians made up most of the UNIA's leaders, organizers, and members from 1919 until 1940 (McDuffie 2016). Afro-Canadian Canadians espoused a "racial uplift" policy that united institutions such as the church, Freemason lodges, the CLACP, and the UNIA (Mathieu 2010: 143). However, Caribbean organizations maintained an ethnic or nationalist link to their nations of origin which created issues for localized coordinating (Gooden 2008).

During the Great Depression African Canadian leaders contested segregation in Canada's Supreme court (Mathieu 2010). As a result, the GO and shortly after the GOC passed the first anti-discrimination law in 1940 (Winks 1997). Legal frameworks failed to eliminate racism and Caribbean immigrants mobilized against racist immigration laws, lack of employment 
opportunities and racism in the workplace (Flynn 2014, Walker 1984). This can be seen in the emergence of organizations such as the Canadian Negro Women's Association (CANWA) and Negro Citizenship Committee (NCC), both intended to bridge the gap between Caribbean and Canadian-born Black people of all classes and backgrounds (Gooden 2008). CANWA's introduction of Caribana in 1955 led to a Caribbean Caribana Coalition ${ }^{12}$ (CCC) which failed and "foreshadowed how other Black groups would become subjugated to government funding, and as a result, become controlled by the state" (Gooden 2008: 419). This was made possible by active political delegitimization such as government provision of funds to rival groups and has characterized Black organization attempts since (Gooden 2008).

When upwards of 1,000 Caribbean people began migrating to Canada annually in 1952 a more restrictive immigration policy was reintroduced in efforts to, once again, prevent immigrants based on "citizenship, nationality, ethnicity and geographical area of origin" (Walker 1984: 10). Primarily Black Jamaican and Barbadian women were ushered into Canada's paid labor force via the Caribbean or West Indian Domestic Scheme in 1955 (Mensah 2002, Flynn 2014). The government allowed 100 single women, between the ages of 21 and 35, to enter each year (Jones 2017). These women were legally contracted to work for one year, and eligible to apply for citizenship and sponsor family after five years, which many did (Jones 2007; see also Winks 1997, Walker 1984). After five years, the number of women entering tripled (Jones 2007). By 1961, the Black community had visibly outlined their needs to the greater Canadian community (Walker 1984). Canada's all white immigration policy was overturned in 1962 which

\footnotetext{
${ }^{12}$ This was a pan-Caribbean committee of mostly men formed in Toronto to unify the Caribbean community and build on the idea of Caribana. Through this coalition, Caribana became a longstanding street festival (Gooden 2008: 419).
} 
coincided with Jamaican independence, and tougher immigration policies in other European nations with large Jamaican populations, such as the United Kingdom (Jones 2007, Mensah 2002, Walker 1984). In response to the increased "ethnic vote" as well as globalized decolonization movements, then Prime Minster Diefenbaker sought to make colorblindness, or the notion of not seeing color, the cornerstone of Canadian race relations (Walker 1984: 12). Discourses of white supremacy were replaced with colorblindness and multiculturalism to accompany a classist and elitist immigration "point system" (Maynard 2017, Mensah 2002). The Bill of Rights "rejected discrimination" in immigration and prioritized "training, education, and skill," leading to an influx of non-white, professional immigrants from Asia and the Caribbean (Walker 1984: 12). Ontario's need for anglophone teachers and nurses led to over 12,000 skilled Caribbean immigrants settling between 1961-1966 (Walker 1984). Canadian embassies opened in the Caribbean during the 1970s and Caribbean immigration reached its peak (Walker 1984).

Caribbean and African American leaders met from the $11^{\text {th }}$ to the $14^{\text {th }}$ of October 1968 at McGill University when a Congress of Black Writers honored murdered Black heroes of the Civil Rights movement. Speakers included C.L.R. James, Stokely Carmichael and Walter Rodney. One speaker, Rocky Jones, was Canadian, and none of the speakers were women (Austin 2007). Representing a differing national consciousness from that of African Americans, Jones encouraged ACB solidarity with Quebecois and Indigenous struggles (Austin 2007, Calliste 1995, Fanon 1968). Black youth were more militant than older, middle class and bluecollar community developers and organizers (Calliste 1995). Unperturbed by the risk of deportation and frustrated with the moderate demands of older generations, several radical youth organizations emerged between 1968-9. These include, but are not limited to, the moderate Black Liberation Front, the militant Afro-Canadian Liberation Movement in Nova Scotia, and the 
National Black Coalition of Canada (Calliste 1995, Gooden 2019; 2008). In line with the cycle of demise, these programs did not last (Kitossa 2019). Programs that did not require funding were eventually co-opted by the state while those that did require funding were underfunded by the state (Calliste 1995).

In 1973, CANWA organized the first congress of Black women which began a series of conferences until 1982 (Gooden 2008, Mills 2015). One conference included a workshop that revived the intersectional concept of "Triple Oppression" based on gender, class, and race (Mills 2015). The success of these conferences led to the formation of the Congress of Black Women (CBW) in 1980 (Mills 2015). The CBW's mandate included eliminating poverty as well as sexism, health, racial profiling, pay inequity, and institutionalized racism (Mills 2015). They focused on the Black family, how multiculturalism weakened one's ability to change Canadian institutions, and sexuality (Mills 2015). Sexuality came to the forefront when the CBW in Manitoba demonstrated visible solidarity with Black lesbian women in 1982 (Mills 2015). Advocacy for sexuality as a category of gendered oppression shaped the development of theory, Black feminist praxis, and Black leadership in Canada (Mills 2015).

\subsection{Wave Three: Multiculturalism and Immigration}

Africans previously trickled into Canada in small numbers as interpreters, enslaved people, students, and professionals. The third wave is marked by a formal political transition to multiculturalism and colorblindness, as well as a dominance of continental African immigrants amongst Afro-Canadian migrant populations. At just under 1.2 million, the number of ACB people in Canada has increased 76.2 \% since 1996 (StatsCanada 2019; 2017). Prior to 2011, most Afro-Canadian people were migrants who were sponsored by family (StatsCan 2019). From 2011 to 2016, there was an increase in African economic migrants and refugees (StatsCan 2019). 
In 2016 African immigration surpassed Caribbean, making continental Africans who are relatively recent immigrants the largest proportion of Black Canadians.

From an African perspective, three major periods within this third wave of immigration to North America are evident. The first occurred between the 1950s and 1970s when intellectuals were sent to the United States and Canada to prepare for "nation building" following decolonization (Arthur et al. 2012). After the 1970s, many Africans began looking for a way out due to political conflicts or neoliberal policies to attain political, economic, or social security (Arthur et al. 2012). For example, Nigerians began arriving in 1967 during the Biafra War and Ghanaians following the neoliberal policies in the 1980s (Arthur et al. 2012, Mensah 2002). An increased number of Africans arrived at a time when in response to labor needs, Pierre Trudeau's government introduced the first version of a Multicultural Policy in 1971 (Maynard 2017). Immigration policies were updated to include new restrictions focusing on occupational and employment experience rather than education, and individual persons rather than families (Mensah 2002). Municipal, provincial, and federal anti-racist frameworks of diversity and inclusion legislation aimed at creating a society free of racism and xenophobia began to emerge (King 2014, Nájera \& Maldonado 2017).

Data regarding women, Aboriginal people, non-white people or visible minorities, and disabled people was first collected in the 1981 census (StatsCan 2017). Visible minorities describe "persons, other than Aboriginal peoples, who are non-Caucasian in race or non-white in colour" (Employment Equity Act 2017: C. 44 S. 3; see also StatsCan 2017). The Canadian state's reluctance to identify racial demographics leads to the problematic grouping of Black people as “visible minorities" (James 2019: 5; see also BEP 2017). For Statistics Canada, Black Canadians represent "a vastly diverse community of people in terms of history, ethnic and cultural origins, 
place of birth, religion and languages" (StatsCan 2019: n.p.). Despite this, the racial category, "Black", is the official population marker for people of African descent. This is only done with one other group, Whites, while other visible minorities are not racially but nationally, ethnically, or geographically categorized.

Multiculturalism was introduced as a policy in 1971 and formally inducted as an act in 1988 as state recognition of cultural diversity within the population. By that time, long standing anti-imperialist or political conflicts and recently introduced neoliberalist policies created unsavory environments in some nations on the African continent (Arthur et al. 2012). Almost a revival of the middle passage, the number of Africans immigrating to Canada has tripled since the 1980s (Loxley et al. 2015). Some come by choice while other movements are determined by political conflict, neocolonialism, or legacies of imperialist relations of power (Arthur et al. 2012). For instance, some Africans are leaving as refugees with little social capital, while onethird of all African migrants have a bachelor's degree, and $2 \%$ have specialized degrees in dentistry, medicine, and the like (Loxley et al. 2015). This percentage of educational attainment is higher than the average of all Canadian immigrants and has contributed to what some have named an African "Brain Drain" (Loxley et al. 2015).

Continental Africans prefer forms of social or political mobilization such as nationalist, ethnic, or regionally based organizations that are often led by university educated professionals (Arthur et al. 2012). These organizations can be on a national basis, such as the National Congress of Ghanaian Canadians, ethnic basis such as one's ancestral or ethnic background, or hometown basis such as one's place of birth in their nation of origin (Arthur et al. 2012). Which type of association develops depends on forms of social organization in their countries of origin and the distribution of immigrants in the residential area. For example, hometown associations 
are common especially in West African communities. Many national associations are geographically based in Toronto or Montreal, where most Black people live (Arthur et al. 2012). As these organizations are often geared towards settlement for African immigrants, factors such as high levels of education, higher levels of income, and longer length of stay in Canada impact one's likelihood to join (Arthur et al. 2012). Immigrants who are $2^{\text {nd }}$ or $3^{\text {rd }}$ generation or more are usually not present as these organizations do not serve their needs. These types of organizations can preserve animosity across ethnic groups (Arthur et al. 2012). National organizations developed to minimize such conflicts, and out of a need for collective survival as immigrants. These have potential to force the creation of identities recognized by the host country but not necessarily the immigrants themselves, such as Blackness (Arthur et al. 2012).

\subsection{Anti-Racist Policy Making: Anti-Blackness, Mobilization and Law}

During this influx of African migration, and perhaps based on the discourse of a crisis of leadership within ACB communities, a shift towards organizing against anti-Black racism in Canada's Afro-Canadian communities occurred. Recently, pressure from transnational social movements such as BLM, and national, provincial, and municipal organizations have resulted in or influenced the formation of anti-racism policies. Federally, transnational institutions such as the United Nations (UN) centered Blackness via a Declaration of the Decade for people of African Descent (UNDPAD) from 2015 - 2024, and a special working group that assessed antiBlackness in Canada in 2016. The UN working group found that legacies of slavery and antiBlack racism have detrimental impacts on African Canadians (United Nations Human Rights Council [UNHRC] 2016). Forty-two recommendations were made for all levels of Canadian government including reparations for enslavement, legal recognition of Black Canadians as a distinct group, and disuse of the homogenizing term visible minorities (UNHRC 2016). Soon 
after, Prime Minister Justin Trudeau acknowledged anti-Black racism in Canada and the GOC (2019: n.p.) held a series of engagement sessions ${ }^{13}$ in 2017 to, "gather input from Canadians, especially those with lived experiences of racism and discrimination, in order to help inform the development of a new federal anti-racism strategy." Prime Minister Trudeau again acknowledged Canada's anti-Blackness in February of 2018 (The Canadian Press 2018, GO 2017, Tasker 2020).

Provincially, the first document to call for the elimination of anti-Black racism in Ontario's criminal justice, child welfare, and education system was the Stephen Lewis report in 1992 following the Yonge Street riots ${ }^{14}$ (Calliste 1995). The GO established an Anti-Racism Directorate (ARD) on February 4, 2016, ten years after it had originally been promised (GO 2017: np). The ARD met with racialized communities to develop a mandate and released its Anti-Racism Strategy (ARS) in March 2017, passing the Anti-Racism Act four months later (GO 2017: np). The Anti-Black Racism strategy (ABRS) is a tenet of the act. An anti-Black racism subcommittee was created but it was eliminated under the Ford government (Bueckert 2018, Yang 2018).

Municipally, a forum titled "Addressing Anti-Black Racism in Ottawa" was hosted in 2016. Over 300 community members, most of whom self-identified as Black, participated in small group discussions led by “experts in Ottawa’s Black communities” (Forum 2016: 2-4). Two overarching concerns of the participants were "1) Recognition of Anti-Black racism and

${ }^{13}$ The GOC held twenty-two in-person forums across the country, including approximately 600 people and 443 organizations.

${ }^{14}$ After the acquittal of police officers who brutalized Rodney King, an undercover Toronto Police Officer murdered 22-year-old Raymond Lawrence. A local organization, the Black Action Defense Committee, organized a protest. Afterwards, the protest became what some describe as a youth rebellion or uprising against anti-Black racism rather than riots. Stephen Lewis was commissioned by the Federal Government to investigate race relations in Ontario following this event. 
institutional accountability for addressing it; and 2) Effective civic engagement of Ottawa's diverse Black community members" (Forum 2016: 4). The report indicates that "since the forum, the visibility of anti-Black racism has increased" (Forum 2016: 11). Collaboration amongst ACB leaders led to the election of the city's first Black city councilor, Rawlson King (2019), and police chief, Peter Slolely (2020). King was appointed the city council's liaison for anti-racism and ethnocultural relations (Willing 2020). Anti-Blackness has yet to be specifically addressed in policy. In June 2020, Ottawa announced a budget for an Anti-Racism Directorate that will address systemic racism, and "remove barriers based on race" through ensuring that the city collects race-based data and applies an anti-racism lens in policy development (City of Ottawa [CO] 2020: np). This announcement came after a global rise in the BLM movement following the murder of George Floyd. Student leaders unified under a coalition called No Peace No Justice Ottawa hosted a march to call for a defunding of Ottawa's Police Service, and justice for victims of police brutality in unity with BLM (Pringle 2020). Prime Minister Justin Trudeau attended and symbolically took a knee in solidarity and as a pledge to act. Perceptions of his inclusion, as well as his act of kneeling, were varied amongst Black leaders with some arguing it was an act of virtue signaling while others celebrated it as a symbolic step forward. Moreover, not all Black activists in Ottawa espoused abolitionist perspectives calling for the $\mathrm{CO}$ to fully defund the police as some called for reformative practices such as increased quotas for AfroCanadian officers within Ottawa's police service. This is an example of the diversity in thought amongst African Canadian leaders and people in general. This multiplicity was articulated via a discourse of crisis as newspapers and social media outlets presented Afro-Canadian leaders in Ottawa as disorganized, disunified and unprepared based on the recommendations of some Black led organizations not to attend the march while others voiced their support (Lord 2020, Vlasveld 
2020). Still, thousands gathered, and the march was a success. Another successful protest was organized by Justice for Abdirahman, an advocacy organization founded to address police brutality following the murder of Abdirahman Abdi in 2016 (Lord 2020). ACB leaders were able to organize marches of this magnitude in short spaces of time because of pre-existing networks.

\subsection{The Fire This Time: Racial Reckonings in the Capital}

A recent report about systemic racism in Ottawa compared the experiences of the general population, "racialized" population, and Black population. Racialized and Black populations face underemployment, poverty, poor healthcare services, housing instability, and discrimination in education, child welfare and the criminal justice systems (SPCO 2020). Black people experience high rates of poverty (28.4\%) compared to the general population (12.6\%) (SPCO 2020: 3). Also, ACB people face twice the rate of unemployment (13\%) as the general population (6.8\%) (SPCO 2020: 2). Unemployment rates are nearly triple that of the general population for Black youth (24.8\%) (SPCO 2020: 2). Black people are concentrated in high risk, underpaying jobs in fields such as health, sales, and service that produce lower employment incomes compared to the general and "racialized" populations (SPCO 2020). For example, Black people in Ottawa's average income was $\$ 23,712$ compared to a general average of $\$ 41,055$ (SPCO 2020: 3 ).

Black Ottawa Connect, a Facebook group turned blog founded by an Afro-Canadian leader, identifies at least 48 Black led and Black serving organizations in the region. Some examples include: National Black Law Student Association of Ottawa, a longstanding branch of a national student association founded in 1992 at the University of Ottawa that supports Black law students (BLSA 2020); Black History Ottawa, a charity that promotes African Canadian history and culture, as well community programs (Black History Ottawa 2021); and the AfroCaribbean Mentorship Program (ACMP), recently developed in 2018 to support ACB and 
racialized undergraduate and graduate students attending Carleton, the University of Ottawa, and Algonquin's campuses (Carleton University Faculty of Arts and Sciences 2021). Organizations founded on the principles of maternal advocacy include the Canadian Somali Mother's Association, founded in 2007 to support parents of incarcerated youth and combat the overrepresentation of Somali and other Black youth in the criminal justice system (BlackOttawaScene 2017; see also Menzel 2018). As evidenced by the variation in these associations, Black leaders and Black-serving organizations in Ottawa are diverse and seek to address varying tenets of anti-Black racism. Is there is a rise in what can be described as "PanAfrican" organizations devoted to the unification of people of African descent?

\subsection{Conclusion}

Canada is a space of Pan-Africanism, Black consciousness, and Black liberatory thought (Walcott 2003). A specific set of historical circumstances, such as influence from communities of Caribbean ancestry, forge the intersecting, multiple identities that characterize ACB thought (Austin 2007, Calliste 1995, Dei 2019, Maynard 2017, Mensah 2002, Walcott 2019). As well, the BRT of leadership has played a role in relation to the navigation of national, provincial, or domestic anti-Black policy and multiculturalist space-making practices (Bashi 2004). Black people's history in Canada is distinct and complex, characterized by strategies of resistance, and often articulated through a three-wave model (Mensah 2002). Wave one is characterized by colonialism and enslavement, wave two by the racialization of and demand for labor, and wave three by the era of multiculturalism. Wave three remains ongoing and presents a site of inquiry regarding the impact of an influx of African immigrants on formations of Black Canadian diasporic consciousness. Afro-Canadians have consistently strategized, individually and collectively, locally, regionally, nationally, and transnationally, to resist white supremacy and 
make Canada more habitable for Black people. Black women developed organizations to represent their interests due to patriarchy within Black movements and racism within wider women's movements (Gooden 2019). The next chapter will describe the methods used to explore African Canadian leadership in Ottawa as well as how the Canadian nation state directs or redirects the political possibilities of African diasporic conversations via recent anti-racism, and anti-Black racism legislation. 


\section{Description of Data and Methods}

\subsection{Introduction}

The research methods for this thesis are qualitative, in that emphasis is on description of uncovered social patterns or processes, rather than quantification (Altheide 2000, Bowen 2009). Research was conducted in two phases. Phase one featured a document analysis and phase two consisted of semi-structured respondent interviews. Qualitative document analysis (QDA) is the analytic and systemic review of either print or online documents in qualitative research (Bowen 2009). The data set included some recent federal, provincial, and municipal policies regarding anti-Blackness or anti-racism. Semi-structured interviews include loosely structured, open ended questions that facilitate discussion and provide the respondent with an opportunity to articulate their views in depth. There were twelve semi-structured interviews with ACB leaders in the Ottawa-Gatineau region. The document analysis provides context for the interviews, as well as insight on the governments' contemporary position towards anti-Blackness or anti-racism, plan of action, and commitments to the Black community. The semi-structured interviews address the BRT in Ottawa, Afro-Canadian leadership and understandings of race, Canadian settler colonialism and policy. In so doing, these methods examine Black Canadian racial thought among African Canadian leaders in Ottawa.

\subsection{Document Analysis}

As the concept of anti-racism becomes prominent within Canadian policy, all three levels of government have developed anti-racism bodies in response to the mobilization of AfroCanadian and other racialized communities. Document analysis enables empirical evaluation of such governmental documents (Bowen 2009). While Canada prides itself on being a haven for ACB Canadians, the previous chapter discussed the nation's history of anti-Black policy making. 
Postcolonial theorists argue that political discourses of anti-racism are Eurocentric, and hegemonic tools utilized to maintain existing settler relations. In line with Dei's call for a politics of language and place, this QDA will enable examination of Canadian discourses of anti-racism in regard to Black liberation at a federal, provincial, and municipal level.

\subsubsection{Methods}

The QDA was carried out in five main steps: identification of a data set, developing research questions, creation of a protocol, in depth reading and analysis.

Identification of Data Set: The documents selected for this analysis were the most recent pieces of legislation relating to anti-Black racism or anti-racism in Canada in April of 2020. This includes the federal anti-racism strategy from 2019 - 2022, the provincially instituted Ontario Anti-Black Racism Strategy 2017 - 2021, and Ottawa's Equity and Diversity Policy. The names of the documents in the data set are: Building a Foundation for Change: Canada's Federal AntiRacism Strategy (GOC 2019), Ontario's Anti-Black Racism Strategy (GO 2017), and Ottawa's Equity and Diversity Policy (CO 2017) in the workplace. These documents are publicly available through their respective official governmental domains. Some supporting documents were accessed from library archives such as the Stephen Lewis Report (1992). All the main documents were collected in April 2020 and supporting documents by July 2020 .

Research Questions: To address the question of the effectiveness of Canada's anti-racism policies in creating a "safe space" for Afro-Canadians, this QDA asks these main questions: 1. How is the government responding? For example, where is the locus of responsibility placed? 2. How are racism, anti-Blackness and Blackness in Canada framed or defined within anti-racist policy? 3. Is Canada's position as a settler colony founded on a history of Indigenous genocide, 
enslavement, and forced assimilation acknowledged in anti-racist policies? 4 . What is being promised to or asked of African Canadian communities?

Protocol: To ensure systemic collection of data, a template of a data collection sheet, known as a protocol, was created (Altheide \& Schneider 2013). Initially, an original, base prototype was developed. As documents were read, the protocol was updated. Once reading was complete, the final protocol was utilized as a template for the data set.

Reading and Context: This step includes thoroughly reading the documents. Also, a brief examination of the political climate in relation to which each document emerged: for example, global prompts such as the UNDPAD from 2014 to 2025, the rise of BLM in Ontario, and municipal calls for action such as Ottawa's anti-Black racism forum. Do these external pushes have any impact?

Analysis: The analysis consists of five steps:

(1) Identify the targeted community, and all relevant social actors the document is addressing such as the governmental body responsible for implementing the policy or the group the policy is intended to address.

(2) Identify keywords and topoi. Topoi are key words in specific discourses typically identified during the analysis (Wodak 2009). Wodak (2009: 9) defines topoi as "the content-related warrants or 'conclusion rules' which connect the argument or arguments with the conclusion or the central claim. They justify the transition from the argument or arguments to the conclusion." Different topoi were identified for each document, although there are overlaps.

(3) Examine language and framing of some of the key terms in this study: racism, colonialism, and anti-Blackness. Are they named? If so, how are they defined? If not, 
how is the issue of anti-Black racism or racism framed? Is there historical context? If so, is Canada's history of enslavement and anti-Blackness towards African Canadian immigrants included in the narrative? This step will shed light on the government's perspective and locus of responsibility.

(4) Locate metaphors and nationalist myths: Use of common, everyday metaphors are central to political discourse to shape public memory (Charteris-Black 2011). While metaphors are common in everyday dialogue, they are utilized politically to "tell the right story" or preserve a nationalist memory (Charteris-Black 2011: 28). In Canada, as shown in Chapter 1, hegemonic nationalist memories are preserved by myths that preserve white settler innocence, legitimize Canadian nationalism, and outline the boundaries of belonging and exclusion (Thobani 2018). The most prominent and widely used metaphor deployed in each policy was located and the myth of Canada it allowed the reader to visualize examined.

(5) Commitments and Requirements: What are the economic, social, or political commitments the governmental body is making to address racism or anti-Blackness? What, if anything, is being asked of the Black community?

\subsection{Semi-Structured Interviews}

Semi-structured interviews are loosely structured with a series of tentative questions in an interview schedule and probing questions that allow for elaboration. This is a preferred method as they are flexible and enable compilation of in-depth data from diverse participants (McIntosh \& Morsh 2015). This was vital due to the range of who is racialized as Black in Canada. Twelve interviews were conducted with ACB leaders in the Ottawa-Gatineau region between August 1, 2020, and August 31, 2020, in Ottawa, Ontario via Zoom because of COVID-19 protocols. As I 
did not meet any of the participants prior to the interviews, it was imperative to provide my positionality as context for participants. After each interview, the participant was provided with $\$ 25.00$ compensation. This population was selected based on their location within Canada's BRT, and common misconception that there is a "crisis" in Black Canadian leadership that lends itself to the invisibility of activists, leaders, and community organizers in making Canada an increasingly livable space for Afro-Canadians (Kitossa 2019).

Interview Structure:

The interviews were broken down into three main sections:

(1) Identity: Participants were first asked to provide their positionality, how they racially identify and if their background influenced their racial identity or perceptions of race, racism, colonialism, and anti-Blackness.

(2) Leadership/ activism/ organizing work: Participants were asked to discuss their work and whether they feel their efforts are recognized by the government or community. This section also explores Pan-African unity building amongst Black leaders in Ottawa.

(3) Blackness, race, and colonialism in Canada: Participants were asked for their perceptions of racism, Blackness, and the efficacy of the concept anti-Blackness in future unity building endeavors.

The first section of the interview explored the participant's story. Questions explored who they are, where they are from, the colonial structure in their nation of origin, how they racially self-identify, and if they feel their background impacts this process of identification. The next section considered what kind of leadership work they were engaged in and the forms of recognition of it. As well as how long have they been serving, how they started, if they work with other Afro-Canadian groups, and if ACB groups in Ottawa form Pan-African affiliations in 
general. All participants were asked if their work is recognized by the government or their community, and why or why not. The last section was about perceptions of anti-Blackness. Participants were first asked if they are familiar with the concept, what it means to them, and how they use it in their work. This was followed up with questions regarding how racism towards Black people manifests in Canada, and if they feel the concept of anti-Blackness is useful in articulating Black people's racial experiences or building Pan-Africanist collaborations within the community. In closing, participants were asked what they would like to add that they felt was relevant and may have been missed in the interview questions. A semi-structured format enabled adaptation of the research questions as the interviews progressed. For example, questions that were not relevant to a participant or that they had answered in a previous response were not asked or modified. Please see Appendix G for the schedule of questions.

\section{Recruitment:}

Interviewees were recruited from the seven largest subpopulations of African Canadian communities in Ottawa; Somali, Congolese, Burundian, Ethiopian, Haitian, Jamaican, and Trinidadian or based on their service to the ACB community (StatsCan 2019). Ninety-seven activists, leaders, and community organizers who are Black and serve the Black community in the Ottawa-Gatineau region were identified through social media, websites, networking, and media searches. Some of these leaders are people I identified while attending events in the AfroCanadian community prior to COVID-19. I also located African Canadian led- and -serving organizations in the region, as well as who the people are running those organizations. While emphasis was on the seven largest communities listed above, any ACB community organization I found was included. This includes Black, African, and Caribbean community organizations, Black youth organizations, Black History Month organizations, Black Women's organizations, 
nationalist organizations, ethnic organizations, cultural organizations, and other Black serving groups. From there, I joined and observed Black community groups on social media, such as BlackOttawaConnect and NoJusticeNoPeace where many leaders are active and engage in dialogue with the larger community. Black media outlets including magazines such as Black Ottawa Scene and Shifter Magazine, artistic platforms such as CapCityCyphers and websites dedicated to the unification of people of African descent including BlackOttawa411 or 613819 Black Hub were examined alongside national databases such as 100 Most Influential ACB Women in Canada. Lastly, I examined discussions of African Canadian leaders in non-Black media outlets such as news articles or award ceremonies.

Once leaders were identified, locating contact details, and getting in contact with the potential participants was the most challenging part of the recruitment process. I visited Instagram, twitter, LinkedIn, and Facebook pages to obtain e-mail addresses however many leaders' e-mails and phone numbers were not publicly available unless they had a personal website. The first round of invitations was sent out during the COVID-19 lockdown in June 2020. Twenty-five participants were selected and contacted, however none responded. This was likely due to the circumstances and environment created by the pandemic. The second round of invitations occurred in mid-July 2020. Sixty participants, not including the previous twenty-five, were contacted this round. One participant responded directly to a personal e-mail invitation. Organizations were also contacted rather than specific individuals. In contacting organizations, the leader of one large collaborative organization, a gatekeeper, reached out to me based on my affiliation with Carleton's Institute of African Studies. This community leader advised me to update some of the language in the invitations as well as the age range based on experience with ACB leadership in Ottawa for the past twenty-five years. The invitation was updated and shared 
within the organization and in this way, eight participants recruited. Without the assistance and advice of this supportive community gate keeper, the interviews would not have occurred.

Near the end of the second round, any existing connections the researcher had in the Black community were contacted to refer anyone they felt may be interested in participating. One participant was recruited through a referral from an existing relationship after updating the age range. The third round of invitations included final follow-ups. The researcher contacted any respondents that had shown interest one final time. The final two participants responded in late August to invitations submitted during the first round in June citing a return to normalcy following an uplift of the COVD-19 social distancing restrictions.

Participants were selected based on whether they fit the outlined requirements, their interest, and their availability. The population consisted of African, Caribbean, and Black people, aged 25 to 55 , who self-identified as leaders, activists, or community organizers, and served the Black community in Ottawa. They had to have served in an Afro-Canadian centered organization or served African Canadian people in the Ottawa-Gatineau community for at least two years. The participants represent the gender proportions in the municipal and national population, with slightly more women (7) than men (5) who were interviewed. The interviews were one hour in length, oftentimes longer, which enabled the researcher to ask questions that prompted long responses with different paths. The length of the interview also gave participants, most of whom did not know and were not otherwise familiar with the researcher, enough time to get comfortable and begin to share. As the interviews were semi-structured, a general interview guide was prepared, and questions adapted during the interview. The semi-structured interviews serve to provide data regarding who the activists and leaders in the Ottawa-Gatineau region are, 
the existence or lack thereof of Pan-Africanism or Pan-Black unity building, and how activists and leaders in ACB communities in Ottawa understand race and anti-Blackness.

\subsubsection{Coding}

Interviews were recorded with the participant's consent. After transcribing the interviews, the audio files were deleted. The coding process for this project was inductive, and the coding emergent (Altheide 2000). Emergent coding refers to codes that appear as the data is analyzed (Altheide 2000, Leavy \& Hesse-Biber 2010). As only one researcher was coding the data, it was imperative to develop a simple coding scheme to ensure reliability (Campbell et al. 2013). The scheme included four phases: deep reading, categorization, re-reading, and thematic analysis.

Each transcript was read three times and general notes taken that pointed to potential categories. Then, each line of the data was assessed, and specific units of meaning identified according to the topic at hand or research question the unit of meaning is related to. Units of meaning were selected as opposed to "demarcated sections of text" such as paragraphs or sentences (Campbell et al. 2013). This preserves the context of the answers and accounts for the participant's full meaning as responses ranged in content from single sentences to a full page in text (Campbell et al. 2013: 304). Units of meaning were marked in the text, and then coded according to themes that emerged during the deep reading. The number of major themes was kept down to a minimum to ensure reliability. Themes were compared to identify any patterns, arguments, or positions and those were then analyzed in relation to existing theories regarding the BRT, Blackness and Black identity formation in Canada discussed in the literature review.

\subsubsection{Limitations}

Conducting research amidst the uncertainty of a global pandemic is a major limitation. Semi-structured interviews were a change in strategy due to the COVID-19 pandemic as 
originally, the interviews were to be ethnographic. Ethnographic interviews are spontaneously developed through connections made during participant observation, or within an existing relationship (Allen 2017). The interviews are less formal, with more natural or conversational settings (Allen 2017). I did not know any of the participants ahead of time, so the interviews cannot be considered ethnographic.

The participant observation was to occur at Black-led or -centered events, to establish connections with Black leaders, organizers, or activists in Ottawa over the summer of 2020. However, that was not possible due to the COVID-19 pandemic and the resulting social distance measures as all social gatherings of $10+$ people were prohibited from March to April 2020. As a newcomer to Ottawa, I did not have many established relationships with leaders, outside academic ones, prior to the pandemic and I relocated due to COVID-19. The nature of interviews with participants, participant availability, and the emotional, mental, and physical wellbeing of both participants and the researcher were drastically altered. For example, one potential participant responded September 13, 2020, stating they were just returning to "normal" and would still be happy to participate. As such, being on lockdown halted the recruitment process, and altered the interviews of some of the participants who availed themselves.

Participants were not asked about their sexuality or ability, so the data does not account for sexual minorities or disabled Afro-Canadians. There is a low representation of participants with a lower socio-economic background due to the recruitment process and instrument used to conduct the interviews. Additionally, the seven largest groups are not equally represented with no participants having genealogical connections to Ethiopia, Burundi, Haiti, or Trinidad. Leaders with different ethnic backgrounds were selected based on their commitment to the Black community at large. 


\subsection{Conclusion}

This qualitative research includes two phases, a QDA of governmental policies and twelve in-depth semi-structured interviews with African Canadian leaders in Ottawa. Phase one facilitated evaluation of how anti-racism legislation addresses anti-Blackness in Canadian institutions. The second phase draws upon the knowledge of Black community leaders and activists. This step enabled empirical evaluation of what Black leadership in Ottawa looks like as well as how Afro-Canadian leaders, community organizers, and activists in Ottawa understand race, Blackness, and anti-Blackness in a Canadian settler state. Combining these objectives, these research methods enable inductive exploration of how a heterogenous group such as AfroCanadians are exhibiting leadership in their communities, and articulating their identities, racial experiences, and political demands about race. 


\section{Focus on Ottawa: Analysis of Findings}

\subsection{Introduction}

This work is part of ongoing conversations about the BRT of African Canadian leadership in Canada, Pan-Africanism and Black Canadian consciousness, and the concept of antiBlackness. This contribution discusses African Canadian leaders' perspectives on race, colonialism, and anti-Blackness in the understudied Ottawa region. As law is the instrument in which racial structures are maintained, this chapter will outline the findings of the QDA. The chapter will close with an examination of who the leaders are, how they understand race/ colonialism/ Blackness, the influence of their past experiences with colonialism, and the efficacy of the concept anti-Blackness in ACB leadership/activist circles in Ottawa. The key findings in this study are the relationship between Black mobilization and anti-racist policy; the multiplicities of Black Canadian consciousness; the rise of Pan-Africanist solidarity; development of a language for anti-Blackness in Canada; and a need to celebrate difference. These findings address Dei's (2019) call for a politics of language, leadership, and place in studies of Afro-Canadian leadership with an emphasis on regional specificity, as evident in the focus on Ottawa, as well as a nationalist consciousness that accounts for how anti-Blackness may operate at a provincial or federal level. Leadership is diverse, and leaders have multiple, overlapping identities, as well as perceptions of race, colonialism and anti-Blackness influenced by their positionalities and experiences. Pan-Africanism is a growing force amongst leaders forming strategic alliances. Overwhelmingly, leaders agree that anti-Blackness is a valuable concept for African Canadians to articulate their racial experiences and continue to build unity across communities. However, the term requires redefinition, clarification, and simplification. 


\subsection{Qualitative Document Analyses (QDA)}

\subsubsection{Municipal: Ottawa's Equity and Diversity Policy (2017)}

Ottawa's Equity and Diversity Policy ${ }^{15}$ is devoted to ending discrimination towards "designated groups" in the workplace (CO 2017: 1). This is a corporate policy under the Human Resources (HR) department with two main objectives: 1) eliminate workplace barriers to foster diversity and equity and 2) support the City's "business goals and client service delivery" (CO 2017: 1). The focus of these objectives is "to provide a supportive work environment and corporate culture" (CO 2017: 1). It states that the Equity and Diversity Lens will outline barriers, address how to eliminate them, and contain a schedule for implementation (CO 2017: 1). The targeted communities and relevant social actors are all City employees ${ }^{16}$ and "designated groups" (CO 2017: 1). Designated groups are Aboriginal people, disabled people, women, and visible minorities (CO 2017: 1). According to the policy statement the city would like to establish a qualified workforce that represents diverse the population in the region (CO 2017: 1).

Racism, anti-Blackness, and Canada's status as a settler colony are not discussed. The topoi in this document include diversity, equity, barriers, and systemic discrimination. Diversity and equity are viewed as the end goals of the policy in which barriers such as systemic discrimination must be removed to achieve. The major metaphor in this policy is the topoi of barriers, used to represent systemic discrimination. For example, one of the policy's main objectives is "to eliminate barriers in the workplace, commonly known as systemic discrimination" (CO 2017: 2). In this metaphor, discrimination is reframed as a barrier to workplace equity.

\footnotetext{
${ }^{15}$ This is a four-page policy released November 5, 2002, and revised May 24, 2017. (CO 2017)

${ }^{16}$ Including full time, part time, temporary, consultants, contractors, and summer coop students.
} 
To oversee implementation of this policy a Joint Management Union Committee (JUMC) will be formed (CO 2017: 2). The JUMC (comprised of general managers and directors, immediate supervisors and managers, and employees) is to "foster a discrimination free workplace" according to, "training from Human Resources and Employment Equity staff" (CO 2017: 2-3). Employees are encouraged to report any potential barriers they identify as well as any discriminatory treatment to their department prior to contacting any relevant Human Rights Commission (CO 2017: 3). Anonymous claims are not to be investigated and those who do not adhere to the policy are threatened with disciplinary action or dismissal.

\subsubsection{Provincial: Ontario's Anti-Black Racism Strategy (2017)}

The "vision" of the $\mathrm{ABRS}^{17}$ is the "elimination of disparity outcomes for Black Ontarians in the child welfare, education and justice sectors by 2024 to align with the close of the United Nations International Decade for People of African Descent" (GO 2017: 3). This will be achieved through five objectives: 1) lead long term change across systems; 2) build system capacity and competency; 3 ) partner with 'early adopter' service providers to study application on a wider scale; 4) increase Black community engagement and capacity; and 5) increase public awareness and understanding of systemic racism (GO 2017: 3-4). The targeted groups are the GO and Black Ontarians, and relevant social actors include the Ministry of Child and Youth Services (MCYS), Ministry of Community Safety and Correctional Services (MCSCS), the Ontario education system, and ACB led and serving organizations (GO 2017: 4). Black Ontarians (8x) was the preferred term for the population (GO 2017). (GO 2017).

${ }^{17}$ Five-page PDF/word document published online December 14, 2017, active from 2018-2024 
The strategy begins with a positioning of Ontario as a multicultural, diverse space where Ontarians "pride ourselves on our multiculturalism and celebrating our differences" (GO 2017: 2). While diversity is said to be Ontario's "strength" the GO (2017:2) argues that "for some, it's not enough" because of "barriers" such as racism. Racism is defined as systemic inequity maintained by "hidden institutional biases in policies, practices, and procedures" (GO 2017: 2; see also ARS 2017). Enslavement is mentioned twice in reference to anti-Black racism, although anti-Black racism is not defined, and the GO does not identify colonialism. For example, the GO (2017: 5) will "take a collaborative government approach to breaking down the intergenerational impacts of slavery and systemic racism." Or that, "whether they're recent immigrants or descendants of people who were enslaved, Black Ontarians live a shared present-day experience of anti-Black racism" (GO 2017: 2). This shared experience is said to be related to stigma and stereotypes in public health, policy, provision of services, employment, education, child welfare and representation of youth in the justice system (GO 2017: 2). The GO encourages educational awareness through statements such as, "public education will help create a society where Ontarians are aware of and are better prepared to identify and challenge anti-Black racism" (GO 2017: 5).

Barriers, build, and engagement are the topoi used to justify the argument that, "real and sustainable change does not happen overnight" (GO 2017: 5). Barriers are a metaphor for antiBlack racism as the strategy reads "the impact and consequences of our history have created systemic barriers that prevent people from fully participating in all parts of society," or "we cannot thrive as a society when certain communities face barriers that prevent them from reaching their full potential" (GO 2017: 2). Building demonstrates the work being done such as calls to "build system and capacity" and, "stronger community relationships" (GO 2017: 5). This 
is cemented by an extension of the metaphor such as "lay the foundation/groundwork" for change (GO 2017: 5).

The GO argues that "histories of racism and discrimination," have developed, "unequal access to government-decision making processes for Black communities" (GO 2017: 5). This strategy affirms governmental responsibility to provide "equal access to life opportunities," and to "increase the capacity of Black community members and organizations to actively engage with government processes" (GO 2017: 3, 5). This includes "targeted engagements with Black communities and anti-racism advocates" such as Independent Review of Street Checks Regulation, Correctional Services Reform, Ontario Black Youth Action Plan ${ }^{18}$ (OBYAP), and One Vision, One Voice ${ }^{19}$ (OVOV) (GO 2017: 5). The GO also promised that data on Black community engagement and the development of disaggregated race data will be gathered to inform scalable, targeted initiatives and pro-Black capacity/competency training (GO 2017: 5). The government will: 1) develop solutions for future policies; 2) manage targeted sectors based on available data; 3 ) use public awareness initiatives to increase understanding of anti-Black racism; 4) develop case management tools such as an anti-Black racism intake tool for social workers; and provide 5) annual reports on implementation of ARD Data Standards and AntiRacism Impact Assessment tool across government and public sector organization (GOC 2017: 5). The GO also commits to reforming child welfare, criminal justice, and public education through establishment of a leadership table relevant ministries and an advisory committee in MCSCS, for example (GO 2017: 5). Other initiatives include those with school boards,

\footnotetext{
1847-million-dollar plan for 10,800 Black youth and families support in education and employment in the GTA, Hamilton, Ottawa, and Windsor (OBYAP 2017)

${ }^{19}$ Anti-Black racism clinical practice guidelines by MCYS, Children's Aid Societies and ACB leaders (GO 2017: 4)
} 
Children's Aid Society of Toronto, Youth Justices Division and Correctional Services, and Central Region Institutions through the BYAP and OVOV (GO 2017: 5).

\subsubsection{Federal: Building a Foundation for Change (2019 - 2022)}

The strategy's ${ }^{20}$ "guiding principles" are: 1) building a foundation for change; 2) moving forward and building awareness/ changing attitudes; and 3) ensuring a lasting impact (GOC 2019: 3-4, 14, 20, 29). The Minister of Heritage and Multiculturalism and the federal AntiRacism Secretariat ${ }^{21}$ (ARS) are responsible for implementing this strategy and engaging with provinces, territories, NGO partners, Indigenous peoples, and “communities" (GOC 2019: 2, 6). The GOC argues that racism is intersectional (2019: 2). As such, Indigenous people, "racialized" communities, and religious minorities are targeted because they, "face systemic barriers, notably in employment, justice, and social participation" (GOC 2019: 7; see also 8, 10, 15, 20).

The GOC (2019: 1) begins by reaffirming that "Diversity and inclusion are cornerstones of Canadian identity" in which "challenges" such as racism "still" persist. Race, racism, and antiBlackness are defined in a terminology section before the appendix. Race is a process that occurs through a process of racialization or "the process through which groups come to be socially constructed as races, based on characteristics such as ethnicity, language, economics, religion, culture, politics" (GOC 2019: 23 see also Canadian Race Relations Foundation [CRRF]). Racism is "any individual action, or institutional practice which treats people differently because of their color or ethnicity. This distinction is often used to justify discrimination" (GOC 2019: 23, see also CRRF). Systemic racism refers to "patterns of behavior, policies or practices that are part of the social or administrative structures of an organization, and which create or perpetuate a

${ }^{20}$ This is a 37-page document released by the GOC July 17, 2019, and active until 2022.

${ }^{21}$ The federal anti-racism plan set aside 4.6 million dollars to establish this secretariat in 2017. 
position of relative disadvantage for racialized persons" (GOC 2019: 23; see also CRRF). Islamophobia, anti-black racism, and anti-Semitism are the types of racism the strategy underscored and noted that two are religious minorities and may not necessarily be "visible." For example, Black people experience the highest proportion of hate crimes of any racialized group (GOC 2019: 17). The definition of anti-Black racism is "prejudice, attitudes, beliefs, stereotyping and discrimination that is directed at people of African descent and is rooted in their unique history and experience of enslavement" (GOC 2019: 16). This is the only mention of enslavement in the report however they acknowledge that "anti-Black racism is manifested in the legacy of the current social, economic, and political marginalization of African Canadians in society" (GOC 2019: 16).

Reference to Black Canadians and colonialism is in the appendix, in sections titled: Addressing the Challenges Faced by Black Canadians and Indigenous Focused Approach. Addressing the Challenges mentions Trudeau's 2018 recognition of UNDPAD, Budget 2018's 19-million-dollars to Black communities, and Budget 2019's \$25 million to Black organizations "in response to the United Nations Declaration of the Decade for People of African Descent" (GOC 2019: 26). Indigenous Focused Approach is a commitment to continue working with Indigenous people to educate Canadians about the impacts of colonialism (GOC 2019: 11-15). Canada's status as a settler colony is confirmed, as in "Settler colonialism — such as in the case of Canada" and defined as "the unique process where the colonizing population does not leave the territory, asserts ongoing sovereignty to the land, actively seeks to assimilate the Indigenous populations and extinguish their cultures, traditions and ties to the land" (GOC 2019: 21).

Change, barrier, and challenges connect the argument that racism is an obstruction to diversity, inclusion, and multiculturalism and/or full participation in society. The most prominent 
metaphor in this piece is the notion of "Building a Foundation." In this context, this is a colonial euphemism as the foundation is being built for inclusion of those on the cusp of settler society as evidenced by the second tenet of the policy, "empowering communities" geared towards "racialized" and Indigenous Canadians. The policy states "The Government of Canada is committed to building a foundation for change by removing barriers and promoting a country where every person is able to fully participate and have an equal opportunity to succeed" (GOC 2019: 2). Diversity and inclusion are said to be the "base" of this foundation which this strategy is building to "address the impacts of racism, and barriers faced by racialized communities, Indigenous Peoples and religious minorities" (GOC 2019: 2). Notions of "change" demonstrate a desire to address racism. Mention of the "challenges" present the difficulty of the work.

The report said that Department of Heritage will invest $\$ 45$ million to add to the $\$ 13$ billion that has gone to anti-racism initiatives since $2016^{22}$ (GOC 2019: 8). Funding is devoted to the existing Community Support, Multiculturalism and Anti-Racism Initiatives program ${ }^{23}$ (GOC 2019: 12). Socially, the GOC is guided by three principles in their action against systemic racism: 1) federal leadership; 2) empowering communities; and 3) building awareness (GOC 2019: 3, 5). Federal leadership includes the ARD's work with provinces and territories, provision of public reports, and the Treasury Board Secretariat's "ongoing diversity and inclusion work" 24 (GOC 2019: 10; see also 7). Empowering communities includes funding, recognizing expertise, and encouraging innovation (GOC 2019: 5, 13). Building awareness refers to education campaigns, accumulation of disaggregated data, adopting an Indigenous lens, and reducing hate

${ }^{22}$ Please see Appendix F for a breakdown of the allocated funds.

${ }^{23}$ This program is through Canadian Heritage and fosters diversity and inclusion by supporting marginalized communities, promoting discussions, and engaging in research (GOC 2019).

${ }^{24}$ This refers to a more diverse and inclusive public service (GOC 2019: 7). 
crimes (GOC 2019: 15, 17-19). Focus is on commitment to everybody's "social participation" (GOC 2019: 7, 12, 20, 23) with the government to help "build a foundation."

\subsubsection{Summary: Anti-Racism Policies and Anti-Blackness}

Ottawa's Equity and Diversity Policy does not recognize race, anti-Blackness, or address issues in the Afro-Canadian community caused or exacerbated by racism. Instead, Ottawa's policy places the burden of proof and onus of responsibility on the individual being discriminated against. Furthermore, it remains unclear how many members of the parties responsible for implementing the policy will represent designated groups, or what (if any) antiracism or decolonization training that management, supervisory, HR, or Employment Equity staff will have received to implement the policies. On a provincial and federal level Canada's prompt governmental response to the United Nations and the international community represents Canada's hegemonic maintenance of itself as a safe, multicultural space. No such response was given to African Canadian activists and their allies as early as $1992^{25}$. This alludes to the ways in which the Canadian state ignores Black Canadian thought, voices, and political mobilization. Of the two documents that directly address racism, both call for an increase in awareness with reminders that change is a timely process. However, as Walker (1984) reminds us, African Canadians have been sharing their needs with the larger community since the early 1960s.

The policies that address race present colonialism as part of Canadian history, and do not acknowledge the constitutive relationship between colonialism and enslavement within settler colonies. Canada's current position as a settler colony is not framed as the context in which racist and anti-Black relations must be addressed. Enslavement is mentioned only to describe Black

\footnotetext{
${ }^{25}$ The Stephen Lewis Report produced following the Yonge St. Riots.
} 
Canadians while colonialism is discussed in reference to Indigenous people. This framing serves to preserve Canada's culture of silence and settler innocence by remediating colonialism and enslavement to two distinct pasts and erasing the ongoing presence of settler colonialism and the afterlife of enslavement (Hartman 2007, Smith 2017, King 2019, Smith 2010, Rowe \& Tuck 2016, Veracini 2016, Wolfe 2006). The metaphoric framing of systemic discrimination or antiBlack racism as a "barrier" to full participation in society, rather than as foundational or central to the maintenance of settler colonies, makes it possible to imagine racism as more of an obstacle than a social determinant. Terms such as multicultural or diverse are often used as descriptor of Canadian society to present anti-Blackness or racism in general as an abnormality, challenge, or barrier rather than foundational. Moreover, although these anti-racism policies are aimed at assimilation, it is unlikely that they will facilitate the "safe spaces" for Black people promised in Canadian discourses of multiculturalism without challenging systemic racism and colonialism (King 2019). This burden falls on ACB leaders.

\subsection{Semi-Structured Interviews}

\subsubsection{Coding}

The twelve participants were assigned the code names: Shirley, Vanessa, Beatrice, Marcus, Orlando, Rachel, Langston, Warsan, Audrey, Chimamanda, Jawar and Wale. The data was sorted by important or relevant units of meaning. Emergent codes were cross referenced with ten larger themes within the project: Activism and Leadership, Anti-Blackness, Black Consciousness, Identity, Migration, Racism, Enslavement and Colonialism, Multiculturalism and Policy, Pan-Africanism or Unity, and Positionality. Please see Appendix H for the codebook. Within these larger themes, data was sorted according to topic and key quotes and patterns identified. 


\subsubsection{Positionality and Identity: Multiplicities of Blackness}

The first set of questions retrieved reflexive "stories" regarding leaders' positionalities to shed insight on the influence of one's previous experiences on current understandings of race, colonialism, and anti-Blackness. Canada presents a unique site of Black positioning and identity formation due to the concentration of ACB people, community organizations and leaders, in large cities such as Ottawa, and shared experience of being racialized as Black (Walcott 2003). Participants represented some of this diversity, with a higher representation of people of continental African descent (67\%) than those of Caribbean, or American descent. When asked about their immigration backgrounds: 1) $42 \% 2^{\text {nd }}$ generation; 2) 33\% $1^{\text {st }}$ generation; 3) $16 \% 1.5$ generation and 4) $8 \% 3^{\text {rd }}$ generation or more. Approximately a quarter of participants spoke French as a primary or additional language and one participant identified as a practicing Muslim, while two others were from communities with a high population of Muslims. Of those comfortable sharing, 33\% came from lower socio-economic status and experienced what they considered extreme poverty in their country of origin, grew up in low-income housing in North America, and/or migrated as refugees. An equal percentage (33\%) were children of privilege with access to social capital. The rest identified as upper-middle to lower-middle class, while one did not respond. Nearly all participants, 92\%, completed at least one college/university degree. In line with a previous study (Arthur et al. 2012) of Black leadership in the Toronto and Montreal region, a majority of leaders in the Ottawa region may be predominantly university educated or of a higher socio-economic status. There exists a need to include perspectives of leaders with lower socio-economic or academic status, and less access to social capital, in future research on continental African identity formation in Canada. 
All participants self-identified as Black, however Black identity formation is a complex process that differs for each person. First-generation leaders such as Warsan based this on their experiences with colonialism in their nation of origin "Oh, no! From my birth I know that I am Black. It did not start in Canada... We have that. We know that fight. Way before coming to Canada. Yeah, I am very Black!” (Emphasis in original) Blackness is not a choice as Marcus explained "Our lives are defined by our racial identity." Blackness becomes significant by force through racialization which includes microaggressions, social isolation, and systemic discrimination (Robinson 1983). As Chimamanda described "I don't go out of my way to tell everybody- Hey, everybody, I'm Black! Did you know I'm Black? It never happened that way. Racism, it came to me!"

Blackness was predominantly identified as a broad racial label which other identities may exist alongside, behind, or at the forefront of. This is best exemplified by Audrey's explanation that "I usually say Black in regard to like race identity but when people go further than that I would always say growing up African American or African Canadian." Others stated: In the great gambit of things, it is trivial to say I'm Black. Especially because it's obvious and I can't hide it right, I'm a brown skinned person. But if need be- if I can't identify myself in personand somebody asks me I'll say yeah. Yeah, I'm a quote unquote 'Black'.... So, it also depends on the context in which the question is asked. - Langston

It also depends on who is asking the question as Chimamanda explained "Oftentimes when I meet a fellow -like someone from the African or Caribbean- you gain for more specific not just a kind of a broad, like racial label of Blackness." Nobody identified themselves by their ethnicity and it was stated that this is a personal identifier that is irrelevant due to the homogenization of Afro-Canadian people. Two identified as global citizens. 
A quarter of participants reflected on the development of a Black consciousness as a process of "Becoming Black" (Creese 2018, Dei 2018, Dei \& James 1998, Ibrahim 2004; 1999). For some first-generation migrants, Blackness took on a different meaning in Canada that they are still navigating. Vanessa clarified "Actually, until today, it's still something that I have to - it's not the first thing that jumps to my mind - especially when interacting with people... To me, becoming Black, not even was but is still an ongoing process." Others identified becoming Black within Canadian education systems. A second-generation immigrant reflected on her experience as the only Black child at school:

Culturally, they put meaning to race for me. I as a Black child, and then, you know, young woman, that woman had to really navigate that and being like, what is this race thing and what does it mean to them? Okay. Then I was able to learn the history and then kind of insert like lived experience and it became-culturally- it just became something significant. It became. It was kind of a leading factor of my identity in many aspects. - Chimamanda

Those who related with a process of "Becoming Black" indicated they had little to no contact with whiteness or did not receive any racial education about what it meant to be Black until "becoming." Contrarily, some leaders spoke of parents who espoused a racial or decolonial consciousness and educated them about race such as Rachel "Growing up even as a very young child, my family, my parents always made it clear that life for me would be very different because I'm colored..." Shirley, a first-generation immigrant who did not identify with "becoming Black", pointed out that during her formative schooling years in another nation her family immigrated to prior to Canada "I definitely knew I was different, but I was prepared for that by my parents." Those whose backgrounds where race was not central to their upbringing or identity, or who were not prepared by parents, were in a sense unprepared for the negative meanings attached to Blackness. 
Unsuspecting leaders' previous understandings of oppression were not connected to race, but rather ethnicity, poverty, or politics. This was visible in Langston's reflection:

I did notice that coming from a country that was developing and coming here I never knew what poverty was, I never knew what being Black meant.... When you think about racism, it's always centered around something else, and I found that poverty was the main thing that it was centered around how I experienced racism.... Coming here I did notice that it was my first taste of racism. Becoming Black can, in some cases, leads to the development of a Black consciousness as Biko (1978: 52) argued "Merely by describing yourself as black you have started on a road towards freedom, you have committed yourself to fight against all forces that seek to use your blackness as a stamp that marks you out as a submissive being." This develops into an empowered pro-Black consciousness as seen in Rachel who became emotional when explaining how even though she was aware of her Blackness and prepared by her parents for racism "it's taken me a lifetime to say I'm okay with being Black," and claim it as a source of power.

All leaders espoused context specific, interchangeable identifiers depend on positionality. These were nationalist (i.e., Ghanaian-Canadian), regional (i.e., Afro-Caribbean, or African Canadian [in the context of first-generation immigrants of African descent]) and Pan-Africanist (i.e., Afro-Canadian [in the context of descendants of the enslaved or African Canadian people with a long history in Canada]) descriptors in congruence with or rather than Canadian identity markers. Due to Canada's emphasis on multiculturalism many Black leaders with immigrant backgrounds preserve their cultural, ethnic, and national identities (Gooden 2008). Beatrice explained:

I was born here but my parents- they- hold on to that African culture. When I'm at school I identify more as Canadian and then when I'm at home everything about my personal life at home outside of work and school is very much (nation of origin) and is centered on that culture. 
Jawar who identified as "Black and then (nation of origin), African. Well Black African and then (nation of origin)" as well as Canadian discussed this multiplicity as a result of the hybridity of Canadian identity "To be Canadian, you can, also keep whatever background you come with. I tend to stick with those modifiers that I really resonate with. Being Canadian kind of, almost doesn't speak of an identity in itself it's just everybody."

Participants of all backgrounds who identified as Canadian first, or alone, did so in efforts to challenge what they argued are present understandings of what a "Canadian" is and looks like. Shirley described "I'd say either Afro-Canadian or just Canadian because, logically, everybody here is an immigrant except for Indigenous people. We are Canadians but Canadian of African or Chinese descent, so I just identify myself as Canadian if I want.” Those with longer standing ties to Canada presented identity as a point of conflict due to perceptions of $\mathrm{ACB}$ people as perennial newcomers (ACLC 2003, Garner 2011, Mullings et al. 2016, StatsCan 2017):

I had a really interesting incident, I think about grade three, with a lunch monitor. She asked meyou know- where are you from? I answered Canadian and she wouldn't accept the answer to the point where I felt like we were arguing with each other.... You go through this thing, saying Canadian in Canada and then being rejected. Essentially having your citizenship rejected and learning to answer (nation of origin) and then truly identifying with people that look like you, that you want to sound like, eat the same food and you have family over there and people that you love. Then you go and visit, and you're being told you're a foreigner, you're being told that your Canadian... It turns into this very confusing battle and inner turmoil. Now, because I feel the need to push this notion that you don't have to have European ancestry or need to have white skin to be viewed as being Canadian, I do in my adulthood say Canadian. - Orlando

If I go on ancestry.com it's not going to be able to tell me shit! It's not going to be able to say like this is where your people are actually from, and I think that for me that's like one of the most 
heartbreaking part of colonialism. I don't know how I ended up on this land and people are like oh where are you really from? - Audrey

Orlando described this conflict as well as the navigation of a diasporic consciousness when one maintains a link to the source or nation of origin (Gooden 2008). Based on her length of time in Canada, Audrey did not describe a link but rather an "unknowing." This represents the complexity of questioning "place" in a diasporic context, especially for descendants of the enslaved such as Audrey who view Africa as their origin prior to the new world (Gilroy 1993, Robinson 1983).

Experiences with colonialism and racism, or lack thereof, influence perceptions of racism, Blackness, and colonialism in a Canadian context. Those who argued they had no previous personal experiences with racism turned out to be first-generation migrants who did not grow up in Canada. For these leaders, the murder of George Floyd was a significant event:

The conversation went down to, Vanessa, to what degree- how much have you done to educate yourself about the system, and the structure, and the color? Like maybe this skin color doesn't jump out to me first thing because I have never faced any direct, like I've never faced any racist advances. I've never faced slurs. I've never faced anything negative that was knowingly because of the color of my skin.... Maybe because of those situations, I find it harder to, I want to say, relate? Still look at people and have skin be the first thing that's going to jump up. - Vanessa

For Shirley "I would be the only Black kid at my school but I never really, to be honest I never really got like, any racial attacks. I mean my first day people were staring of course but I never really experienced any personal discrimination." Primarily participants who had experienced racism-described altered ways of knowing, or double, triple, or multiple consciousness, based on dual or sometimes triple cultural upbringings and navigation of racism and colonialism (Mensah \& Williams 2015): 
It's interesting for me - being second generation, having parents who immigrated - growing up here in Canada, and just having kind of a dual upbringing in terms of identities. My parents, I'm very much aware of their history and their experiences and what their communities are like growing up in (nation of origin) and coming here... They never really had to encounter race like they did until they came to this Western, Canadian society. In context, because of course the population in (nation of origin) we're black... Nobody is constantly pointing out race or the racial tensions that happened in South Africa. - Chimamanda

Both leaders who had experienced racism and those who had not sometimes espoused a decolonial consciousness in which race was understood through the colonialism in one's nation of origin, or from the perspective of one's identity as an immigrant. Beatrice, who is from a former African settler colony but was born in Canada, explained:

I'm very dissociated to race in Canada, and more aware of inequalities that exist for immigrants coming to Canada.... Obviously, there's Black people who've been here for generations and generations. I don't understand their history as much as I understand the history from people who migrated over and the barriers that they face vs. barriers that people who've been here for years face because there's still a difference. - Beatrice

Vanessa echoed "Where I find the biggest issue systematically is from the perspective that as an immigrant you are behind the starting line. Now maybe that's because of my life as a firstgeneration immigrant." This perspective was strengthened by the lack of racial data and education in Canada (Smith 2017, Thompson 2018).

Half of the leaders espoused a feminist consciousness, arguing that Blackness is not a monolith and intersectionality is required to comprehend the layers of Black identity and experience in Ottawa:

I think there are people that believe that Blackness is a monolith of sorts. But in reality... We have Black people who are disabled, we have Black LGBTQ, we have Black Muslims. Many share 
similar to varying degrees of extremities, extreme treatment as it pertains to institutions and are interfaced with those institutions as it pertains to anti-Black racism. - Marcus

Intersectionality is required to analyze issues Black people are disproportionately harmed by and how they operate in cohesion such as the rates of COVID 19 in Ottawa's already strained AfroCanadian communities:

We know that from way before, the racism and inequality in healthcare and education and all is what puts people at risk. If you have all that - equal housing, employment, education, health, and social network - if you have it the way the other community have, especially the white community, we won't have that problem anymore. COVID won't touch us anymore, you know, because it's there from the beginning. Like it's never just COVID and oh let's take care of COVID, no! the struggle was there, still there. - Warsan

Blackness is a position that influences and is influenced by one's positionality, identities, and experiences with colonialism, white supremacy, and anti-Black racism. Positioning such as upbringing, racial education, socioeconomic status, geographical location, phenotypical appearance, language, and exposure to racism or colonialism determine leaders' identities and perceptions of racial relations in the Ottawa region. ACB leaders' identity proved to be a fluid, contextual and complex reality that African Canadian leaders navigate based on one's positionality, as well as intersecting identities such as their gender, age, religion, socio-economic, immigration, racial, ethnic, or national statuses. Many espoused not only a Black consciousness but also a multiple consciousness, or multiplicity in their identities and ways of seeing the world based on their lived experiences. Those who identified with a process of becoming Black also espoused sentiments regarding multiple identities or consciousness such as immigration, socioeconomic status, or ethnicity (Creese 2018, Dei 2018, Dei \& James 1998, Howard et al. 2019, Ibrahim 2004; 1999). 


\subsubsection{ACB Leadership: The BRT in the National Capital}

The second set of questions addressed the type, length, and recognition of African

Canadian leadership in Ottawa as well as unity building based on Blackness in the region. Historically, African Canadian people created their own organizations to address issues caused by or related to anti-Black racism that the government was creating, enabling, or refusing to address (Calliste 1995, CWC 2005, Gooden 2008, Walker 2013). Some of the first anti-slavery legislation, anti-discrimination legislation, and inclusive immigration laws in Canada were a result of mobilization by ACB leaders, communities, and allies (Cooper 2007, Flynn 2014, Henry 2018, Mathieu 2010, Walker 1984, Winks 1997). This tradition of abolitionist mobilization characterizes the current BRT:

Every advancement, human rights advancement, civil rights advancement that has been made in North America- have been made on the backs of Blacks in Canada and the United States.... From the sleeping car porters to people like Lincoln Alexander and others who pushed for change and pushed for human rights for Blacks that created opportunities for policy and legislative changes that gave us the rights that we enjoy today. - Marcus

\subsubsection{Types of Leadership}

Leaders in Ottawa are poised to address issues at a municipal, provincial, and national level and do so in formal and informal capacities. Radical and resistant types of formal leadership such as active community organizing and collaboration, collective action, maternal activism, community AIDS activism, anti-hierarchical feminism, and church leadership were most represented in this project with a high number of community leaders involved in such activities (Kitossa 2019, Lawson 2019, Tecle \& Austin 2019). Notably, Marcus put forth that "Christian faith groups" are not active in Ottawa as "BLM has taken the space today of what the church groups took back in the 1960s." Historically, Black churches such as the Baptist, 
Episcopal, or Methodist played a large role in ACB leadership in cities such as Halifax (Adjei 2019). If these groups are inactive in Ottawa today, pastors within growing African communities and their roles should be considered in future studies of leadership in the region.

Non-formal types of leadership include some forms of maternal advocacy such as the racial education provided by parents, hairdressers and other professionals trained in trades catered to the Black community, or social media content creators. As well as the roles as the educator or representative in conversations with friends, coworkers, or intimate partners. Chimamanda described this as "cultural taxation" in which there exists a "weight that's sometimes put on the visible minority to be the educator in almost all areas of life that they occupy." Others described their career choice and resulting presence in predominantly white spaces as an informal form of activism. Leaders espoused a desire to provide needed resources to underserved Afro-Canadian communities and observed that organizations arise to meet the needs of specific populations such as youth or immigrants or address specific issues as education or employment. As Warsan shared 'I'm fighting for the community and the people left behind. The marginalized and racialized community.... I love to work for my community and build my community." Nearly half of leaders worked with Black youth exclusively while the remainder worked with youth in general but acknowledged the specificity of Black youth's struggles such as underemployment, discrimination at school, and overrepresentation in the criminal justice system (Maynard 2017).

Participants have been serving the African Canadian community for anywhere from two to twenty-two years, indicating a tradition. People got involved through personal connections such as family and friends, in response to large events or lived experiences with racial trauma, and university. Large events within the community over the past few years such as the Herongate 
evictions or tragic murder of Abdirahman Abdi in 2016 alongside global protests such as BLM or incidents such as the xenophobic events in South Africa motivated leaders here in Ottawa to deal with anti-Black racism and xenophobia in the region. Universities provided access to social capital as well as Black and African student associations, literature about Blackness, and space to ask questions and express disappointment with Canada's lack of racial education.

Youth leaders are underrepresented in this sample as the average age of participants was 41 years old. While this project cannot explore that dimension of ACB leadership, it presents an opportunity to examine perspectives on youth leadership, often grounded in an emphasis on upward social mobility:

Youth are taking the lead.... Their [parents'] form of activism was to focus on their families, focus on their offspring and focus on their biological legacies and a lot of the coming together was for fun. I mean those fun cultural or celebratory experiences or what have you for the various nations. But as the children have grown up and they have built a life for them where they are privileged enough to attend post-secondary and don't have to work three jobs. We are occupying spaces at law firms, in medical school, now on mainstream media and it's easier for us to take the lead on the bigger picture. - Orlando

When transgenerational relations were discussed, younger leaders spoke positively:

This idea that the older generations are like useless, and they've been stuck in their ways for too long is completely false. They, if given the tools and having the space to have these conversations, and maybe we have to bring it to them in a more a gentle way depending on how receptive they are, I think I've seen some good examples of how that can be done. Of course, some people aren't as receptive or just don't understand so they don't want to hear about it, but I think in Ottawa I've been lucky to meet pretty cool middle-aged folks. - Audrey 


\subsubsection{Politics of Recognition}

Recognition can be organized into three main groups: 1) by both the government and the community; 2) by the community only; or 3) by another audience. No participants felt their work had been recognized by the government alone. For some, it was necessary to be out in the public eye, while others worked behind the scenes. Those whose work has been recognized in any capacity felt that it put them in a position to impact change.

Half of participants felt recognized by both the Black community in Ottawa and some level of government. These leaders can be strategically positioned occupationally, artistically, or politically, are highly visible, and usually representatives or exemplary figures. These are leaders such as Shirley who explained:

I've seen a lot of the youth that I know that I've mentored that are now also progressing in their respective fields, not necessarily in my field, but in something that they want to do. In some ways all the things that I do are rewarding to see other people following my footsteps and succeeding even greater which makes me even happier. For me I think that's a huge thing because like as a Black Canadian, it's good to show a good example and have the future generation kind of also see, oh you know what, that's amazing, she can do it, you know, I can too. - Shirley

I argue that this exemplary status may create environments in which leaders are tokenized or may prioritize their occupational safety through strategic employment of advocacy or activism or leadership to maintain their social location. This type of recognition is also attained by leaders through establishment of organizations that engage with all levels of government, community service and development, and participation in collaboration with other Afro-Canadian organizations. These leaders did not seek to challenge systems of diversity, inclusion, or multiculturalism but rather to reform or include African Canadian people within them. Wale described "We reach out to each of these different levels of government, depending on the area 
that we want solutions, or we want to collaborate on. We work with the federal government on multiculturalism, every year, with a partner." Leaders such as Wale view multiculturalism as a means to build unity in ACB communities:

Multiculturalism is something that we celebrate. We celebrate it yearly because Africa is a diverse continent of diverse people and diverse culture, and diverse beliefs. During our multiculturalism event we showcase all these various beautiful cultures.... This brings people together and makes people understand that we may be different, but we are all the same. - Wale

Alternatively, some leaders are not personally recognized but their work or projects they contribute to are recognized by the government and community alike:

Recognition from government, usually when I'm working with groups, is the final stage; it would be like brainstorming and then it goes up.... The impact is made in some way. Is it always fast and effective? Does the message you want always get communicated? No. It's a macro approach in terms of, okay, you're looking at policy or changing the whole society. - Chimamanda

Of participants who felt recognized by the community alone, some are supported by the larger Black and/or non-Black communities in Ottawa and others by the community the group represents. For those recognized by the larger Afro-Canadian communities, their work may be funded by the government but remains unrecognized in any official or unofficial capacity. Others are individually or organizationally recognized by the government or community from their nation of origin alone:

The community that we're serving, definitely. I think people check in and see what we're up to. They really do like some of the social events that we've put on and they ask when the next one is coming up. The larger Ottawa community, kind of not so much. We do get some media requests and requests for interviews and stuff like that- but like to honor the work that we're doing or like to recognize it? Haven't seen it too much yet. - Jawar 
Community support is based on the culturally, ethnically, or nationally specific services provided through informal and formal support networks, community-based programming, events, and/or integrative services.

In the "other" cases, entirely different situations emerge. Vanessa argued that her personal leadership work has yet to be recognized but cultural events she leader partakes in are recognized by the non-ACB Ottawa community to promote "diversity." Some leaders are not supported by government and receive backlash alongside the recognition and praise from the community:

Yeah, it's not about me, it's about the greater good. I have to remind myself to stay energized because it is easy to burn out and feel tired and then also get the backlash from the community that doesn't understand that you're doing battles on the daily and going to war for them; you just can't say so publicly. - Orlando

A minority ( $8 \%$ ) did not feel their work was recognized by either the government or the community.

\subsubsection{Pan-Africanism and Strategic Engagement}

A small percentage of leaders, $16 \%$, have devoted themselves primarily to the unification of people of African descent in the Ottawa region. Wale explained that following a large-scale event he and other leaders, "started discussing this need to come together. All the African communities. Not just everybody do their own thing, we should all come as one." Every participant argued that this was necessary with many espousing a strong desire for unification as Warsan aptly stated "our unity is not strong enough to face the other racism that's coming towards Black people.”

When asked if leaders work alone or together across groups, the most common responses were "both", "yes and no" or that they are starting to do so now. The "both" and "yes and no" responses were based on the notion that each community has different needs and there exist 
divisions within the Black community. Langston indicated "We're not a monolith one, so it doesn't mean we always have to work together, or we'll always go along." Leaders navigate this multiplicity by developing services that represent the interests of specific populations. For existing Afro-Canadian populations, development of a Black consciousness and unification under the identity of "Black Canadianness" with an emphasis on shared experiences of antiBlackness presents a means to Black political solidarity in Ottawa:

We are fragmented based on nationality and culture... Growing up in Ottawa it's kind of like, "no, I'm Somali," "no, I'm Jamaican," "no, I'm Haitian," "no, I'm Nigerian" and there was a little- there's enough of your community here to stick to your own [laughs] so to speak. And people didn't necessarily see the need to come together, nor did they truly understand one another on that level. I'm not mad that it didn't exist before, but we are certainly starting to see it now and I think we've recognized the need for it now and if we have more of an identity as being Black Canadians then it makes sense. - Orlando

Currently, collaboration can be understood through the concept of strategic engagement and the notion of Black allyship within Ottawa's African Canadian communities and leadership:

Black communities are expected to agree on everything and when we don't all come together as one voice the system always says "well, you guys, you don't have your act together, you're not all aligned on these issues," when that's really an unrealistic and purely racist interpretation of what is required. Of course, there is allyship where my view on allyship is that you ally on issues when it is convenient and when it is mutually beneficial to you.... Often times different groups will come to ally on different issues so we've kind of, I wouldn't even call it vulcanization, I would call it sort of strategic engagement. For organizations and for communities that find that issues are important to them, it's important to get them together and engaged. - Marcus

For example, there are many ACB-led and -serving organizations that do not work under the banner of Blackness but rather their specific ethnic, national, or cultural groups. These 
organizations maintain links to their nations of origin while working with local Black-led or PanAfricanist groups (Gooden 2008). Alongside organizations, there are individual activists, as Vanessa described, "I know there is Sarah Onyango, Sarah Onyango tries to bridge and bring information from the Caribbean and African side.”

Leaders have utilized the momentum of BLM, the global backing of UNDPAD, and Canada's international presentation of itself as an upholder of human rights, to advance Black communities. All participants alluded to an increase of African Canadian leaders and organizations strategically engaging to address issues that impact the Black community in Ottawa as best described by Jawar I think it is definitely siloed.... But in the last couple years, I've seen some more strategic meetings, asking how we can better align ourselves, how we can better apply for funding, and work together in specific issue areas." Others echoed:

When I had just come 10 years- even 5 years ago- I found that each organization was doing its own thing.... But with the coming up of ACAO [African Canadian Association of Ottawa], I'm not even sure how old ACAO is, I think it's like two or three years, I thought it was a good umbrella because I feel as if it's bringing more associations. - Vanessa

Two leaders, Jawar and Wale, mentioned an attempt by Afro-Canadian leaders in Ottawa to establish a centralized body to further Black political solidarity ${ }^{26}$. Although unsuccessful, the last five years have seen a rise in centralized, Pan-African organizations dedicated to the unification of people of African descent such as the African Canadian Association of Ottawa (ACAO), established in 2016 to unify all African and African descent community organizations in Ottawa (ACAO 2021), and, 613-819 Black Hub, founded in late 2017 to unify all people of

${ }^{26}$ Two leaders briefly touched on this meeting, but little detail was provided. Jawar indicated this meeting took place five years ago while Wale simply alluded to its failure. 
African descent in the Ottawa-Gatineau region and foster change in business, politics, education, and justice (613819BlackHub: n.d.). Or others which aim for the elimination of anti-Black racism such as the Ottawa Black Diaspora Coalition (OBDC), established by two young black women following the murder of Abdirahman Abdi in 2016 to address systemic anti-Black racism at a municipal, provincial, and federal level through "community care" and "transformative justice" and care (OBDC: n.p.) and Justice for Abdirahman, mentioned earlier. Prior to and during this rise, individual activists, smaller organizations, and university students have been consistent along the lines of Pan-African or Pan-Black organizing. The increase of communities finding it necessary to strategically engage and partner with or lend their energies to Pan-African organizations demonstrates a shift towards an understanding of the necessity of unity in the face of anti-Blackness. If Afro-Canadian people are to achieve abolition and decolonization, may it include a grounding in a Black Canadian identity bolstered by a return to a praxis of antiimperialism, such as Pan-Africanism, in lieu of the politics of multicultural recognition as Coulthard (2014) proposed to Indigenous Canadians?

\subsubsection{Perceptions of Racism, Colonialism and Anti-Blackness}

The final section of questions asked activists about their perceptions of racism, colonialism, and the efficacy of the concept anti-Blackness. This section was intended to address the research question regarding the influence of one's prior experience with colonialism on their current understandings of race, colonialism, and anti-Blackness in a Canadian context.

Additionally, the final question regarding the efficacy of the concept anti-Blackness. Leaders agreed that race is a social determinant of non-white people's livelihoods and as Orlando pointed out "it's not just the systemic, it's the interpersonal." 
Half of the leaders connected the current existence of racism with Canadian colonialism and enslavement while 33\% discussed how this has resulted in racial capitalism. Racism in Canada is maintained through colorblindness, denial, and deflections to the U.S. All of which create an environment of polite, subtle, or "smiling" rather than overt racism:

In Canada it's this- it's the idea that racism is not a problem because Canadians are much more polite and inviting towards ethnicity and different, like we don't have that issue with "Mexican borders" you know what I mean? So therefore, we are not racist. But when you take a look at all the stuff that's learned in schools, when you take a look at the job force, when you take a look at the neighborhoods that are what we would consider under the poverty line or having socioeconomic conflicts or difficulties, and even when you look at the prison system there is evidence that we have an issue with racism. - Langston

As this form of racism is not explicit it is difficult to prove, and the burden of proof is often on the ones being disadvantaged. This is relevant to Ottawa's Equity and Diversity policy as evidenced by one participant's working experience:

I thought I'm going to go to the office of Human Rights, you know- the employer I work with. The problem is that I never went ahead with that because you are always asked how can you prove its racism? And how can you prove it is harassment? You end up just continuing to face those aggressions and harassments and microaggressions every day. - Rachel

For newcomers, Canada may present a space of "ambivalent safety" although confronted with these insidious forms of racism (Walcott 2003). This was the case for Rachel who chose to come to Canada following a traumatic racist experience in her childhood:

It was a key moment in my life because I always say that I was five years old, and I made the decision that I would learn English so that I could leave (nation of birth). I knew I never wanted to live in that country because it didn't want me. I had to make it a mission to find a country that would accept me. That country is Canada. - Rachel 
However, this ambivalence is complex and influenced by experiences with racism in Canada. For those whom Canada is an ambivalent space of safety, the interests of Black people already within the space cannot be overwhelmed or erased (Cooper 2017, Walcott 2003). This proves relevant in the modern-day context with the influx of African migrants who may see Canada as a greener pasture. Those invested in helping newcomers, like Beatrice, spoke of how some were essentially "selling themselves short" in efforts to assimilate. Orlando explained:

The dynamic that they [newcomers] walk into is that they are so happy to be here in the first place that they may be compromising some of what they expect to achieve and thinking that it's just a natural part of the process. As, you know, I just got here. I have to work hard, and I'll make it. But then it's like your five years in and you're still driving a taxi and you realize that working hard doesn't mean making it Canada. - Orlando

Black Canadians are on the periphery of anti-racism policies that are not specifically intended to address anti-Blackness, such as Ontario's ABRS. Still, notions of equality are subtly maintained by the presupposition in each policy that the region being addressed is already a multicultural, diverse, or inclusive space for "racialized" people. Notably, the descriptor "racialized" was used exclusively to refer to "visible minorities" or non-white people by leaders, in anti-racism reports, and within Canadian anti-racism policies (BEP 2017, Employment Equity Act 1995, StatsCan 2017). Referring solely to non-white people as "racialized" presents white people as if they are not racialized, or raceless, and normalizes whiteness (BEP 2017, James 2019). In practice, racialization as white is central to the development and maintenance of racial categories (Bonds \& Inwood 2015, Christian 2002, Crenshawe et al. 1995, Robinson 1983, Stanley 2014). Going forward, leaders must return to academic definitions of racialization, grounded in Robinson's dialectic matrix, that "race" whiteness, or present white people as 
racialized, and white racialization as key to the maintenance of white supremacy (Horne 2018, Leroy 2016, Robinson 1983).

A large majority, $67 \%$, of participants were familiar with settler colonialism or understood it when explained. It was newer for some who operate outside public service, academic, and activist circles and made sense but was not yet part of their syntax. Half of the participants' experiences with colonialism were based on their nation of origin and the remaining half based their experiences with how colonialism has functioned in Canada, supplemented with transnational understandings of how it functioned outside Canada in participant's nation of origin, the Caribbean, Africa and/or the United States. The latter is best exemplified by this explanation:

Many of us that grew up here or were born here don't really understand the impacts of colonialism on our day to day lives. The colonialism, the enslavement of Blacks, the creation of the construct of race and the subsequent white supremacist sort of ideals of what these nations in North America are all about. That stuff affects us and affects policy and affects everything in our lives now... This place is oppressive in its subtle implementation of white supremacy. So much. Not like how the Americans do it because it's easier to fight, it's in your face generally speaking; but here it's done with a smile. They stroke your back and say go sit in that corner for the rest of your career, train somebody to become your boss. - Marcus

In terms of making conceptual connections, $42 \%$ of participants framed colonialism as a part of a global system of white supremacy that included Canada's Indigenous genocide and enslavement of people racialized as Black, $25 \%$ connected colonialism to settler situations in nations such as South Africa or Zimbabwe as well as the Indigenous genocide in Canada, $16 \%$ connected the concept of colonialism to their nation alone, and $16 \%$ of activists understood or framed their responses regarding colonialism solely through the lens of the Indigenous people in Canada. 
Most participants were familiar with the term anti-Blackness while $33 \%$ were familiar with the name or had heard it around but did not know what it meant. Just over half of participants utilized anti-Blackness in their personal, or professional dialogue while the remaining do not use the term. Of the group that do not use it many argued that they planned to use it in the appropriate contexts. Familiarity with the term, akin to what attracted leaders to getting involved, was influenced by the murder of George Floyd and the visibility of BLM. For instance, $33 \%$ of participants, only one of whom actively utilized the term, argued that concepts such as an "anti-Blackness" and "microaggressions" came onto their radar through BLM. For example, Rachel “...Like a lot of micro aggressions which I didn't know how to label at the time, I just, you know, learnt that word recently with what's happening around George Floyd's death."

Those familiar use the language and logic of anti-Blackness to center the systemic abuse of Afro-Canadians, prevent deflection, specify differing forms of racism amongst people racialized as non-white, and conceptualize the universality of anti-Black racism:

How do I describe that this is a real issue? I shouldn't have to prove it. It should be very obvious but like how can we have a language? I think again going back to the fact that Canada has such little research, I think language is such a key determinant for Black people, especially Black organizers...; it's [anti-Blackness] not just in the States and when we talk about colonial issues it's not just in the Caribbean or in the continent, there's all of these same issues, they're all the same or similar issues even if they manifest differently, happening in Canada right now. - Audrey

This sentiment of specificity was shared by those who use or are familiar with and use the term: The reason is some Africans that are not Black do not experience what Black people experience. So, we have to call it out as anti-Black, it is racism towards Black people and a majority [Africans] 
are Black people. The Black people are the ones experiencing the acts of racism because of the color of the skin, that's why we spell it out, we call it out, anti-Black racism. - Wale

Audrey also discussed experiences with non-Black people of color: "anti-Blackness can be perpetuated by anybody who is not Black regardless of if they still have their own experiences of discrimination and racism." For those unfamiliar with the concept, it provides a new language for one's experiences as well as a basis for continued unification and development on a Pan-Black or Pan-African level.

When asked how anti-Blackness manifests Orlando described "Canadians are very passive aggressive. This passive aggressive nature has hindered our abilities to a lot of the time actually be able to call out some of the anti-Black experiences that we have gone through because it hasn't been explicit." Interpersonal anti-Blackness was discussed chiefly through microaggressions and the ways in which racial trauma negatively impacts African Canadian people's mental health. Rachel reflected "Microaggressions is like bullets, almost like the amount of shots that we took over the years.... I've been diagnosed with PTSD.... People end up having PTSD because of the micro aggressions they face every day.” Langston provided a masculine perspective "I realized as a father and as a Black man I realize that I have nobody to turn to, nobody to talk to about that cycle of trauma and violence that is passed down that probably came from slave experience."

Systemically, leaders identified anti-Blackness as an intersectional problem visible in Ottawa's workplace, education, criminal justice, immigration, and healthcare systems, amongst others:

Anti-Blackness manifests in Canada through, well is foundational to what Canada is. The first prime minster of this country made a famous speech about ensuring that Canada stays white and ensuring that our policies and programs kept people like the Chinese out, and so that was over 150 
years ago. The first department was the department of Justice, and the department of Justice in Canada was charged with ensuring that laws were put in place to protect the whiteness in Canada. Those laws have been foundational to everything that we do, so anti-blackness is-is built into- the foundations of this country. - Marcus

Anti-Black racism in the workplace and education were discussed most often. Audrey described anti-Black racism in the workplace as "under employment or lack of employment or whether it be treatment in the workplace and often not being put in decision-making roles, not having a lot of room to move up in their roles." Others discussed visibility:

You know you have a very, I guess, English or Western name, right? See even I didn't know that you're Black. If you have to apply it will be like, "Oh yeah, okay yeah, Sarah George, we would interview her." You know? and you don't have an accent, so you get there and then as soon as they see you, you know, the face and everything changes. These things are still happening to Blacks, and I guess other people of color. Like you may have an impressive resume, like talk about the research you are doing now, but just because of the color, you know, you don't get to work. Shirley

Rachel experienced being told to 'sit in her corner' when "I got completely overlooked for somebody who had zero experience, and then asked to help the person become a manager..." Anti-Blackness in Ottawa's education systems manifests through a lack of racial education, research, and data:

There is a lot less research in Canada and pretty much every faculty and every department there's such little resources and research in Canada and especially for ACB folks. I think it's easy [this denial] because there's nowhere to really look for except for people's lived experience, so people will just be like well it doesn't exist. - Audrey 
An overwhelming $92 \%$ of participants argued that anti-Blackness is a useful concept in building unity and creating a language to articulate the shared experiences of ACB people in

\section{Ottawa:}

The concept of anti-Blackness has the ability to bring some unity because I think sometimes we can get so caught up. One thing I see often is getting so caught up in certain identity politics around what kind of Black are you. Like are you West African, East African? Are you from Trinidad? Are you Barbadian? You're Canadian, you're not Black enough. You're from the States, oh your ghetto! Like it's just like, there's so many different things! And like "Oh, our history is not the same," and the culture clash, and were brought up different. Which is all real, everybody has grown up differently, like not every black person has the same experience but every Black person is disadvantaged by anti-Blackness. - Audrey

Doubtfulness about the efficacy of the term came from concerns about the term's usage in white communities as anti-Blackness may be too combative or heavy to achieve Black Canadians' goals in a white supremacist space:

I don't know, I feel like it's very strong and heavy.... But [pause] I always do put myself in the other shoes. I even as a Black person I was just like hmm, if I was a white person who's like never really encountered or understood any of this, all of these terms and all this information, I think, this is not negating the responsibility, but I just know from the conversations I have or just their reactions of it can be overwhelming, it can be strong. It's not. Or I'm not suggesting we sensitize ourselves or you know fit ourselves in a box that's perfect just to appeal to a certain audience because that's what we're trying to challenge, but around the conversation language is very important. - Chimamanda

This critique is valuable and additional research is required regarding the efficacy of the concept within non-Black Canadian communities, as Afro-Canadian populations are the focus of this project. Additional critiques include a need for clearer, less academic, and more simple definition 
of this term, alongside others that have been popularized during the movement such as microaggressions. As the term was popularized outside academia during the rise of BLM, antiBlackness must be simplified for those outside of leadership circles and academia and clearly articulated. As the process of this term embedding itself into people's vocabularies remains underway, definitions must emerge that are transnational and account for multiplicities of Blackness in Canada (Walcott 2003). A baseline language, accessible to people of all educational backgrounds, may assist with the usage of this concept:

You can't go into the community spewing these words and this language and then expect people to just hop on board when they have no idea what you're talking about.... My approach is always going to be story based, so it's anecdotal, and people get anecdotes; they don't get theories that they have never studied [laughs].... Even when I talk about white privilege, microaggressions and antiBlackness, it's very academic and so, even some of the older generations are like what are you talking about, racism? Like are you talking about racism and what is all this jargon that you're throwing at us? So that's important to consider too, the language that people actually use like regular people. - Orlando

The term anti-Blackness requires not only a Pan-Africanist extension but careful consideration of the population it is intended to benefit or describe. This may include favoring use of inclusive language over academic jargon.

\subsubsection{Politics of Language: Prioritizing Subversive Voices and Difference}

Centering Blackness cannot mean erasing Africa or the hybridity or creolization of the new world and ongoing settler colonies such as Canada (Gilroy 1993). Rather, it may provide an articulation point for the diverse and understudied voices of subaltern Afro-Canadians to improve their present conditions in Canada's settler colonial society (Walcott 2019). Some leaders made 
this clear in discussions of Pan-Africanist or Pan-Black organizing in university student associations:

The international students or those who identified with the motherland with the continent of Africa really project to the Caribbean students that you are African because that's where we all came from and see the Caribbean students kind of push back because there was no, true or strong, emotional connection to the continent; there was no knowledge of some of the customs that took place there, and so to have that projected on you, and especially in the Caribbean where we are so mixed race.... If I own Africa so wholeheartedly, do I not owe it to myself to own my European ancestry or my Asian ancestry to that same degree? - Orlando

Going forward, it is imperative to prioritize difference amongst people racialized as Black, and their vast experiences with enslavement or imperialism while unifying under the identity of “Black Canadian” (Bledsoe \& Wright 2018, Dei 2014, Thomas 2018, Walcott 2019). This includes prioritizing the voices of women, the politically subversive, the ethnically marginalized, youth, disabled, LGBTQ2+, poor and other marginalized members of ACB communities. Moreover, many with roots outside of Canada, in Africa or the Caribbean, describe a process of detachment upon migration and a sense of being in limbo or not belonging at "home" or the space in which they have relocated. As such, creating space for self-identification, hybridity, and the acknowledgement and acceptance of differences amongst people racialized as Black within African Canadian communities is key (Walcott 2019). Theories that acknowledge and celebrate difference can adequately articulate the influx of African immigrants and the impact of this change on Afro-Canadian leadership in Canada. Lastly, in this era of ongoing ambivalence, the fungibility, experiences, and needs of African Canadians must be centered. 


\subsubsection{Diversity in Thought: Leaders Recommendations}

Of those who discussed non-Black solidarity, there were differing perspectives. Some such as Marcus called for transracial allyship and inclusivity under Black leadership that counters systemic anti-Blackness with alternatives to racial capitalism. This was based on a lack of institutional, financial, and organization power and called for "Not so much allies but collaborators, people who are collaborating on, actually actively engaged in the work of change and disrupting the very systems that benefit them." While Audrey argued that due to Ottawa's position as the national capital, leaders are too concerned with making African Canadian liberation palatable to non-Black Canadians.

Leaders who discussed policy recommendations had mixed advice. Some advocated for a federal "Anti-Black racism strategy" guided by a "Black lens" to achieve "Black inclusion" under the guidance of ACB leaders:

A strategy includes, to some extent, reparations, and not money, but changes to policies, programs, legislation. you know, taking a look with a black lens at things like policing, criminal justice, public safety, health, education, housing, homelessness, poverty, economics, and economic opportunities. - Marcus

Others argued for Black leadership outside governmental realms and decried existing policies:

He's [Prime Minister Trudeau] got some kind of task force group or whatever that's going to do some kind of survey or research to see if systemic racism exists. We don't need another study on this at the government level there are other organizations like BLM that have conducted this kind of research that have the numbers that have proven its out there. Now we need a government that takes concrete actions to address the issue and because the government is not doing it, we need to rely on organizations like BLM to implement those changes. I think if we want to see any concrete 
actions being taken and if we want to rally the Black community around that issue we need to rally with organizations like BLM. - Rachel

This sentiment was echoed in a leader focused on combatting racial capitalism and the poverty in Afro-Canadian communities:

We need to build things that we need.... It doesn't matter if it's small because my ancestors were able to build something from nothing! We have to be honest and apparent about the [financial] gap existing.... In terms of closing the gap and Black people who are still struggling to find financial balance, I think Black communities don't need any more entities provided by the government where we have to keep going back to them. We need sustainable private enterprises and businesses and investments. - Langston

Leaders more invested in macro or political approaches to addressing racism called for awareness-raising amongst non-Black people:

I think to simplify things. I know that wouldn't be a popular opinion but it's just that we have to go in stages, and we have to be able to conversations about these things without being too negatory.... There's a lot we have to examine but I think just honest, direct wording and intention is the best way to go and I feel just also rooting it academically. - Chimamanda

Shirley echoed "It's time to teach people also, you know? We need to tell people in a way that they would understand that this is what they are doing." These leaders argued that eradication of anti-Blackness will require simplification of language, a neutralized approach, and academic, race-based statistics to provide some form of proof. On the other hand, leaders such as Marcus argued "I'm not big on education and training on this stuff, like I think that the education and training does come through the actions for change."

In reference to navigation of microaggressions, systemic discrimination and racial trauma, leaders argued for additional African Canadian family supports: 
Some of our parents and our ancestors have done so much surviving and so much just going through so many fires and trying to make it through a lot of their own trauma that what happens is we end up passing it down, that trauma gets recycled and goes to generations so to break that therapeutic grounded in healing programs for Black families to come and support each other. Langston

Notably, there are some organizations within Ottawa such as Jaku Konbit, founded in 2000 to provide support to ACB families and communities (Jaku Konbit 2021), and the Somali Centre for Family Services, a non-profit organization established in 1991 that focuses on youth, seniors, and settlement and for immigrants and refugees, particularly of Somali origin (Somali Centre for Family Services 2021). Additionally, the OBYAP (2019) dedicated \$47 million to Black youth and families. However, no leaders referenced this so additional research is required regarding how leaders have may have accessed that funding.

\subsection{Conclusion}

The nation's capital presents an understudied site of Black Canadian mobilization. This research disputes the notion of a crisis in Afro-Canadian leadership in favor of the celebration of the diversity of recognized and unrecognized Black leadership in Ottawa. ACB leaders espouse multiple, layered Black consciousness based on their positionalities and perceptions of race, racism, colonialism, and anti-Blackness influenced by prior experiences with racism, colonialism, and white supremacy. The feasibility of Pan-African organization among Black Canadians in Ottawa is on the rise alongside the implementation of anti-racist policies. This is influenced by the rise of abolitionist movements such as BLM, political events such as UNDPAD and evidenced by the establishment of organizations such as ACAO, 613819Black Hub, Justice for Abdirahman, OBDC, ACMP, and Canadian Somali Mother's Association which embody these principles. Smaller organizations designed to serve specific needs within African Canadian 
communities strategically engage with one another to serve their respective communities and the Black community at large. Leaders understand racism as both a systemic and interpersonal determinant and anti-Black racism as specific. Anti-Blackness is a useful tool for African Canadians to articulate their racial experiences and build unity. The logics of anti-Blackness must account for the afterlives of imperialism as well as slavery, and the language must be clarified and simplified for use by Afro-Canadians outside academic and activist spaces.

\section{Conclusion}

\subsection{Summary}

This research explores Pan-Africanism, Black consciousness, and anti-Black racism within the context of Canadian multiculturalism through the BRT amongst ACB leaders in Canada's national capital region. The major research questions are: Who are the leaders in Ottawa's Black communities and how do they understand anti-Blackness? Does one's previous experiences with colonialism influence these understandings? Does the logic and language of anti-Blackness provide an explanatory tool or organizing political concept which a community as heterogenous as Black Canadians can utilize to articulate their experiences with race in Canada? These questions were answered via a QDA of some of the most recent anti-racism policies and twelve semi-structured in-depth interviews with leaders in the region.

Afro-Canadian leaders have a distinct history based on Canada's status as a settler colony, history of enslavement, and white supremacist policies. They are a diverse group representative of the populations they serve with multiple, layered Black consciousness based on their positionality and previous experiences with racism or colonialism. They understand antiBlackness as racism towards people racialized as Black, with some arguing that this is central to Canada's status as a settler colony as well as systems of imperialism worldwide. These 
understandings are influenced by their individual experiences with colonialism, as well as proximity to white supremacy and processes of racialization. Leaders agree that anti-Blackness is a useful conceptual tool for a group as diverse as African Canadians to articulate their specific experiences with race as well as build solidarity across diverse groups. However, the definition must be expanded to account for African colonialism and the multiplicities of Blackness, clarified, and simplified for use outside academia.

\subsection{Key Findings}

Canada houses a diverse Black population that is both the longest standing non-white settler group in the nation as well as one of the fastest growing due to migration (Mullings et al. 2016, Stats Can 2019; 2017). Representing over 170 ethnicities, Black Canadians have varying national, ethnic, linguistic, and cultural backgrounds (StatsCan 2019). The process of homogenizing ACB people minimizes their multiple identities, which contribute to hybridized diasporic Black Canadian identities and consciousness (Walcott 2019). Within this population, there is a long-standing BRT heavily influenced by Caribbean Canadians with longstanding ties to Canada that is silenced, alongside anti-Black racism, in discourses of anti-racism, diversity, and inclusion (Austin 2007, Calliste 1995, Mathieu 2010). The notion of a "crisis" exists surrounding Black leadership in Canada, which does not represent the perspectives of the community and serves to further erase Black Canadian leadership and deflect issues of antiBlack racism to the United States (Kitossa 2019).

In practice, there is a strong sense of Afro-Canadian leadership in Ottawa as well as a strong relationship between the BRT of mobilization and Canadian anti-racist policy (Cooper 2007, Flynn 2014, Henry 2018, Walker 1984, Winks 1997). African Canadian leaders are currently using the momentum from the global rise of liberatory organizations such as BLM and 
the global recognition of anti-Blackness via UNDPAD to continue to advocate for ACB people. This momentum has resulted in anti-racism policies which may recognize anti-Blackness but continue to reframe demands for abolition or decolonization in the language of multiculturalism, diversity and inclusion in a way that preserves nationalist myths and encourages Black assimilation (King 2019, Mullings et al. 2016, Robinson 1983, Thobani 2018; 2007). This maintains Canada's hegemonic presentation of itself as a "safe space" for Afro-Canadian people, thus promoting assimilation and diminishing threats to the settler state or current anti-Black relations of racial capitalism (King 2019, Tuck \& Yang 2012).

The BRT is on the rise as evidenced by an increase in non-identarian Pan-Africanist Black solidarity building centered on the unification of all people of African descent racialized as Black. This is also visible in the UNDPAD's recognition of the racism towards ACB Canadians and the Canadian government's efforts to respond to the U.N. In the past, Canada was a space of ambivalent safety for African Americans, Caribbean people and African people organizing Black liberation movements (Walcott 2003). However, the interests of African Canadians were not represented in these interventions. Going forward, a nationalist consciousness or politics of place may center the experiences of people racialized as Black within the geographic region to ensure that specific regional concerns are not overwhelmed (Dei 2019, Fanon 1968).

As ACB people are a diverse group with multiple identities, there is a need for language of Canadian anti-Blackness that accounts for the specificities of racism in a Canadian context. Anti-Blackness presents a viable concept by which a group as diverse as Black people can articulate their specific experiences as well as build political solidarity based on Blackness. To achieve this, the current language of ant-Blackness must be extended from the afterlife of slavery to account for both slavery and imperialism and the multiplicities of Blackness. In this way, anti- 
Blackness may present a transnational conceptual tool that enables analysis of Blackness in a Canadian context.

Going forward, difference must be celebrated outside the discourse of multiculturalism and beyond ethnicity, nationality, and culture. This format of celebrating difference may be meaningful for establishing solidarity amongst communities racialized as Black, however it is embedded within discourses of multiculturalism intended to assimilate Afro-Canadian people. Adoption of an intersectional perspective of Blackness and all its complexities may enable the inclusion of more intersectional perspectives and subversive voices, within African Canadian communities, to include perspectives about sexuality, ability, and class for example.

\subsection{Limitations}

Completing this research as a newcomer to Ottawa at the height of the COVID-19 lockdown was a major limitation that greatly impacted the structure of this project. Due to the changes in the recruitment process, most participants were recruited through one gatekeeper at a community organization. As such, activists who represent community organizations are the majority of participants and that perspective of leadership is most represented in this analysis. As the interviews were carried out over Zoom, and there was no prior relationship established with participants, the researcher was unable to analyze qualitative elements such as body language. Most importantly, there is a lack of intersectional perspectives as none of the participants were: Afro-Indigenous, disabled, sexual or gender minorities, non-citizens, or youth. As this research was limited by the COVID 19 pandemic social isolation restrictions it will be important to examine how ACB leadership in Ottawa operates in a post-COVID lockdown world. 


\subsection{Advice for Future Research}

Although the recruitment process was made difficult due to COVID 19 social pandemic restrictions, it is imperative for future researchers to establish themselves within the community and gain some rapport with potential participants to ensure a wider range of participants. Additionally, or alternatively, the researcher may seek to use a different instrument, such as a survey, to get a wider array of responses from a larger and more diverse audience. Future studies are required that examine leadership outside the community organization realm. Also, studies must be intersectional, and account for the diversity of Black experience and intersecting areas of oppression such as gender, age, ability, sexuality, health, and religion for example.

\subsection{Contribution to the field}

This project is engaged with an existing body of literature about the BRT in a Canadian context, leadership, and the existing logics and language of anti-Blackness. The main contributions to the field are: 1) a focus on Black leadership in Canada, which is a vastly understudied topic, with a focus on the Ottawa region that has not yet been studied in terms of the growing Black population or active leadership; 2) an emphasis on the multiplicities of Canadian Blackness and how one's positionality or previous experiences may influence their current perceptions of race; 3) Pan-African/ Pan-Black organization building in the Ottawa region; and 4) the importance of a language for Blackness amongst a diverse and fast growing Afro-Canadian population in Ottawa.

Studies of African Canadian people in Canada must emphasize subversive voices, such as those who may have been criminalized, as well as marginalized voices, such as those who have not pursued post-secondary education or attained high levels of social capital, as well as those who represent communities internally marginalized in their diasporic communities or nations of 
origin. Going forward, it is essential for academics studying anti-Blackness to celebrate difference, engage more closely with gender, ability, and other disregarded determinants, and cement the constitutive relationship between anti-Blackness and Indigenous genocide in settler colonies. In this way, we may assist ACB Canadians in their formulation of a radical, PanAfricanist perspective that centers Blackness as an ontological, social, and political position, alongside a cultural identity. 


\section{Appendices}

Appendix A: Tri-Council Policy Statement 2 - Certificate of Completion

\section{PANEL ON}

RESEARCH ETHICS

TCPS 2: CORE

\section{Certificate of Completion}

This document certifies that

Sarah George

has completed the Tri-Council Policy Statement:

Ethical Conduct for Research Involving Humans

Course on Research Ethics (TCPS 2: CORE)

Date of Issue: 13 March, 2020 
Appendix B: CUREB Ethics Approval Letter

\section{Sarah George}

From:

Sent:

To:

Cc:

Subject:

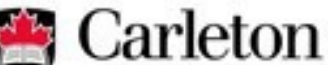

U N I VERSITY

Canada's Capital University
Leslie.MacDonald-Hicks@carleton.ca

April 2, 2020 4:33 AM

Sarah George

Hassim Shireen (Research Supervisor); Rutherford Blair

(Research Supervisor); EthicsMailbox; Leslie.MacDonald-

Hicks@carleton.ca

CUREB-A Clearance Certificate (Project \# 112640)

Office of Research Ethics

4500 ARISE Building | 1125 Colonel By Drive

Ottawa, Ontario K1S 5B6

613-520-2600 Ext: 2517

ethics@carleton.ca

\section{CERTIFICATION OF INSTITUTIONAL ETHICS CLEARANCE}

The Carleton University Research Ethics Board-A (CUREB-A) has granted ethics clearance for the research projectdescribed below and research may now proceed. CUREB-A is constituted and operates in compliance with the Tri- Council Policy Statement: Ethical Conduct for Research Involving Humans (TCPS2).

Ethics Protocol Clearance ID: Project \# 112640

Project Team Members: Sarah George (Primary Investigator)

Shireen Hassim (Research Supervisor)

Blair Rutherford (Research Supervisor)

Project Title: Pan-Africanism in Canada: Anti-Blackness and Black Consciousness in Canada's Capital

Funding Source (If applicable):

Effective: April 02, 2020

Expires: April 30, 2021. 


\section{Please ensure the study clearance number is prominently placed in all recruitment and consent materials:CUREB-A Clearance \# 112640. \\ Restrictions:}

This certification is subject to the following conditions:

1. Clearance is granted only for the research and purposes described in the application.

2. Any modification to the approved research must be submitted to CUREB-A via a Change to Protocol Form. Allchanges must be cleared prior to the continuance of the research.

3. An Annual Status Report for the renewal of ethics clearance must be submitted and cleared by the renewal datelisted above. Failure to submit the Annual Status Report will result in the closure of the file. If funding is associated, funds will be frozen.

4. A closure request must be sent to CUREB-A when the research is complete or terminated.

5. During the course of the study, if you encounter an adverse event, material incidental finding, protocol deviationor other unanticipated problem, you must complete and submit a Report of Adverse Events and Unanticipated Problems Form, found here: https://carleton.ca/researchethics/forms-and-templates/

Failure to conduct the research in accordance with the principles of the Tri-Council Policy Statement: Ethical Conduct forResearch Involving Humans 2nd Edition and the Carleton University Policies and Procedures for the Ethical Conduct of Research may result in the suspension or termination of the research project.

Upon reasonable request, it is the policy of CUREB, for cleared protocols, to release the name of the PI, the title of theproject, and the date of clearance and any renewal(s).

In light of the COVID-19 outbreak, The REB has developed guidance for human participants' research at https://carleton.ca/researchethics/. However, the situation is evolving rapidly so please check back regularly to keepup with any ongoing changes to this guidance.

Please contact the Research Compliance Coordinators, at ethics@carleton.ca, if you have any questions.

\section{CLEARED BY:}

Date: April 02, 2020

Natasha Artemeva, PhD, Chair, CUREB-A

Janet Mantler, PhD, Vice-Chair, CUREB-A

This email contains links to content or websites. Always be cautious when clicking on external links or attachments. If in doubt, please forward suspicious emails to phishing@carleton.ca. 


\title{
Informed Consent Form
}

\section{Name and Contact Information of Researchers:}

Sarah George, Carleton University, Department of Sociology and Anthropology and the Institute of African Studies, Faculty of Arts and Sciences

Tel.:

Email: Sarah.George3@carleton.ca

Supervisors and Contact Information: Prof. Shireen Hassim: ShireenHassim@,cunet.carleton.ca and Prof. Blair Rutherford: Blair.Rutherford@,carleton.ca

\section{Project Title}

Pan-Africanism in Canada: Black Consciousness and Anti-Blackness in Ottawa

\section{Carleton University Project Clearance}

\author{
Clearance \#: Project \# 112640 \\ Date of Clearance: April 2, 2020
}

\section{Invitation}

You are invited to take part in a research project because you are an activist or leader who belongs to or represents the African, Caribbean, or Black (ACB) community in Ottawa. The information in this form is intended to help you understand what I am asking of you so that you can decide whether you agree to participate in this study. Your participation in this study is voluntary, and a decision not to participate will not be used against you in any way. As you read this form, and decide whether to participate, please ask all the questions you might have, take whatever time you need, and consult with others as you wish.

\section{What is the purpose of the study?}

The purpose of this study is to provide empirical research about colonialism, anti-Blackness and Black consciousness formation in Canada's capital that may assist with effective governmental responses to communal demands and strengthen pan-African and pan-Black Canadian collaborations. It will examine the logics and language of anti-Blackness as both an explanatory 
theoretical tool and an organizing political concept within the heterogenous ACB Canadian communities. Additionally, it considers the heterogenous nature of ACB Canadians and enquires whether one's prior experiences with colonialism impacts the formation, or rejection, of their Black consciousness. Leaders' and activists' analyses and perceptions of municipal, provincial, and federal government policies or strategies regarding anti-Black racism will be documented and evaluated to assist with future collective demands.

\section{What will I be asked to do?}

If you agree to take part in the study, it will involve one 60-minute interview that will take place over Skype or the telephone. If social isolation measures for the corona pandemic are lifted, we can agree to meet in a mutually convenient and safe location. There are no ongoing requirements, however the research findings will be shared with the participants following completion. The nature of the requested information pertains to your personal experience of Black consciousness formation as well as your political experience as an activist or leader in an ACB community. The activities are expected to last approximately 60 minutes. With your consent, the interview will be audio taped. Due to the nature of data analysis, participants who do not consent to audio taping will not be included in the study.

\section{Risks and Inconveniences}

I anticipate minimal risks and inconveniences as you may find some of the questions regarding racism and colonialism to be sensitive or cause you distress. If you do feel any form of distress because of answering any of these questions, I will refer you to a healthcare professional who has experience working with African, Caribbean and Black Canadians for counselling services. Additionally, as this project will ask about institutionalized anti-Blackness, there are some potential professional risks to you for any employment you have if your statements are critical of governmental or institutional responses to community demands for the Canadian government to address anti-Blackness. To mitigate these risks the I will emphasize confidentiality. This will be done to ensure that participation in the research will not result in social or economic harm for you, including future occupational opportunities. All your data will be de-identified to protect your privacy. Additionally, no quotations will be attributed to you and any descriptions of any public events you may provide will be disguised to mitigate concern regarding attribution of comments or viewpoints to you.

\section{Possible Benefits}

You may not receive any direct benefit from your participation in this study. However, your participation may allow researchers, governmental bodies and other activists and leaders in Canada's ACB communities to better understand Black consciousness formation, different conceptions of anti-Blackness and the impacts, if any, of colonialism on both processes. In this way, providing additional data to the empirical repertoire from which ACB activists can utilize to 
articulate demands on behalf of their respective communities. Additionally, to continue facilitation of pan-African and pan-Black social organization.

\section{Compensation/Incentives}

You will be compensated for your participation in this study with $\$ 25.00$. The compensation is yours to keep should you choose to withdraw.

\section{No waiver of your rights}

By signing this form, you are not waiving any rights or releasing the researchers from any liability.

\section{Withdrawing from the study}

If you withdraw your consent during the study, all information collected from you before your withdrawal will be discarded, unless you permit it to be used in the study data.

After the study, you may request that your data be removed from the study and deleted by notice given to the Principal Investigator (named above) before September 1, 2020.

\section{Confidentiality}

I will remove all identifying information from the study data as soon as possible, which will be after the audio interviews are transcribed.

I will treat your personal information as confidential, although absolute privacy cannot be guaranteed. No information that discloses your identity will be released or published without your specific consent. Research records may be accessed by the Carleton University Research Ethics Board in order to ensure continuing ethics compliance.

All data will be kept confidential, unless release is required by law (e.g., child abuse, harm to self or others).

The results of this study may be published or presented at an academic conference or meeting, but the data will be presented so that it will not be possible to identify any participants unless you give your express consent.

You will be assigned a code [or pseudonym] so that your identity will not be directly associated with the data you have provided. All data, including coded information, will be kept in a password-protected file on a secure computer. 
I will encrypt [or password protect] any research data that I store or transfer.

\section{Data Retention}

After the study is completed, your de-identified data will be retained for future research use.

\section{New information during the study}

In the event that any changes could affect your decision to continue participating in this study, you will be promptly informed.

\section{Ethics review}

This project was reviewed and cleared by the Carleton University Research Ethics Board A. If you have any ethical concerns with the study, please contact Carleton University Research Ethics Board (by phone at 613-520-2600 ext. 2517 for CUREB A or by email at ethics@carleton.ca.

\section{Statement of consent - print and sign name}

I voluntarily agree to participate in this study.

I agree to be (audio recorded)

Yes No

(Note: Recordings are mandatory for participation)

I agree to be contacted for follow up research

Yes No

Signature of participant

Date

\section{Research team member who interacted with the participant}

I have explained the study to the participant and answered any and all of their questions. The participant appeared to understand and agree. I provided a copy of the consent form to the participant for their reference.

Signature of researcher

Date 


\section{Letter of Invitation}

Title: Pan-Africanism in Canada: Black Consciousness and Anti-Blackness in Canada's Capital

Date of ethics clearance: To be determined by the REB (as indicated on the clearance form)

Ethics Clearance for the Collection of Data Expires: To be determined by the REB (as indicated on the clearance form)

(Insert date)

Hello,

My name is Sarah George, and I am a master's student in Sociology in the Department of Sociology and Anthropology specializing in African Studies at Carleton University. I am working on a research project under the supervision of Prof. Shireen Hassim and Prof. Blair Rutherford.

I am writing to you today to invite you to participate in a study on antiBlackness, colonialism, and Black racial and political subject formation amongst Ottawa's African, Caribbean, and Black (ACB) activists and leaders. This study aims to explore the influence, if any, of prior experiences with colonialism on Black consciousness formation as well as the usefulness of anti-Blackness as an explanatory and politically unifying concept. This study involves one 60-minute interview that will take place in a mutually convenient, safe location. With your consent, interviews will be audio-recorded. Once the recording has been transcribed, the audiorecording will be destroyed.

While this project does involve some professional and emotional risks, care 
will be taken to protect your identity. This will be done by keeping all responses anonymous and allowing you to request that certain responses not be included in the final project.

You will have the right to end your participation in the study at any time, for any reason, up until July 1,2020 . If you choose to withdraw, all the information you have provided will be destroyed.

As a token of appreciation, I will be providing you with refreshments during the interview. You will also be provided with a pre-paid Visa gift card worth twenty-five Canadian dollars. (The compensation is yours to keep, even if you choose to withdraw.)

All research data, including audio-recordings and any notes will be encrypted. Any hard copies of data (including any handwritten notes or USB keys) will be kept in a locked cabinet in the researcher's office. Research data will only be accessible by the researcher and the research supervisors. This ethics protocol for this project was reviewed by the Carleton University Research Ethics Board, which provided clearance to carry out the research. Should you have questions or concerns related to your involvement in this research, please contact:

\section{CUREB-A:}

If you have any ethical concerns with the study, please contact the Carleton University Research Ethics Board-A (by phone at 613-520-2600 ext. 2517 or via email at ethics@carleton.ca).

This research project is being carried out under the supervision of Prof. Shireen Hassim and Prof. Blair Rutherford. Please contact them if you have any questions or concerns. You can contact Shireen Hassim by phone at 613-520-2600 ext. 3828 or via email at ShireenHassim@cunet.carleton.ca. You can contact Prof. Blair Rutherford by phone at 613-520-2600 ext. 2601 or via e-mail at BlairRutherford@cunet.carleton.ca.

If you would like to participate in this research project, or have any questions, please contact me or Sarah.George3@carleton.ca.

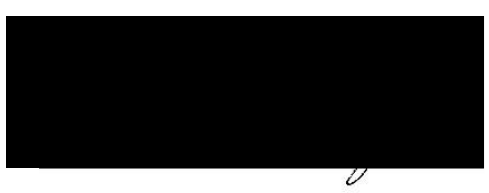

Sarah Ivana George 


\section{Data Collection Sheet}

- Title

- Type: Plan, Policy, Strategy etc.

- Governmental Body

- Date Released

- Dates Active

- Length

- Section analyzed

- Author(s)

- Source(s)

- Topic(s)

- Targeted Community

- Key words (Topoi)

- Language and Framing

○ Use of the word "racism"

- Description/ Definition of racism

- Use of the word "African, Caribbean or Black", "African Canadian", "AfroCanadian"

- Use of the word "anti-Blackness"

- Description/ Definition of anti-Blackness

- History of enslavement and contemporary systemic racism towards Black people in Canada

- Locus of Responsibility

- Focus

- Commitments

○ Economic

- Social

- Political

- Future Plans

- Miscellaneous

- Comparative Analysis 
Appendix F: Federal Anti-Racism Policy Budget

\section{Building a Foundation for Change (2019 - 2022): Federally Allocated Funds}

Building a foundation for change is a 45-million-dollar investment on top of the $\$ 13$ billion invested in anti-racism organizations since 2016 (GOC 2019: 8) which includes:

○ \$4.6 million - Anti-Racism secretariat in department of Heritage (GOC 2019: 7)

- \$30 million-Anti-Racism action program focused on employment, social participation, and justice for "community-based projects that aim to address racism and discrimination" at local, regional, and national level (GOC 2019: 12)

- Includes $\$ 5$ million digital/ cyber campaign and .9 for hate speech (GOC 2019: 18)

- Additional funding will be directed to the existing Community Support, Multiculturalism and Anti-Racism Initiatives Program (CSMARI) (GOC 2019: 12)

○ \$3.3 million public awareness campaign (GOC 2019: 17)

- \$6.2 million dollars for aggregated data on race and discrimination "Investments also include support to Statistics Canada's Expert Advisory Committee on Ethno-cultural and Immigration Statistics, and support to the Department of Justice's National Legal Problems Survey (GOC 2019: 19)

In efforts to recognize the decade the GOC committed $\$ 19$ million for Black Communities over a five-year period in Budget 2018 to support Black community programming for youth and racebased research (GOC 2019: 26). Additionally, \$25 million dollars were given to the Black community for "capital assistance", projects, capacity building initiatives, and efforts related to the UNDPAD (GOC 2019: 26). 


\section{Carleton \\ U N I V E R I T Y}

\section{Semi-Structured Interview Guide}

\section{Introduction and Background Information Overview:}

- Tell interviewee about myself and provide positionality

- Explain goal of project

- Ask if they have any questions before beginning

\section{Interview:}

Begin questions and prompts.

Note: The discussion may prompt different questions or prompts but these will be used as a guide.

Questions and Prompts:

- What is your story, where are you from?

- Are you Canadian or foreign born?

- What is the colonial structure in your nation of origin?

- Do you have prior experience living in a settler colony?

- How do you identify yourself?

- If Black: Have you always identified yourself this way?

- If no: What changed?

- What occurred during the process of "becoming Black"?

- If they do not identify as Black: why?

- Do you feel that your background influences your perceptions of Blackness, racism, and colonialism in Canada? Please discuss. 


\section{Carleton}

U N I V E R I T Y

- What kind of activist or leadership work do you engage in?

- How long have you been serving?

- How did you become an activist or leader?

- Do you work with other members of different community groups?

- If so, whom? Have you experienced unity in the ACB community in the form of coalition building, for example?

- If so, from whom?

- If not, have you attempted to build connections with other activists/ leaders/ groups without success? Have you experienced unity in the form of coalition building, for example?

- If so, from whom?

- Do ACB activists/leaders in the Ottawa-Gatineau region work together across interest groups?

- Are there any Pan-African or Pan-Black connections? Please explain.

- Is your work recognized by either the government or the community?

- If yes to government or community:

- How is your work recognized?

- By the state?

- The community?

- Why do you think this is?

- What did you have to do to gain recognition?

- Has said recognition put you in a position to help create change?

- If yes, in what way?

- If no, why do you think that is?

o What is Anti-Blackness?

- Are you familiar with this concept?

- If so, how do you use it? 


\section{Carleton}

U N I V E R I T Y

- How does racism towards Black people manifest in Canada?

- Does this concept account for or provide you with a means by which to articulate ACB Canadians' racial experiences?

- If not, why?

- If so, how?

- Do you feel this concept is useful in aiding the ACB community with addressing Canada's structural anti-Blackness?

- If not, why? If so, how?

- Do you feel that this concept is useful in building or maintaining unity in the ACB community?

- What is its relationship, if any, to race and racism?

- What is its relationship, if any, to settler colonialism?

- What is its relationship, if any, to Canadian multiculturalism?

- Closing remarks

- Is there anything you would like to expand on that we previously discussed?

- Anything you would like to add that you feel is relevant and I missed?

- Do you have any questions for me?

The ethics protocol for this project has been reviewed and cleared by the Carleton University Research Ethics Board. If you have any ethical concerns with the study, please contact the Carleton University Research Ethics Board-A (by phone at 613-520-2600 ext. 2517 or via email at ethics@carleton.ca). 


\section{Codebook}

\begin{tabular}{|c|c|}
\hline Name & Description \\
\hline Activism and Leadership & $\begin{array}{l}\text { Resistance to oppression, colonial domination, and racism to achieve } \\
\text { Black Liberation }\end{array}$ \\
\hline Anti-Blackness & $\begin{array}{l}\text { Ontological position of social death or colonial subject; racism towards } \\
\text { people racialized as Black }\end{array}$ \\
\hline Black Consciousness & $\begin{array}{l}\text { Self-awareness and acceptance of one's Blackness accompanied by an } \\
\text { altered way of seeing, being and knowing; awareness of racism or a } \\
\text { racialized conscious }\end{array}$ \\
\hline Identity & Sense of self; group \\
\hline Migration & $\begin{array}{l}\text { Movement of people from one place to another with the intention of } \\
\text { settling }\end{array}$ \\
\hline Racism & $\begin{array}{l}\text { Systemic political, social, and economic oppression of a marked group } \\
\text { based on processes of racialization }\end{array}$ \\
\hline $\begin{array}{l}\text { Pan-Africanism/ Pan-Black } \\
\text { Unity }\end{array}$ & $\begin{array}{l}\text { African- centred consciousness, developed in the Caribbean, that calls } \\
\text { for the pan-Black unification of all people of African descent }\end{array}$ \\
\hline Positionality & $\begin{array}{l}\text { The stance or positioning of the researcher in relation to the social and } \\
\text { political context of the study including the community, the } \\
\text { organization, or the participant group }\end{array}$ \\
\hline Multiculturalism and Policy & $\begin{array}{l}\text { Canadian policy management of diversity through formal initiatives in } \\
\text { the federal, provincial, territorial, and municipal domains }\end{array}$ \\
\hline $\begin{array}{l}\text { Enslavement/ Settler } \\
\text { Colonialism }\end{array}$ & $\begin{array}{l}\text { Transatlantic enslavement; racialized geopolitics of ongoing white } \\
\text { settlement; imperialism in Africa }\end{array}$ \\
\hline
\end{tabular}




\section{References}

Abdulle, M. H. (2000). Somali Immigrants in Ottawa: The Causes of their Migration and the Challenges of Resettling in Canada. [M.A. Thesis: University of Ottawa, Ottawa]. doi.org/10.20381/ruor-7504

Adjei, P.B. (2019). Is there no Balm in Gilead?: The Search for Radical Leadership in the Black Church of the Twenty-First Century. In P. Howard, E. Lawson \& T. Kitossa (Eds.), African Canadian Leadership: Continuity, Transition, and Transformation (311 - 344). University of Toronto Press. doi.org/10.3138/9781487531409

African Canadian Legal Clinic (ACLC). (2003). The Hidden Side of Paradise: Violations of the Economic and Social Rights of African Canadians. Ontario Human Rights Commission. https://www2.ohchr.org/english/bodies/cescr/docs/info-ngos/ACLC.pdf

Allen, M. (2017). Ethnographic Interview. In The SAGE Encyclopedia of Communication Research Methods (1-5). SAGE Publications. doi.org/10.4135/9781483381411.n168

Altheide, D. (2000). Tracking Discourse and Qualitative Document Analysis. Poetics, 27(4), 287-299. doi.org/10.1016/S0304-422X(00)00005-X

Altheide, D. \& Schneider, C. (2013). Qualitative Media Analysis. SAGE Publications. doi-org.proxy.library.carleton.ca/10.4135/9781452270043

Arthur, J. A., Takougang, J., \& Owusu, T. (2012). Africans in Global Migration: Searching for Promised Lands. Lexington Books. https://ocul-

crl.primo.exlibrisgroup.com/permalink/01OCUL_CRL/1vru3a1/cdi_proquest_ebookcentr al_EBC1108238

Aylward, C. (1999). Canadian Critical Race Theory Racism and the Law. Fernwood. https://oculcrl.primo.exlibrisgroup.com/permalink/01OCUL_CRL/1vru3a1/cdi_proquest_ebookcentr al_EBC3249822

Austin, D. (2007). All Roads Led to Montreal: Black Power, the Caribbean, and the Black Radical Tradition in Canada. The Journal of African American History, 92(4), 516-539. doi.org/10.1086/JAAHv92n4p516

Banton, M. (2000). The Idiom of Race. In L. Back and J. Solomos (Eds.), Theories of Race and Racism. A Reader (55 - 67). Macmillan Education UK. doi.org/10.1007/978-1-34922911-6_2

Barnstead, J. A. (2008). Black Canadian Studies as the Cutting Edge of Change: Revisioning Pushkin, Rethinking Pushkinology. Journal of Black Studies, 38(3), 367-373. doi.org/10.1177/0021934707306571 
Bashi, V. (2004). Globalized Anti-Blackness: Transnationalizing Western Immigration Law, Policy, and Practice. Ethnic and Racial Studies, 27(4). 584 - 606.

doi/abs/10.1080/01491987042000216726

Biko, S. (1978). I Write What I Like. Bowerdean Press.

Black Experience Project (2017, July). The Black Experience Project in the GTA: Overview Report 2018. https://www.ryerson.ca/content/dam/diversity/reports/black-experienceproject-gta---1-overview-report.pdf

Black History Ottawa. (2021). About Us. https://www.blackhistoryottawa.org/about_us

Black Law Students' Association, University of Ottawa Chapter. (2020). About Us. https://www.blsaottawa.com

Black Ottawa Scene. (2017, November 6). Canadian Somali Mothers Association Receives Crime Prevention Ottawa Award. http://blackottawascene.com/canadian-somali-mothersassociation-receives-crime-prevention-ottawa-award/

Bledsoe, A., \& Wright, W. J. (2018). The Anti-Blackness of Global Capital. Environment and Planning D: Society \& Space, 37(1), 8-26. doi.org/10.1177/0263775818805102

Bly, A. T. (1998). Crossing the Lake of Fire: Slave Resistance during the Middle Passage, 17201842. The Journal of Negro History, 83(3), 178-186. doi.org/10.2307/2649014

Bonds, A., \& Inwood, J. (2015). Beyond White Privilege: Geographies of White Supremacy and Settler Colonialism. Progress in Human Geography, 40(6), 715-733. doi.org/10.1177/0309132515613166

Bowen, G. (2009). Document Analysis as a Qualitative Research Method. Qualitative Research Journal, 9, 27-40. doi.org/10.3316/QRJ0902027

Branch, L. S. (2014, April 1). Consolidated Federal Laws of Canada, Canadian Multiculturalism Act. https://laws-lois.justice.gc.ca/eng/acts/c-18.7/page-1.html

Bueckert, K. (2018, September 18). Ontario's anti-Racism Directorate Cuts a Step Backwards, NDP's Lindo says. CBC. https://www.cbc.ca/news/canada/kitchener-waterloo/antiracism-directorate-cuts-lindo-tibollo-1.4827091

Cabral, A. (1973). Return to the Source: Selected speeches. Monthly Review Press.

Calliste, A. (1995). The Influence of the Civil Rights and Black Power Movement in Canada. Race, Gender \& Class, 2(3), 123-139. https://oculcrl.primo.exlibrisgroup.com/permalink/01OCUL_CRL/1vru3a1/cdi_jstor_primary_4167 4712 
Campbell, J. L., Quincy, C., Osserman, J., \& Pedersen, O. K. (2013). Coding In-depth Semi structured Interviews: Problems of Unitization and Intercoder Reliability and Agreement. Sociological Methods \& Research, 42(3), 294-320. doi.org/10.1177/0049124113500475

The Canadian Press. (2018, February 13). Trudeau Says it's Time to Recognize Anti-Black Racism Exists in Canada. CBC. https://www.cbc.ca/news/politics/trudeau-black-historymonth-1.4533194

Canadian Sociological Association (CSA). (2020) CSA@Congress 2021. https://www.csascs.ca/conference/en/

---. (2012). History of the CSA. https://www.csa-scs.ca/history

Caribbean African Canadian Social Services (CAFCAN). (2019, November 26). Canadian Government Throws Support Behind an Institute for Black Canadians. https://cafcan.org/2019/11/26/canadian-government-throws-support-behind-an-institutefor-black-canadians/

Carleton University Faculty of Arts and Social Sciences (FASS). (2021). Against All Odds: The Afro-Caribbean Mentorship Program (ACMP) at Carleton University. https://carleton.ca/fass/story/against-all-odds/

Charteris-Black, J. (2011) Politicians and Rhetoric: The Persuasive Power of Metaphor. Palgrave Macmillan.

Christian, M. (2002). An African-Centered Perspective on White Supremacy. Journal of Black Studies, 33(2), 179-198. doi.org/10.1177/002193402237224

City of Ottawa. (2017). Ottawa Equity and Diversity Policy. https://app06.ottawa.ca/calendar/ottawa/citycouncil/csedc/2002/09-17/ACS2002-HMRLAB-005\%20Document\%201\%20Equity\%20Diversity\%20Policy.html

City of Ottawa and City for All Women Initiative (CAWI). (2018). Ottawa Equity \& Inclusion Lens Handbook. https://www.cawi-ivtf.org/sites/default/files/publications/ei-lenshandbook-en-web-2018.pdf.

Clarke G.E. (1996). Must All Blackness Be American?: Locating Canada in Borden's. Canadian Ethnic Studies, 28(3), 56-71. https://oculcrl.primo.exlibrisgroup.com/permalink/01OCUL_CRL/1vru3a1/cdi_gale_incontextgauss _ISN_A30409681

Clarke, J. H. (1988). Pan-Africanism: A Brief History of an Idea in the African World. Présence Africaine, 145, 26-56. doi.org/10.3917/presa.145.0026 
Clark, S. D. (1975). Sociology in Canada: An Historical Over-View. The Canadian Journal of Sociology, 1(2), 225-234. doi.org/10.2307/3339809

Colón, A. (2008). Reflections on the History of Black Studies. The Journal of African American History, 93(2), 271-279. doi.org/10.1086/JAAHv93n2p271

The Coloured Women's Club. (2005, March 15). The Coloured Women's Club. http://colouredwomensclub.tripod.com/

Cooper, A. (2017). "Deluded and Ruined": Diana Bastian-Enslaved African Canadian Teenager and White Male Privilege. Brock Education, 27(1). doi.org/10.26522/brocked.v27i1.623

--. (2007) Acts of Resistance: Black Men and Women Engage Slavery in Upper Canada, 17931803. Ontario History, 99(1), 5-17. doi.org/10.7202/1065793ar

--. (2000) Constructing Black Women's Historical Knowledge. Special Issue: Feminism and Canadian History (25 ${ }^{\text {th }}$ Anniversary Vol. Pt 1), 25(1), $39-50$. https://journals.msvu.ca/index.php/atlantis/article/view/1544

Coulthard, G. (2014). Red Skin, White Masks: Rejecting the Politics of Colonial Recognition. University of Minnesota Press.

Creese, G. (2018). “Where are you from?” Racialization, Belonging and Identity Among SecondGeneration African-Canadians. Ethnic and Racial Studies, 42(9), 1476-1494. doi.org/10.1080/01419870.2018.1484503

Crenshawe, K., Gotanda N., Peller G., \& Thomas, K. (1995). Critical Race Theory: The key writings that formed the movement. New Press.

Crichlow, W. (2019). Black Consciousness and the Heteronormative Sexual Politics of Black Leadership in Toronto: A Commentary. In P. Howard, E. Lawson \& T. Kitossa (Eds.), African Canadian Leadership: Continuity, Transition, and Transformation (289-310). University of Toronto Press. doi.org/10.3138/9781487531409

Curry, T. J., \& Curry, G. (2018). On the Perils of Race Neutrality and Anti-Blackness: Philosophy as an Irreconcilable Obstacle to (Black) Thought. American Journal of Economics and Sociology, 77(3/4), 657-687. doi.org/10.1111/ajes.12244

Day, I. (2015). Being or Nothingness: Indigeneity, Antiblackness, and Settler Colonial Critique. Critical Ethnic Studies, 1(2), 102-121. doi.org/10.5749/jcritethnstud.1.2.0102

Dei, G. (2019). 13: An Indigenous Africentric Perspective on Black Leadership. In P. Howard, E. Lawson \& T. Kitossa (Eds.), African Canadian Leadership: Continuity, Transition, and Transformation (345 - 369). University of Toronto Press.

doi.org/10.3138/9781487531409-015 
---. (2018). "Black Like Me": Reframing Blackness for Decolonial Politics. Educational Studies, 54(2), 117-142. doi.org/10.1080/00131946.2018.1427586

---. (2014). The African Scholar in the Western Academy. Journal of Black Studies, 45(3), 167179. doi.org/10.1177/0021934714525198

Dei, G. J. S., \& James, I. M. (1998). 'Becoming Black': African-Canadian Youth and the Politics of Negotiating Racial and Racialised Identities. Race Ethnicity and Education, 1(1), 91108. doi.org/10.1080/1361332980010107

Du Bois, W.E.B. (1903). The Souls of Black Folk. A. C. McClurg \& Co.

Employment Equity Act (2017, December 12). Consolidated federal laws of Canada, Employment Equity Act. https://laws-lois.justice.gc.ca/eng/acts/E-5.401/page1.html?txthl=minorities + minorit\%C $3 \% \mathrm{~A} 9 \mathrm{~s}+$ visibles + visible\#s-3

Esedebe, P. O. (1994). Pan-Africanism: The Idea and Movement, 1776-1991 (2nd ed.). Howard University.

Evans, J., Grimshaw, P., Philips, D., \& Swain, S. (2003). Equal Subjects, Unequal Rights: Indigenous peoples in British settler colonies, 1830-1910. Manchester University Press.

Evans, L. (2009) The Black Atlantic: Exploring Gilroy's Legacy. Atlantic Studies, 6(2), 255-268, doi.org/10.1080/14788810902981308

Fanon, F. (1968). The Wretched of the Earth. (1 ${ }^{\text {st }}$ Black Cat ed.). Grove Press.

---. (1952). Black Skin, White Masks. Pluto.

Farah, H. K. (2011). Exploring the Narrative Experience of Somali Djiboutian Youth In and About Ottawa Public Schools [Ph.D. Thesis: University of Ottawa, Ottawa]. http://www.proquest.com/docview/1365708847/abstract/59754CD03184269PQ/1

Fatona, A. (2006). In the Presence of Absence: Invisibility, Black Canadian History, and Melinda Mollineaux's Pinhole Photography. Canadian Journal of Communication, 31(13), 227-238. https://oculcrl.primo.exlibrisgroup.com/permalink/01OCUL_CRL/1vru3a1/cdi_proquest_journals_2 19575528

Forum Report. (2016). Addressing Anti-Black Racism in Ottawa: Forum Summary Report Ottawa City Hall. https://www.cawi-ivtf.org/sites/default/files/publications/antiblack_racism_forum_report_2017-02.pdf.

Flynn, K. (2014). Black Canadian Feminist Theorizing: Possibilities and Prospects. The CLR James Journal, 20(1/2), 179-193. doi.org/10.5840/clrjames20149158 
Franks, M. (2002). Feminisms and Cross-ideological Feminist Social Research: Standpoint, Situatedness and Positionality - Developing Cross-ideological Feminist Research. Journal of Internal Women's Studies, 3(2), 37 - 50. https://vc.bridgew.edu/cgi/viewcontent.cgi?article=1601\&context=jiws

Gilroy, P. (1993). The Black Atlantic: Modernity and Double-Consciousness. Harvard University Press.

Gonzalez-Sobrino, B., \& Goss, D. R. (2018). Exploring the Mechanisms of Racialization Beyond the Black-White Binary. Ethnic and Racial Studies, 42(4), 505-510. doi.org/10.1080/01419870.2018.1444781

Gooden, A. (2019). African Canadian Leadership: Pan-Africanism, Transnationality, and Community Organizing. In P. Howard, E. Lawson \& T. Kitossa (Eds.), African Canadian Leadership: Continuity, Transition, and Transformation (111-149). University of Toronto Press. doi.org/10.3138/9781487531409

---. (2008). Community Organizing by African Caribbean People in Toronto, Ontario. Journal of Black Studies, 38(3), 413-426. doi.org/10.1177/0021934707309134

Gordon, L. R. (2018). Thoughts on Afropessimism. In Afro pessimism, Contemporary Political Theory, 17(1), 105-112. doi.org/10.1057/s41296-017-0165-4

Government of Canada. (2019, July 17). Building a Foundation for Change: Canada's Anti Racism Strategy 2019-2022. https://www.canada.ca/en/canadianheritage/campaigns/anti-racism-engagement/anti-racism-strategy.html

Government of Ontario. (2017, December 14). Archived-Ontario's Anti-Black Racism Strategy. https://www.ontario.ca/page/ontarios-anti-black-racism-strategy

---. (2017, July 27). Ontario's Black Youth Action Plan. Ministry of Children and Services. http://www.children.gov.on.ca/htdocs/English/youthopportunities/eoyap/obyap.aspx

---. (2017). Enhanced Youth Outreach Worker Program: Call for Applications. Ministry of Children and Youth Services, Ontario Black Youth Action Plan. https://www.GOgle.com/search?rlz=1C1GCEA enCA831CA831\&sxsrf=ALeKk03b6Vb IYKrEHRM5626dZlfvM04TPg\%3A1594597018010\&ei=mp4LX_8QnsnQ8Q_HppLID Q\&q=enhanced+youth+outreach+worker+plan+\&oq=enhanced+youth+outreach + worker + plan+\&gs_lcp=CgZwc3ktYWIQAzIGCAAQFhAeOgQIABBHOgQIIxAnOgIIADoFC CEQoAFQozlY5z5ggUBoAHABeACAAaIBiAGGBZIBAzQuMpgBAKABAaoBB2d3c y13aXo\&sclient=psyab\&ved=0ahUKEwj_xcXm8MjqAhWeJDQIHUeTBNkQ4dUDCAw\&uact=5

---. (2017). Stop Now and Plan Program: Call for Applications. Ministry of Children and Youth 
Services, Ontario Black Youth Action Plan.

http://www.children.gov.on.ca/htdocs/English/documents/youthopportunities/obyap/BYA P-SNAP-Application-EN-April\%209.pdf

---. (2017). Together We Can: Call for Applications. Ministry of Children and Youth Services, Ontario Black Youth Action Plan. http://www.children.gov.on.ca/htdocs/English/documents/youthopportunities/obyap/OBY AP-Q\&ATogetherWeCan.pdf

Grimes, K. (2018) Let Black People Be: A Plea for Racial Specificity in the Afterlife of Africanized Slavery. Journal of Religious Ethics, 46(3), 496-520. doi.org/10.1111/jore.12229

Hartman, S. V. (2007). Lose Your Mother: A Journey Along the Atlantic Slave Route (1st ed.). Farrar, Straus and Giroux. https://oculcrl.primo.exlibrisgroup.com/permalink/01OCUL_CRL/1gorbd6/alma9910126078497051 53

---. (1997) Scenes of Subjection: Terror, Slavery, and Self-Making in Nineteenth Century America. Oxford University Press. https://oculcrl.primo.exlibrisgroup.com/permalink/01OCUL_CRL/1gorbd6/alma9910027143497051 53

Hayes, F. W. (2000). A Turbulent Voyage: Readings in African American Studies. Rowman \& Littlefield.

Henry, N. (2018). Black History in Canada. Canada's History Magazine for Kids: Kayak, Special Digital Edition. https://www.canadashistory.ca/getmedia/8a0fa57e-fac9-4f54-ba56fd8725a12d72/Kay2018BlackHistory.pdf

Hill, L. (2007). Freedom bound. The Beaver: Exploring Canada's History, 87(1), 16-23. https://www.lawrencehill.com/freedom_bound.pdf

Horne, G. (2018). The Apocalypse of Settler Colonialism. New York University Press, 69(11), 121. doi.org/10.14452/MR-069-11-2018-04_1

Howard, P., Kitossa, T., \& Lawson, E. (Eds.) (2019). African Canadian Leadership: Continuity, Transition, and Transformation. University of Toronto Press. doi.org/10.3138/9781487531409

Howe, S.G. (1864). The Refugees from Slavery in Canada West: Report to the Freedman's Commission. Boston, Wright \& Porter Printers. https://books.google.ca/books?id=e$\mathrm{WRbMHueBcC \& printsec}=$ frontcover\&source $=$ gbs_ge_summary_r\&cad $=0 \# \mathrm{v}=$ onepage $\&$ $\mathrm{q} \& \mathrm{f}=$ false

Hudson, P. J., \& Kamugisha, A. (2014). On Black Canadian Thought. The CLR James 
Journal, 20(1/2), 3-20. doi.org/10.5840/clrjames201492216

Ibrahim, A. (2004). One is not Born Black: Becoming and the Phenomenon(ology) of Race.

Philosophical Studies in Education, 35(1), 77 - 87. http://ovpes.org/wp-

content/uploads/2012/01/ibrahim2004.pdf

---. (1999). Becoming Black: Rap and Hip-Hop, Race, Gender, Identity, and the Politics of ESL Learning. TESOL Quarterly, 33(3), 349-369. doi.org/10.2307/3587669

Iton, R. (2008). In Search of the Black Fantastic: Politics and Popular Culture in the Post-Civil Rights Era. Oxford University Press.

Doi.org/10.1093/acprof:oso/9780195178463.001.0001

Jackson-Brown, G. (2020). Afropessimism [Review]. Booklist, 116(14), 24.

https://oculcrl.primo.exlibrisgroup.com/permalink/01OCUL_CRL/1vru3a1/cdi_proquest _reports_2378098452

James, C. (2019). Black Leadership and White Logic: Models of Community Engagement. In P. Howard, E. Lawson \& T. Kitossa (Eds.), African Canadian Leadership: Continuity, Transition, and Transformation. University of Toronto Press. doi.org/10.3138/9781487531409

Jaku Konbit. (2021). About Us. https://www.jakukonbit.com/about/

Johnson, L. (2016). Boundary Spanners and Advocacy Leaders: Black Educators and Race Equality Work in Toronto and London, 1968-1995. Leadership and Policy in Schools, 15(1), 91-115. doi.org/10.1080/15700763.2015.1071401

Johnson, L. (2015). From the Anti-Slavery Movement to Now: (RE) examining the Relationship Between Critical Race Theory and Black Feminist Thought. Race, Gender \& Class, 22(34), 227-243. https://www.jstor.org/stable/26505358

Johnston, J. (2001). Research Note: Mathieu Da Costa along the Coasts of Nova Scotia: Some Possibilities. Journal of the Royal Nova Scotia Historical Society, 4, 152-IX. https://search-proquest-com.proxy.library.carleton.ca/docview/1018076092?pqorigsite $=$ gscholar\&fromopenview $=$ true

Jones, T.-A. (2007). Jamaican Immigrants in the United States and Canada: Race, Transnationalism, and Social Capital. LFB Scholarly Publishing LLC. http://ebookcentral.proquest.com/lib/oculcarleton-ebooks/detail.action?docID=3016807

Karenga, M. (2009). Names and Notions of Black Studies: Issues of Roots, Range, and Relevance. Journal of Black Studies, 40(1), 41-64. https://journals-sagepubcom.proxy.library.carleton.ca/doi/pdf/10.1177/0021934709335134

Kelley, R. D. G. (January 12, 2017). What Did Cedric Robinson Mean by Racial Capitalism? 
Boston Review: A Political and Literary Forum. http://bostonreview.net/race/robin-d-gkelley-what-did-cedric-robinson-mean-racial-capitalism

Kenny, M. (2008). The Integration Experience of Somali Refugee Youth in Ottawa, Canada: "Failure is not an option for us" [M.A. Thesis: Carleton University, Ottawa]. doi.org/10.22215/etd/2008-07807

King, T. (2019). The Black Shoals: Offshore Formations of Black and Native Studies.

Duke University Press. doi.org/10.1515/9781478005681

---. (June 10, 2014). Labor's Aphasia: Toward Antiblackness as Constitutive to Settler Colonialism. Decolonization: Indigeneity, Education and Society. https://decolonization.wordpress.com/2014/06/10/labors-aphasia-toward-antiblacknessas-constitutive-to-settler-colonialism/

---. (2013). In the Clearing: Black Female Bodies, Space and Settler colonial Landscapes. [PhD Thesis: University of Maryland, College Park]. ProQuest Dissertations Publishing. https://oculcrl.primo.exlibrisgroup.com/permalink/01OCUL_CRL/1vru3a1/cdi_proquest_journals_1 461804097

Kitossa, T. (2019). African Canadian Leadership and the Metaphoricality of "Crisis": Towards Theorizing, Research, and Practice. In P. Howard, E. Lawson \& T. Kitossa (Eds.), African Canadian Leadership: Continuity, Transition, and Transformation $(71-111)$. University of Toronto Press. doi.org/10.3138/9781487531409

Lagacé, M., Charmarkeh, H., \& Grandena, F. (2012). Cultural Perceptions of Aging: The Perspective of Somali Canadians in Ottawa. Journal of Cross-Cultural Gerontology, 27(4), 409-424. doi.org/10.1007/s10823-012-9180-3

Lamola, M. J. (2018). Blackhood as a Category in Contemporary Discourses on Black Studies: an Existentialist Philosophical Defence. Transformation in Higher Education, 3(1), 1-9. doi.org/10.4102/the.v3i0.55

Lawson, E. (2019). Mercy for their Children: A Feminist Reading of Black Women's Maternal Activism and Leadership Practices. In P. Howard, E. Lawson \& T. Kitossa (Eds.), African Canadian Leadership: Continuity, Transition, and Transformation $(190-212)$. University of Toronto Press. doi.org/10.3138/9781487531409

Leavy, P., \& Hesse-Biber, S. N. (2010). Handbook of Emergent Methods. Guilford Press. https://oculcrl.primo.exlibrisgroup.com/permalink/01OCUL_CRL/1gorbd6/alma9910152113197051 53

Leroy, J. (2016). Black History in Occupied Territory: On the Entanglements of Slavery and 
Settler Colonialism. Theory \& Event, 19(4), 1 - 13. https://oculcrl.primo.exlibrisgroup.com/permalink/01OCUL_CRL/1vru3a1/cdi_chadwyckhealey_ab ell_R05558130

Lewis, S. (1992, 6 June). Stephen Lewis Report. Legislative Assembly of Ontario. https://collections.ola.org/mon/13000/134250.pdf

Lord, C. (2020, June 19). March for Black lives Planned for Ottawa's Elgin Street on Saturday. Global News Ottawa. https://globalnews.ca/news/7086430/march-for-black-lives-ottawaelgin-street-sunday/

---. (2020, June 3). Update: Ottawa Anti-Racism March Faces Backlash Amid Shifting Plans. Global News Ottawa. https://globalnews.ca/news/7022811/ottawa-anti-racism-marchquestions-george-floyd/

Loxley, J., Sackey, H. A., \& Khan, S. (2015). African Immigrants in Canada: A Profile of Human Capital, Income, and Remittance Behavior. Canadian Journal of Development Studies / Revue Canadienne d'études Du Développement, 36(1), 3-23. doi.org/10.1080/02255189.2015.1015506

Magaziner, D. R. (2010). The Law and the Prophets: Black Consciousness in South Africa, 19681977. Ohio University Press. https://oculcrl.primo.exlibrisgroup.com/permalink/01OCUL_CRL/1vru3a1/cdi_askewsholts_vleboo ks_9780821443309

Mathieu, S.J. (2010). North of the Color Line: Migration and Black Resistance in Canada, 1870-1955. University of North Carolina Press.

http://ebookcentral.proquest.com/lib/oculcarleton-ebooks/detail.action?docID=605923

Maynard, R. (2017). Policing Black Lives. Fernwood Publishing. https://oculcrl.primo.exlibrisgroup.com/permalink/01OCUL_CRL/1gorbd6/alma9910055 89539705153

Mazama, A. (2003). The Afrocentric Paradigm. Africa World Press. https://oculcrl.primo.exlibrisgroup.com/permalink/01OCUL_CRL/1gorbd6/alma9910043 20109705153

Mbuagbaw, L., Tharao, W., Husbands, W., Nelson, L. E., Aden, M., Arnold, K., Baidoobonso, S., Dabone, C., Dryden, O., Etowa, E., Hamid, J., Jackson-Best, F., Kohoun, B., Lawson, D. O., Lofters, A. K., Luyombya, H., Mbulaheni, T., Mkandawire, P., Ndungu, M., ... Etowa, J. (2020). A/C study protocol: A cross-sectional study of HIV epidemiology among African, Caribbean, and Black people in Ontario. BMJ Open, 10(7), $1-8$. doi.org/10.1136/bmjopen-2019-036259

McDuffie, E. (2016). The Diasporic Journeys of Louise Little: Grassroots Garveyism, the 
Midwest, and Community Feminism. Women, Gender, and Families of Color, 4(2), 146170. doi.org/10.5406/womgenfamcol.4.2.0146

McIntosh, M. J., \& Morse, J. M. (2015). Situating and Constructing Diversity in Semi-Structured Interviews. Global Qualitative Nursing Research, 2, 1 - 12.

doi.org/10.1177/2333393615597674

McLaughlin, N. (2005). Canada's Impossible Science: Historical and Institutional Origins of the Coming Crisis in Anglo-Canadian Sociology. The Canadian Journal of Sociology /

Cahiers Canadiens de Sociologie, 30(1), 1-40. doi.org/10.2307/4146156

McLeod, J. (2016). Introduction: Postcolonial Environments. Journal of Commonwealth Literature, 51(2), 192-195. doi.org/10.1177/0021989415626208

McNeil, D. (2021). Wrestling with Multicultural Snake Oil: A Newcomer's Introduction to Black Canada. In M. Johnson and F. Aladejebi (Eds.) Unsettling the Great White North: Black Canadian History, University of Toronto Press.

---. (2011). Sex and Race in the Black Atlantic: Mulatto Devils and Multiracial Messiahs. Routledge. https://oculcrl.primo.exlibrisgroup.com/permalink/01OCUL_CRL/1gorbd6/alma9910020610097051 53

Mensah, J. (2002). Black Canadians: History, Experiences, Social Conditions. Fernwood. https://oculcrl.primo.exlibrisgroup.com/permalink/01OCUL_CRL/1vru3a1/cdi_proquest_journals_3 04017966

Mensah, J., \& Williams, C. J. (2015). Seeing/Being Double: How African immigrants in Canada Balance their Ethno-racial and National identities. African and Black Diaspora: An International Journal, 8(1), 39-54. doi.org/10.1080/17528631.2014.986024

Menzel, Z. (2018). Maternal Generativity in the Afterlife of Slavery. In Afro pessimism. Contemporary Political Theory, 17(1), 112-118. doi.org/10.1057/s41296-017-0165-4

Mills, C.W. (1999). Blackness Visible: Essays on Philosophy and Race. Cornell University Press. doi.org/10.7591/9781501702952

---. (1997). The Racial Contract. Cornell University Press. https://abolitionjournal.org/wp-content/uploads/2020/06/Mills-racial-contracxt.pdf

Mills, J. (2015). Conferencing as a Site for the Mobilization of Black Feminist Identities in the Congress of Black Women of Canada, 1973-1983. Journal of Black Studies, 46(4), 415441. doi.org/10.1177/0021934714568456

Mohamed, H. (2007). Somali Single Mothers in Ottawa: Challenges and Opportunities of 
Resettlement and Implications for Health and Well-Being [M.A. Thesis: Carleton University, Ottawa]. doi.org/10.22215/etd/2007-08156

Mullings, D. V., Morgan, A., \& Quelleng, H. K. (2016). Canada the Great White North where Anti-Black Racism Thrives: Kicking Down the Doors and Exposing the Realities. Phylon (1960-), 53(1), 20-41.

Nájera, L. G., \& Maldonado, K. (2016). Transnational Settler Colonial Formations and Global Capital: A Consideration of Indigenous Mexican Migrants. American Quarterly, 69(4), 809-821. doi.org/10.1353/aq.2017.0067

Okoth, K. O. (2020, January 16). The Flatness of Blackness: Afro-Pessimism and the Erasure of Anti-Colonial Thought. Salvage \#7: Towards the Proletarocene. https://salvage.zone/issue-seven/the-flatness-of-blackness-afro-pessimism-and-theerasure-of-anti-colonial-thought/

Olaloku-Teriba, A. (2018). Afro-Pessimism and the (Un)Logic of Anti-Blackness. Historical Materialism, 26(2), 96-122. doi.org/10.1163/1569206X-00001650

Omorodion, F. I., Etowa, E. B., Kerr, J., Ghose, B., \& Etowa, J. (2021). Correlates of Casual Sex Amidst Vulnerability to HIV Among ACB Heterosexual Men in Ottawa and Windsor, Ontario Canada. Journal of Racial and Ethnic Health Disparities, 1(1), 1 - 12. doi.org/10.1007/s40615-021-00975-z

Park, L. (2020). Afropessimism and Futures of ...: A Conversation with Frank Wilderson. The Black Scholar, 50(3), 29-41. doi.org/10.1080/00064246.2020.1780863

Patterson, O. (1982). Slavery and Social Death: A Comparative Study. Harvard University Press. https://cominsitu.files.wordpress.com/2020/10/orlando-patterson-slavery-and-socialdeath_-a-comparative-study-1985.pdf

Piot, C. (2001). Atlantic Aporias: Africa and Gilroy's Black Atlantic. South Atlantic Quarterly, 100(1), 155-170. doi.org/10.1215/00382876-100-1-155

Pringle, J. (2020, June 5). Thousands Attend Anti-Racism March in Downtown Ottawa. CTV News Ottawa. https://ottawa.ctvnews.ca/thousands-attend-anti-racism-march-indowntown-ottawa-1.4970246

Ramos, H. (2013). From Ethnicity to Race in the Canadian Review of Sociology, 1964 to 2010. The Canadian Review of Sociology, 50(3), 337-356. doi.org/10.1111/cars.12018

Reddock, R. (2014). The First Mrs. Garvey and others: Pan-Africanism and Feminism in the early $20^{\text {th }}$ Century British colonial Caribbean. Feminist Africa 19: Pan-Africanism and Feminism, 19, 58-77.

http://www.agi.ac.za/sites/default/files/image_tool/images/429/feminist_africa_journals/a 
rchive/02/features_-_the_first_mrs_garvey_and_others-_panafricanism_and_feminism_in_the_early_20th_century_british_colonial_caribbean.pdf

Reimer, B. (2000) Complexities of "black" History in Canada. Canadian Mennonite, 4(4), 13. https://proxy.library.carleton.ca/login?url=https://www-proquestcom.proxy.library.carleton.ca/magazines/complexities-black-historycanada/docview/228312780/se-2?accountid=9894

Rieff, D. (1998). In Defense of Afro-Pessimism. World Policy Journal, 15(4), 10-22. https://ciaotest.cc.columbia.edu/olj/wpj/wp_99red01.html

Robinson, C. J. (1983). Black Marxism: The Making of the Black Radical Tradition. University of North Carolina Press. https://libcom.org/files/Black\%20MarxismCedric\%20J.\%20Robinson.pdf

Rotz, S. (2017). 'They Took Our Beads, It Was a Fair Trade, Get Over It': Settler Colonial Logics, Racial Hierarchies and Material Dominance in Canadian Agriculture. Geoforum, 82, 158-169. doi.org/10.1016/j.geoforum.2017.04.010

Rowe, A. C., \& Tuck, E. (2016). Settler Colonialism and Cultural Studies. Cultural Studies, Critical Methodologies, 17(1), 3-13. doi.org/10.1177/1532708616653693

Schramm, K., \& Butler, B. (2010). African Homecoming: Pan-African Ideology and Contested Heritage. Taylor \& Francis Group. http://ebookcentral.proquest.com/lib/oculcarletonebooks/detail.action?docID $=801212$

Sexton, J. (2016). The Vel of Slavery: Tracking the Figure of the Unsovereign. Critical Sociology, 42(4-5), 583-597. doi.org/10.1177/0896920514552535

---. (2010). People-of-color-blindness: Notes on the afterlife of slavery. Social Text, 28(2 [103]), 31-56. doi.org/10.1215/01642472-2009-066

Sharpe, C. E. (2016). In the Wake: On Blackness and Being. Duke University Press. doi.org/10.1215/9780822373452

Shulman, G. (2018). Theorizing Life Against Death. In Afro pessimism. Contemporary Political Theory, 17(1), 118 - 128. doi.org/10.1057/s41296-017-0165-4

Smith, A. (2010). Indigeneity, Settler Colonialism, White Supremacy. Global Dialogue (Nicosia Cyprus), 12(2), 66-90.

https://oculcrl.primo.exlibrisgroup.com/permalink/01OCUL_CRL/1vru3a1/cdi_proquest journals_866741293

Smith, M. E. (2017) Disciplinary Silences: Race, Indigeneity, and Gender in the Social Sciences. In Henry, F., Dua, E., James, C. E., Kobayashi, A., Li, P., Ramos, H., Smith, M. E. (Eds.) The Equity Myth: Racialization and Indigeneity at Canadian Universities (239-263). 
UBC Press. https://ocul-

crl.primo.exlibrisgroup.com/permalink/01OCUL_CRL/1gorbd6/alma9910227359696051 53

Snail, M. (2009). The Black Consciousness Movement in South Africa: A Product of The Entire Black World. Historia Actual On-Line, 15, 51-68. https://www.researchgate.net/publication/40905887_The_Black_Consciousness_Moveme nt in South_Africa_A Product of The Entire Black_World/fulltext/0e60616bf0c46d4f 0ab8 8 f033/The-Black-Consciousness-Movement-in-South-Africa-A-Product-of-TheEntire-Black-World.pdf

Social Planning Council of Ottawa [SPCO]. (2020, July). Summary Portrait of Ottawa's Black Community in Comparison to the General Population. https://neighbourhoodequity.ca/racism/

Somali Centre for Family Services. (2021). Somali Centre for Family Services. https://scfsottawa.org/

Spillers, H. J. (1987). Mama's Baby, Papa's Maybe: An American Grammar Book. Diacritics, 17(2), 65-81. doi.org/10.2307/464747

Stanley, T. J. (2014). John A. MacDonald and the Invention of White Supremacy in Canada. Canadian Issues (Association for Canadian Studies: 1999), 29-32. https://oculcrl.primo.exlibrisgroup.com/permalink/01OCUL_CRL/1vru3a1/cdi_proquest_journals_1 666274951

Statistics Canada [StatsCan] (2019, February 27). Diversity of the Black Population in Canada: An overview. https://www150.statcan.gc.ca/n1/pub/89-657-x/89-657-x2019002-eng.html

---. (2017a, November 29). Ottawa, CV [Census subdivision], Ontario and Canada [Country]. Census Profile. 2016 Census. https://www12.statcan.gc.ca/census-recensement/2016/dp-pd/prof/index.cfm?Lang=E

--. (2017b, February 8). Census Profile, 2016 Census-Canada https://www12.statcan.gc.ca/census-recensement/2016/dppd/prof/details/page.cfm?Lang=E\&Geo1=PR\&Code1 $=01 \&$ Geo2 $=$ PR\&Code2 $=01 \&$ Data $=$ Count $\&$ SearchText $=$ Canada $\&$ SearchType $=$ Begins $\&$ SearchPR $=01 \& B 1=$ Visible $\% 20 \mathrm{~min}$ ority\&TABID $=1$

Syedullah, J. (2018). “When I Fall:” A Reparation of Despair. In Afro pessimism. Contemporary Political Theory, 17(1), 128 - 134. doi.org/10.1057/s41296-017-0165-4

Tasker, J. (2020, June 1). Trudeau says Anti-Black racism is Alive in Canada and "We Need to be Better" CBC. https://www.cbc.ca/news/politics/trudeau-anti-black-racism-1.5593395

Taylor, U. (1998). The Historical Evolution of Black Feminist Theory and Praxis. Journal of 
Black Studies, 29(2), 234-253. https://oculcrl.primo.exlibrisgroup.com/permalink/01OCUL_CRL/1vru3a1/cdi_proquest_journals_1 683885445

Tecle, S. (2016). Anti-blackness: Official Myths Aside, Canadian Anti-Black Racism is Alive, and Deadly. Fighting Racism: Canadian Dimension, 50(1), 22. https://oculcrl.primo.exlibrisgroup.com/permalink/01OCUL_CRL/1vru3a1/cdi_gale_infotraccpiq 4 47636984

Tecle, S. \& Austin, D. (2019). Just Below the Threshold: A Conversation with Dave Austin about African Canadian Leadership. In P. Howard, E. Lawson \& T. Kitossa (Eds.), African Canadian Leadership: Continuity, Transition, and Transformation (370- 391). University of Toronto Press. doi.org/10.3138/9781487531409

Thobani, S. (2018). Neoliberal Multiculturalism and Western Exceptionalism: The Cultural Politics of the West. Fudan Journal of the Humanities and Social Sciences, 11(2), 161174. doi.org/10.1007/s40647-018-0227-x

---. (2007). Exalted Subjects: Studies in the Making of Race and Nation in Canada. University of Toronto Press. https://oculcrl.primo.exlibrisgroup.com/permalink/01OCUL_CRL/1gorbd6/alma9910227743282051 53

Thomas, G. (2018). Afro-Blue Notes: The Death of Afro-pessimism (2.0)? Theory \& Event, 21(1), 282-317. https://oculcrl.primo.exlibrisgroup.com/permalink/01OCUL_CRL/1vru3a1/cdi_proquest_journals_2 157618432

Thompson, C. (2018). Searching for Black Voices in Canada's Archives: The Invisibility of a "Visible" Minority. Public, 29(57), 88-95. doi.org/10.1386/public.29.57.88_1

Tuck, E., \& Yang, K. W. (2012). Decolonization is not a Metaphor. Decolonization: Indigeneity, Education and Society, 1(1), 1-40. https://jps.library.utoronto.ca/index.php/des/article/view/18630

United Nations Human Rights Council (UNHRC). (2017). Report of the Working Group of Experts on People of African Descent on its mission to Canada*. United Nations General Assembly. https://ansa.novascotia.ca/sites/default/files/files/report-of-theworking-group-of-experts-on-people-of-african-descent-on-its-mission-to-canada.pdf

Veracini, L. (2016). Afterword: A History of the Settler Colonial Present. Settler Colonial Studies: Settler Colonial Logics and the Neoliberal Regime, 6(2), 174 - 179. doi.org/10.1080/00048623.2015.1024304

Vlasveld, M. (2020, June 3). Local Anti-black Racism Group Raising Concerns About Friday's 
Ottawa March. CityNews Ottawa. https://ottawa.citynews.ca/local-news/local-anti-blackracism-group-raising-concerns-about-fridays-ottawa-march-2405675

Walcott, R. (2019). The End of Diversity. Public Culture, 31(2), 393 - 408. doi.org/10.1215/08992363-7286885

---. (2003). Black Like Who?: Writing Black Canada (2 ${ }^{\text {nd }}$ ed.). Insomniac Press. http://ebookcentral.proquest.com/lib/oculcarleton-ebooks/detail.action?docID=299581

Walker, J. S. G. (2013). Black Canadians. The Canadian Encyclopedia. https://www.thecanadianencyclopedia.ca/en/article/black-canadians

---. (1984). The West Indians in Canada. Canadian Historical Association. https://chashc.ca/_uploads/5c3747c7b1823.pdf

---. (1976). The Black Loyalists: The Search for a Promised Land in Nova Scotia and Sierra Leone 1783-1870. London: Longman and Dalhousie University Press.

Wane, N.N. (2009). Black Canadian Feminist Thought: Perspectives on Equity and Diversity in the Academy. Race Ethnicity and Education, 12(1), 65-77. doi.org/10.1080/13613320802650964

Wekker, G. (2020). Afropessimism. European Journal of Women's Studies, 28(1), 86-97. doi.org/10.1177/1350506820971224

Whitfield, H.A. (2016). North to Bondage-Loyalist Slavery in the Maritimes. UBC Press. https://www.ubcpress.ca/north-to-bondage

Wilderson, F. (2020). Afropessimism. Liveright Publishing.

---. (2010). Red, White \& Black. Duke University Press.

Willing, J. (2020, June 20) Coun. Rawlson King Confirmed as Council's new Anti-Racism Liaison. Ottawa citizen. https://ottawacitizen.com/news/local-news/coun-rawlson-kingconfirmed-as-councils-new-anti-racism-liaison

Winks, R. W. (1997). The Blacks in Canada: A History. McGill-Queen's University Press.

Wodak, R. (2009) The Semiotics of Racism: A Critical Discourse-Historical Analysis. In Renkema, J. (Ed.) Discourse, of Course: An overview of research in discourse studies (17). John Benjamin's Publishing Company. https://doi.org/10.1075/z.148.29wod

Wolf, K. D. (2008). The Niagara Movement of 1905: A Look Back to a Century Ago. AfroAmericans in New York Life and History, 32(2), 9-22.

Wolfe, P. (2006). Settler Colonialism and the Elimination of the Native. Journal of Genocide 
Research, 8(4), 387-409. https://doi.org/10.1080/14623520601056240

Wright, M. M. (2015). Physics of Blackness: Beyond the Middle Passage Epistemology. University of Minnesota Press. http://www.jstor.org/stable/10.5749/j.ctt130jtph

Yang, J. (2018, September 14). Advocates Fear for Future of Province's Anti-Racism Directorate. The Toronto Star. https://www.thestar.com/news/gta/2018/09/07/advocatesfear-for-future-of-provinces-anti-racism-directorate.html 